QL

430.5

\$56K79

1893

MOLL.

Krhler

Beiträge zur Anatomie der Gattung Siphonaria 



\title{
Beiträge zur Anatomie der Gattung
} Siphonaria.

\author{
Von \\ Dr. August Köhler in Giessen. \\ (Aus dem Zoologischen Institut zu Giessen.) \\ Division of Mollustis \\ Sectional Library
}

Mit 6 lithographischen Tafeln.

\section{Abdruck \\ aus den}

Zoologischen Jahrbüchern.

Abtheilung für Anatomie und Ontogenie der Thiere.

Herausgegeben von Professor Dr. J. W. Spenger in Giessen.

Siebenter Band.

Verlag von Gestav Frschen in Jena.

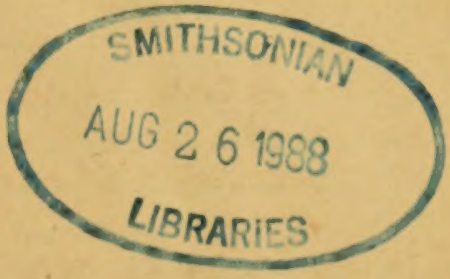




\title{
Beiträge zur Anatomie der Gattung Siphonaria.
}

Von

\author{
Dr. August Köhler in Giessen. \\ (Aus dem Zoologischen Institut zu Giessen.) \\ Division of Mollustrs
Sectional Iibrary
}

Hierzu Tafel 1-6.

Die vorliegende Arbeit soll ein Beitrag zur Lösung der Frage nach den verwandtschaftlichen Beziehungen und der systematischen Stellung der Gattung Siphonaria sein. Meinen Erörterungen liegen ausser den Angaben früherer Untersucher, deren Arbeiten ich an der Spitze des Literaturverzeichnisses zusammengestellt habe, eigne Untersuchungen an mehrern Arten zu Grunde. Dieselben bilden den Gegenstand des ersten Abschnitts dieser Arbeit. Sie erheben allerdings nicht den Anspruch auf eine Vollständigkeit, wie man sie etwa von einer Monographie erwarten müsste, dazu reichte mein Material schon in quantitativer Hinsicht nicht aus, da mir von jeder Art nur einige wenige Exemplare zu Gebote standen; auch in qualitativer Hinsicht war es nicht günstig. Ich hatte durchweg kleinere Arten, deren Präparation, da sie schon längere Zeit in Alcohol aufbewahrt gewesen waren, häufig so viel Schwierigkeiten bot und doch nur unsichere Resultate erwarten liess, dass ich vorzog, die allerdings zeitraubende, aber hier zuverlässigere Ergebnisse versprechende Methode der Untersuchung auf Schnittserien anzuwenden. Auch hier habe ich mich meist auf die Untersuchung der gröbern anatomischen Verhältnisse beschränkt und bin nur bei einzelnen Punkten, wo es unumgänglich schien, auf die Histologie eingegangen, soweit es der Conservirungszustand des Materials gestattete.

Zool, Jahrb, VIl. Abth, f. Morph. 
Der zweite Abschnitt ist der Vergleichung der Befunde bei den von mir untersuchten Arten mit den Ergebnissen der Arbeiten meiner Vorgänger gewidmet. Abgesehen von HaLlez's Arbeit sind es meist nur kleinere Mittheilungen, die, ohne weit in Details einzudringen, in grossen Zügen den Bau einzelner Arten, zum Theil mit Beschränkung auf einzelne Organsysteme behandeln, sie enthalten, wie es bei einer derartigen Behandlung leicht der Fall ist, in manchen Punkten irrthümliche Angaben; da jedoch fast keiner der Untersucher dieselbe Art vor sich gehabt hat, wie der andere (abgesehen von STUdER, v. JHERING und mir), und meine Untersuchungen mich belehrt haben, dass zwischen äusserlich ähnlichen Arten im innern Bau nicht unbeträchtliche Differenzen vorkommen können, so bin ich bei der Kritik dieser Angaben möglichst vorsichtig gewesen, um nicht meinerseits durch übereilte Schlüsse die Zahl der Irrthümer noch zu vermehren.

Im dritten Abschnitt endlich habe ich den Versuch gemacht, die Stellung von Siphonaria zu den übrigen Gastropoden nāher zu beleuchten, soweit mir nach dem gegenwärtigen Stande unserer Kenntnisse eine sichere Entscheidung möglich schien.

Ich ergreife hier die Gelegenheit, den Herren, die mich bei der Abfassung dieser Arbeit unterstützt haben, meinen herzlichsten Dank auszusprechen. In erster Linie bin ich meinem hochverehrten Lehrer, Herrn Professor Spengel, der mir die Anregung zu vorliegender Untersuchung gab, zu wärmstem Danke verpflichtet für das Interesse, das er stets meiner Arbeit bewahrte, und die reichen Unterstützungen an Literatur und Vergleichsmaterial, die er mir stets bereitwilligst zukommen liess; von den hier beschriebenen Siphonarien verdanke ich seiner Güte:

Siphonaria pectinata L. var. lineolata STR, vom Cap;

Siphonaria laeviuscula REeve, von Valparaiso (aus dem Museum zu Kopenhagen);

Siphonaria stellata var. lusonica ReEve, Nordaustralien (aus dem Museum Goderrrox).

Ferner danke ich den Herren Geheimrath Mozbius und Professor von Martens, die mir aus den reichen Schätzen des Berliner Museums folgende Arten überliessen:

Siphonaria pectinata L., aus Gabun;

Siphonaria redimiculum REEvE, von den Kerguelen;

Siphonaria aspera KraUss, von Saldanha. 
Herr Professor von Martens hatte ausserdem die grosse Liebenswürdigkeit, die Bestimmungen der von mir untersuchten Arten zu revidiren resp. die nicht bestimmten zu bestimmen.

Herr Dr. Plate war so freundlich, mir zwei aus dem Senckenbergischen Museum in Frankfurt stammende Arten:

Siphonaria pectinata L., von Casa blanca und

Siphonaria subrugosa Sow., von Chile

zu überlassen, auch ihm statte ich hier meinen besten Dank ab.

Herm Professor Pelseneer bin ich verpflichtet für die leihweise Ueberlassung der Arbeit NoBRE's über Siphonaria, die ich übersehen hatte.

Abschnitt I.

\section{Siphonaria pectinata L.}

Das Thier, das ich Taf. 1, Fig. 1 von der Seite und Fig. 2 von der ventralen Fläche gesehen abgebildet habe, ähnelt äusserlich am meisten einer Patella. Im Ganzen hat es die Gestalt eines flachen Kegels. Die Basis wird zum grössten Theil vom Fuss gebildet; vorn ist dieser abgestutzt, und hier wird der Kopf des Thieres sichtbar. Dieser ähnelt dem eines Limnaeus, doch fehlen die Fühler, und Augen sind am conservirten Exemplar wenigstens von aussen nicht zu erkennen.

Die Ventralfläche des Kopfes wird durch eine seichte Furche in sagittaler Richtung getheilt, auf deren Grund die Mundöffnung liegt; Kopf und Fuss sind durch eine tiefe, quere Furche, die sich noch etwas auf die Seiten des Körpers hinauf erstreckt, getrennt. Auf der rechten Seite liegt in der Fortsetzung dieser Furche, am hintern Rande des Kopfes, die Geschlechtsöffnung ( $g \ddot{o})$. Fuss und Kopf werden von einer Mantelfalte $(m f)$ überragt, die eine ringsum verlaufende Mantelrinne überdeckt, welche vorn über dem Kopf am tiefsten ist. In dieser Mantelrinne bemerkt man rechts, etwas vor der Mitte, eine kurze Falte, die etwa die Höhe der Mantelfalte erreicht. Auf den Fig. 1 u. 2 ist sie mit al bezeichnet. Auf ihrer dorsalen Fläche, dicht am Rand befindet sich die Afteröffnung (Taf. 1, Fig. 3 u. 4 af); ich habe sie daher Anallappen genannt. Der Anallappen und der darüber liegende Theil der Mantelfalte begrenzen eine bei Spiritusexemplaren gewöhnlich spaltförmige Oeffnung, welche in die Athemhöhle führt, das Athemloch (Fig. 1; 3, 4 alo, Taf. 1). Auf der Rückenfläche des Thieres bemerkt man den Ursprung eines hufeisenförmigen Adductors; er weist 
auf der rechten Seite eine dem Athemloch entsprechende Lücke auf, welche eine vorn rechts gelegene, etwa elliptische Partie von dem übrigen Adductor abtrennt; die beiden Theile des Adductors sind mit $a d$ und $a d^{\prime}$ bezeichnet (Fig. 1 u. 3, Taf. 1). Zwischen dem Vorderrand des abgelösten Theiles rechts und dem des ubrigen Adductors links entspringen längs einer schwach nach vorn convexen Linie $(l)$ Muskeln, die in die Mantelfalte und in die Kopfhaut ausstrahlen; in ähnlicher Weise entspringen über dem Athemloch Muskelfasern, die sich in die Mantelfalte begeben. Die Ursprungsstelle des Adductors zeigt bei Spiritusexemplaren eine gelblichgraue Farbe; bei genauer Betrachtung bemerkt man jedoch, dass sie durch hellere, quer verlaufende Streifen mehr oder weniger vollständig in rundliche Abschnitte getheilt wird (Fig. 1 u. 3): diese Querstreifen sind Enden von Faserbündeln, die wir bei der Betrachtung des Bodens der Mantelhöhle näher kennen lernen werden.

\section{Die Athemhöhle.}

Auf der von den Muskelursprüngen umrahmten Rückenfläche sieht man schon von aussen die Organe, die der Decke der Athemhöhle an- resp. eingelagert sind, hindurchschimmern; behufs genauerer Untersuchung eröffnet man jedoch am besten die Athemhöhle, indem man, vom Athemloch ausgehend, ihre Decke am rechten vordern und hintern Rand ablöst und nach links hinüberschlägt. Nach einem solchen Präparat ist Fig. 3, Taf. 1, gezeichnet. Man erkennt, dass die Athemhöhle den von den Muskelursprüngen umrahmten Raum nicht ganz beansprucht, indem am linken Rande, dem Athemloch gegenüber, eine den Vorhof (at) enthaltende Spitze des Herzbeutels vorspringt; um die Decke der Athemhöhle glatt nach links hinüberklappen zu können, muss hier auch die Wand dieser Partie des Herzbeutels durchschnitten werden, so dass man in seine Höhle hineinsieht. Auch hinten reicht die Athemhöhle nicht ganz bis an den Adductor heran, sondern es bleibt ein schmaler, sichelförmiger Raum zwischen dem Adductor und ihrem hintern Rand frei. Die Decke der Athemhöhle wird zum grössten Theil von zwei zum pallialen Organcomplex gehörenden Organen eingenommen.

In der vordern Hälfte liegt der grössere Theil der Niere (ren), der ungefähr die Gestalt eines gleichschenkligen Dreiecks hat, dessen eine abgerundete Spitze nach hinten gerichtet ist, während die ilhr gegenüberliegende Seite vorn quer zur Längsaxe des Thieres verläuft. 
Hinter der Niere zieht in grossem Bogen die sichelförmig gekrümmte Kieme $(c t)$ dahin; ihr dem Stiel einer Sichel entsprechender Theil reicht bis ins Athemloch hinein, fast bis an den Rand der Mantelfalte. Während die Kieme auf das Dach der Athemhöhle beschränkt bleibt, schlägt sich die Niere an der Stelle, wo der Herzbeutel vorspringt, auf den Boden der Mantelhöhle um und bildet dort einen rundlichen Lappen, der etwa ein Drittel des ganzen Organs ausmacht. Hinter diesem untern Nierenlappen liegt ein mit Flimmerepithel überkleideter, schmaler Wulst ( $w b$, Fig. 3, Taf. 1), der in der Nähe des Afters beginnt, parallel dem hintern Rand der Athemhöhle nach links verläuft, dort dicht hinter dem Herzbeutel auf die Decke der Athemhöhle übergeht und am hintern Rand der Kieme, das dort befindliche, auf der Zeichnung roth angelegte Gefäss bedeckend, wieder dem Athemloch zustrebt. Klappt man das Dach der Athemhöhle in seine natürliche Lage zurück, so kommen die beiden Theile des Wimperbandes einander gegenüber zu liegen. Am Eingang der Athemhöhle, der vordern Partie des Adductors angelagert, zeigen Fig. 3 u. 4 noch einen kleinen Wulst (os), auf den wir weiter unten zurückkommen werden.

Nach dieser allgemeinen Orientirung wenden wir uns zur Schilderung der einzelnen die Athemhöhle begrenzenden Theile.

Das D a ch der Athemhöhle, soweit es nicht von den oben erwähnten Organen eingenommen wird, ist eine ziemlich dünne Membran. Beide Seiten, die der Innenfläche der Schale anliegende wie die gegen die Athemhöhle gewandte, sind mit einem niedrigen Epithel bekleidet; zwischen den beiden Epithelien gewahrt man in der Bindesubstanz zahlreiche von geronnenem Blut erfüllte Räume (Fig. 7-12, 14, 15, Taf. 1; Fig. 16, Taf. 2; Fig. 2, Taf. 5, dah). In dem vor der Niere gelegenen Theil des Athemhöhlendaches sind diese Bluträume lange, ungefähr senkrecht zum vordern Nierenrande verlaufende, sich verzweigende oder anastomosirende Canäle; in dem hinter der Niere gelegenen Theil stellen sie jedoch ein unregelmässiges Netzwerk mit nur wenig gestreckten Maschen dar.

Die K ieme, deren Lage in der Athemhöhle wir schon oben kurz geschildert haben, zeigt einen ziemlich complicirten Bau. Schon bei der Betrachtung des Taf. 1, Fig. 3 abgebildeten Präparats überzeugt man sich, dass dieselbe aus einer grossen Zahl neben einander gereihter Blätter besteht, die etwa die Form eines gleichschenkligen Dreiecks haben. Mit ihren Grundlinien, die senkrecht zum hintern Rand der Niere stehen, sind sie am Dach der Athemhöhle ange- 
wachsen, zumeist so, dass grössere und kleinere mit einander abwechseln; im Ganzen nimmt die Grösse der Blätter von dem dem Athemloche zunächst gelegenen Ende nach dem am Pericard gelegenen hin ab. Die beiden Flächen jedes Blattes zeigen eigenthümliche Falten und Runzeln; untersucht man die Kieme auf Querschnitten durch das Thier an den Stellen, wo sie parallel zu ihrer Längsrichtung, die einzelnen Blätter somit senkrecht, getroffen sind, so zeigt sich, dass die Unebenheiten auf den Seitenflächen der Blätter theils durch Faltungen des einzelnen Blattes, theils durch auf beiden Seiten entspringende, secundäre Blättchen verursacht werden (vergl. Taf. 2, Fig. 18, 19, 20 ct). Jedes einzelne Blatt trägt an seinem hintern Rand ein $\mathrm{z} u$ führendes, an seinem vordern ein a bführendes Gefäss. Erstere entspringen alle aus einem am Hinterrand der Kieme unter dem dorsalen Abschnitt des Wimperbandes gelegenen gefässartigen Blutraume ( $k a, \mathrm{Fig}, 3$, Taf. 1), der an seinem hintern Rande durch zahlreiche Oeffnungen mit dem dort entwickelten Lacunennetze in Verbindung zu stehen scheint. Dieser Canal ist die Kiemenarterie oder das zuführende Kiemengefäss. Die abführenden Gefässe münden alle in ein am Vorderrande der Kieme, zwischen ihr und der Niere verlaufendes Gefäss, das abführende Kiemengefäss ( $k v$, Fig. 3, Taf. 1). Auf den Querschnitten Taf. 2, Fig. 16-20 ist seine Lage ebenfalls zu erkennen.

Eine allgemeine Orientirung über die Lage der Niere ist schon oben gegeben, ebenso ihre Gestalt in grossen Zügen geschildert worden. Wir sahen, dass sie aus einem grössern, dem Dach der Athemhöhle anliegenden dorsalen und einem kleinern, dem Boden derselben angehörenden ventralen Theile besteht. Beide Theile gehen auf der linken Seite der Athemhöhle, die Wand des Herzbeutels bedeckend, ohne scharfe Grenze in einander über. Dies ist auf Fig. 3, Taf. 1, da gerade an dieser Stelle der Herzbeutel eröffnet ist, nicht gut zu sehen; jeder Querschnitt durch diese Gegend des Thieres, wie z. B. einer der Taf. 2, Fig. 18-20 abgebildeten, lässt jedoch den Uebergang deutlich erkennen. Weder der dorsale, noch der ventrale Lappen der Niere sind in ihrer ganzen Ausdehnung gleichmässig dick; ersterer ist an seiner nach hinten gewandten Spitze am dünnsten, von da nimmt die Dicke nach vorn und besonders nach rechts (auf das Thier bezogen) beträchtlich zu, und dicht bei der nach dem Athemloche zu gelegenen Spitze des dorsalen Nierenlappens erhebt sich ein ziemlich kräftiger Fortsatz, der sich nach hinten und rechts ein Stück über die Kieme hinweglegt. Diese Nierenpapille (renp) ragt jedoch nicht ganz 
frei in die Athemhöhle hinein, wie es nach Fig. 3, Taf. 1, den Anschein haben könnte, sondern sie ist durch ein dünnes Blättchen, das zwischen den Kiemenblättchen von der Decke der Athemhöhle entspringt, wie durch ein Frenulum an diese befestigt. Auf einer Reihe von Querschnitten (Taf. 2, Fig. 19, 20) erkennt man, dass dieses Blättchen (fre) wie ein Kiemenblatt seitlich secundäre Blättchen trägt; auf dem Fig. 20 abgebildeten Schnitt ist es nur durch das grosse, an seinem freien Rande sich zeigende Gefäss von einem Kiemenblatt zu unterscheiden. Auf der Spitze dieser Nierenpapille liegt die äussere Oeffnung der Niere, der Nierenporus (renpo, Fig. 3, Taf. 1).

Im Innern besitzt die Niere den charakteristischen schwammigen Bau, wie wir ihn bei vielen Gastropoden finden. Das excretorische Epithel besteht aus kleinen cubischen, auf der freien Oberfläche oft halbkuglig vorgewölbten Zeller, in denen ich keine festen Concremente finden konnte. Soweit ich nach den mir vorliegenden Präparaten urtheilen kann, zeigen dorsaler und ventraler Lappen keinen wesentlichen Unterschied in ihrem Bau, nur ist der ventrale Lappen anscheinend reicher an Muskelfasern. Die Niere des in Schnitte zerlegten Exemplars war reichlich mit Blut erfüllt; Fig. 1, Taf. 5, zeigt ein kleines Stück aus einem Schnitt durch dieselbe: man erkennt das excretorische Epithel und die Bluträume im Innern der Niere.

Die Untersuchung der Gefässe ist nicht immer leicht. Sind sie mit geronnenem Blut reichlich erfüllt, so lassen sie sich auf Schnitten und auf Totalpräparaten gut verfolgen; sind sie dagegen leer und ihre Wände collabirt, so ist es nicht möglich, sie mit Sicherheit zu erkennen. Was ich an meinem Material ermitteln konnte, habe ich in Fig. 3, Taf. 1, eingezeichnet. Es fallen zunächst zwei starke Gefässe $\left(k v_{2} u_{.} k v_{3}\right)$ ins Auge, die das abführende Kiemengefäss mit dem Vorh of verbinden. Das eine, $k v_{2}$, verläuft am vordern Rand der Niere und entspringt dicht hinter dem rechten Ende des abführenden Kiemengefässes; das andere, $k v_{3}$, entspringt mehr nach der Mitte zu, vor der hintern Spitze des obern Nierenlappens und verläuft, bald dessen ganze Dicke einnehmend, bald nur der ventralen Wand angelagert, quer durch denselben. Beide Gefässe convergiren nach der Spitze des Herzbeutels und münden gemeinsam in den Vorhof. In die vordere diezer beiden secundären Kiemenvenen, wie ich die Gefässe $k v_{2}$ und $k v_{3}$ nennen will, dringt ein langes, der Vorhofmusculatur angehöriges Faserbündel ein, das an der Decke der Niere, ein gutes Stück rechts von der Medianlinie, inserirt (Taf. 1, Fig. $3 \mathrm{mu}$ ). In dem Vorhof liess es sich, da er zusammengefallen war, nicht weiter 
verfolgen. Ein zweiter kürzerer und schwacherer Muskel liegt in einem kleineru Gefäss, das vou der ohern Seite des dorsalen Nierenlappens herabkommt und mit den liemenvenen gemeinsam in den Vorhof mündet. Ein ahnliches Gefiiss scheint auch etwas weiter nach hinten, an der Vebergangsstelle zwischen dem obern und untern Nierenlappen in die hintere Kiemenvene dicht bei ihrer Ausmündung in das Herz einzutreten; es führt wohl lilut aus dem ventralen Lappen und aus der linken Halfte des dorsalen in das Herz. Wahrscheinlich ergiessen sich auch noch andere kleinere Gefässe in die Kiemenvenen und das abführende Kiemengefäss, wenigstens sah ich eine Anzahl aut einem in Glycerin und Essigsiaure aufgehellten Präparat der Decke der Athemhöhle; leider war jedoch die Blutvertheilung in der Niere des in Qquerschuitte zerlegten Exemplars für die Verfolgung dieser Gefasse nicht günstig, so dass ich dort die liichtigkeit dieser Beobachtung nicht prüfen konnte. Mehr Erfolg hatte die Untersuchung anderer Gefasse, die mit dem zuführenden liemengefass in Verbiudung stehen. Sie sind, soweit sie auf Flächenpräparaten bei schwacher Vergrösserung sichtbar waren, in Fig. 3, Taf. 1, eingezeichnet; auf Schnittserien lisst sich nachweisen, dass sie sich im dorsalen Yierenlappen und zwar zunächst vorwiegend an seiner ventralen Fläche verbreiten. Das eine dieser Gefässe entspringt rechts, gerade der Kiemenpapille gegenülver, und verläuft in dem Frenulum über die Kieme hinweg und dringt am medialen, nach binten gewandten Rand der Papille in die Niere ein, um sich da, wie oben angedeutet, zu verzweigen; das andere steht ganz im Hintergrund der Athemböhle, am Ursprung des zuführenden Kiemengefässes mit diesem in Verbindung und verläuft dem nach rechts und hinten gewaudten Rande der Niere entlang in querer Richtung bis zu dem alführenden Kiemengefass. Auf diesem Wiuge sendet es sowohl nach vorn, als auch nach hinten Gefisse aus. Die vorlern gehen in die Niere, die hintern treten in ein Gefissnetz ähnlich dem vor der vordern Kiemenvene gelegenen ein, das sich links zwischen Hinterrand der Niere und Vorderrand der hieme entwickelt hat. Man kann sich leicht überzeugren, dass das abführende Kiemengefass, soweit es jenes Gefassnetz begrenzt, an vielen Stellen mit ihm communicirt. Ich will die beiden Gefisse rechtes $(r g n)$ und linkes (lzn) zuführendes Niereagefäss nennen (vergl. Fig. 3, Taf. 1).

Mit dem Herzheutel communicirt das Innere der Niere durch eine gut ausgebildete Renopericardial p forte. Sie liegt dicht hinter dem Eintritt der Kiemenvenen in das Atrium und steht etwa senk- 
recht zur Längsaxe des Thieres. Auf Querschnitten erscheint sie daher mehr oder weniger genau längs getroffen; eine Abbildung gebe ich nicht, weil ich von der vorliegenden Art keinen dazu geeigneten Querschnitt habe.

Der Boden der Athemhöhle wird von einer dünnen Membran gebildet, die ich in meiner vorläufigen Mittheilung Diaphragma genannt habe. Das Diaphragma ist wesentlich musculöser Natur. Ich habe schon oben darauf aufmerksam gemacht, dass der Adductor durch quere Streifen, die an seinem äussern Rande entspringen und nach innen verlaufen, in eine Anzahl rundlicher Abschnitte getheilt wird: diese Streifen sind die Ursprungsportionen von Muskelbündeln, die von den Seiten und von hinten in das Diaphragma eintreten, sich dort ausbreiten und unter einander verflechten; ein Theil der hinter der Athemöffnung entspringenden Fasern zieht im Bogen in dem $z$ wischen dem Rande der Athemböhle und dem Wimperbande gelegenen Raum nach der gegenüberliegenden Seite. Auch aus dem Adductor treten Fasern in das Diaphragma ein, besonders in der vordern untern Wand des Herzbeutels (Fig. 12, 14, 15, Taf. 1, und Fig. 17, 18, Taf. 2). Die Aufgabe dieser Musculatur ist wohl die Verengerung resp. Erweiterung der Athemhöhle.

Von den dem Dach der Athemhöhle angehörenden Organen gehen nur die Niere und das Wimperband auf den Boden über, jedoch nicht die Kieme. Am Athemloch, dem rechten abgelösten Theil des Adductors angelagert, liegt der schon oben genannte Wimperwulst (os) und darunter ein Ganglion ( $g o)$; es ist das Osphradium oder Geruchsorgan, auf das ich bei der Schilderung des Nervensystems noch zurückkommen muss (Taf. 1, Fig. 3, 4, 8, 9).

\section{Die Leibeshöhle.}

Unter dem Diaphragma liegt die Leibeshöhle - ich gebrauche diesen Ausdruck hier nicht im Sinne von Cölom - , die grösstentheils von den Ernährungs- und Fortpflanzungsorganen erfüllt wird. Nur links, unter dem untern Nierenlappen, breitet sich der Herzbeutel a 1s. Er ist ein ziemlich ausgedehnter Hohlraum, wie man auf den Fig. 14, 15, Taf. 1, und Fig. 16-20, Taf. 2, erkennt, wo der Herzbeutel mit $p c$ bezeichnet ist. Mit der Grenze der untern Niere stimmt die Grenze des Herzbeutels nicht genau überein: nach vorn und links hinten ragt der Herzbeutel, nach rechts hinten dagegen die Niere weiter vor. Gerade dem Athemloch gegenüber, wo er am meisten 
in die Athemhöhle vorspringt, ist der Herzheutel am weitesten; hier liegt das Her\%. Die dünnwandige Vorkammer (at) liegt nach oben rechts und vorn gewandt, die Kammer (ve) unten, links und etwas nach hinten. Man kann diese Lage des Herzens aus den Querschnitten Fig. 18, 19, 20, Taf. 2, leicht erkennen. Auch Fig. 3, Taf. 1, kann (eine Vorstellung davon geben, wenn man sich das Dach der Athemhöhle in seine natürliche Lage zurückgeklappt denkt. Die in die Vorkammer mündenden Gefasse kommen alle aus dem Dach oder dem Iioden der Athemhöhle und sind schon besprochen; die von der Kammer ausgehenden will ich aus praktischen Gründen spater beschreiluen. /unächst haben wir die Organe, welche in der Leibeshöhle liegen und von jenen Gefässen versorgt werden, näher ins Auge zu fassen. Es sind das, wie schon bemerkt, die Ernährungs- und Fortpflanzungsorgane, und zwar nehmen erstere vorwiegend die linke, letztere die rechte Hälfte des zur Verfügung stehenden Raumes ein.

\section{Die Ernährungsorgane.}

Der Mund ist eine einfache Oeffnung, die bei den conservirten Exemplaren auf dem Grund der an der Ventralseite des Kopfes gelegenen Längsfurche liegt. Fr führt in ein ganz kurzes Rohr nit musculisen Wandungen und sternförmigem Lumen, an dessen oherem Emle in einer quer verlaufenden Furche ein Kiefer liegt. Derselbe ist hallikreisförmig und besteht aus mosaikartig nelen einander gereihten, braunen Stäbchen, die theils am Boden, theils an der Rückenwand der Furche befestigt sind; erstere sitzen direct den Epithelzellen auf, letztere auf einem vom Epithel der dorsalen Wand der Furche ausgeschieden'n, geschichteten Cuticularsaum, der nach dem Rande der Furche hin an Dicke stetig zunimmt; er ist eine Verdickumg der den vordern Theil der Mundhöhle auskleidenden Cuticula. Gute Schnitte durch den Kiefer, welche das beschriebene Verhalten erkennen lassen, erhalt man gewöhnlich nur auf Sagittalschnitten. Ich habe einen solchen, von einer andern Art, auf Taf. 5, lig. 4 alygebildet. IDie Zusammensetzung des Kiefers aus Stähchen ergiebt sich aus der Combination solcher Schnitte mit Flichenschnitten durch den vordern, median gelegenen Theil des Kiefers, wie man sie auf Querschnitten durch das Thier erhält (Taf. 5, Fig. 5) ${ }^{1}$ ). Die Stäbchen am freien, veutral ge-

1. Auch dieser Sichnitt stammt von riner andern Art, von Siphonaria laeviuscula, bei der die Stabchen nur etwas länger sind als bej pertinata. 
legenen Theile des Kiefers sind hier ziemlich genau quer getroffen, nach den Seiten und nach dem dorsalen Rande zu werden die Schnitte schräg, man kann hier die Stäbchen in Zusammenhang mit den Epithelzellen beobachten. Mit dieser Kieferfurche beginnt die eigentliche Mundhöhle. Die nach vorn und oben direct vor dem Kiefer gelegene Wand ist mit einem starken, aus Quer- und Längsfasern bestehenden, wohl musculösen Polster ausgestattet (ein Stück davon zeigt Fig. 4, Taf. 5, po), von hinten springen die zwei lang-eiförmigen, an ihren der Mundhöhle zugewandten Enden mit einander verbundenen Stützbalken der Zunge ( $s t$ ) unter der Radulatasche $(r t)$ vor. Sie sind auf den Querschnitten Taf. 1, Fig. 7-12 eingezeichnet; die Bilder sind jedoch für die Demonstration dieser Organe nicht instructiv, da durch die Geschlechtsorgane und durch Contractionszustände die ursprüngliche symmetrische Lage dieser Theile wesentlich gestört ist. Ich werde daher den Bau der Stützbalken bei einer andern Art, bei der auch ihr Erhaltungszustand besser ist, eingehender beschreiben.

Ueber den von den Stützbalken gebildeten Theil der Mundhöhlenwand breitet sich das vordere Ende der Radula aus. Ihre Bildungsstätte ist eine kurze, nach oben umgebogene Radulatasche $(r t)$, die in ihrem Bau keine wesentlichen Abweichungen von den Verhältnissen darbietet, die schon von andern Gastropoden bekannt sind. Ihren Ursprung aus der Mundhöhle zeigt Taf. 1, Fig. 7 u. 8 ; ziemlich genau quer getroffen ist sie Fig. 9; die folgenden Schnitte fallen dagegen schon in die Gegend, wo sie sich dorsalwärts umbiegt, man erhält also hier keine reinen Querschnitte mehr. An einer herausprïparirten Radula zählte ich ausser dem Medianzahn jederseits 38 Zähne, so dass die Formel 38.1.38 ist. Die Zähne bilden fast gerade, nur schwach nach vorn convexe Querreihen. Um eine Vorstellung von der Form der Zähne zu gehen, habe ich Taf. 2, Fig. 21 ausser dem Medianzahn (mit o bezeichnet) den 2., 11., 20. und 31. Zahn abgebildet. Der Medianzahn ist langgestreckt, auf der schmalen Basis crhebt sich eine ganz kurze, einfache Spitze. Die folgenden Zühne sind breiter und haben eine starke, zweizackige Spitze (Fig. 21 2). Von den beiden Zacken der Spitze tritt zunächst die laterale an Grösse zurück, und am Grunde der Spitze tritt auf der lateralen Seite eine neue '/acke auf (Fig. 21 11). Gehen wir weiter nach der Seite, so stumpft sich auch die mediale Zacke der Spitze al). Sie erscheint jetzt gerade abgestutzt, mit einer leichten Einkerbung in der Mitte, zugleich tritt an ihrem Grunde, gegenüber der lateralen, eine kleine, mediale '/acke auf (Fig. 21 20, Taf. 2). Danń schliessen 
sich Ziihne an, die, indem die Spitze immer kürzer wird und die Zacken an der Basis beiderseits gleich gross werlen, fast symmetrisch gebaut erscheinen (Taf. 2, Fig. 21 31). Diese Form behalten sie bis zum liande, nur werden sie in der Richtung von vorn nach hinten kürzer, während ihr Querdurchmesser ungefähr der gleiche lleibt. Lateral vom letzten Zahn findet man zuweilen noch ein kleines liörnchen, das wohl einem rudimentären 'Zahn entsprechen dürfte. Die Vergrösserung aller in Fig. 21 abgebildeten Zähne ist die gleiche; es geht aus der Ablildung deutlich hervor, dass die Grösse der einzelnen Zähne von der Mitte nach dem Rande stetig abnimmt.

Ueber der Radulatasche, auf der dorsalen Fläche des Schlundkopfes, entspringt der Oesophagus (oe, Taf. 1, Fig. 4, 6, 8-10, 12-14). Er dringt, sich hin und her krümmend, in die Tiefe hinab und geht hier ohne scharfe Grenze in den weiten, sackförmigen M a g e n über. Die Wand des (Vesophagus zeigt zahlreiche Längsfalten, an deren Bildung sich das aus schmalen, hohen Flimmerzellen zusammengesetzte Epithel und eine Längsmuskelschicht betheiligen, während die anssen liegenden, quer verlaufenden Muskelfasern über die Falten hinwegziehen. Der Magen liegt dicht über dem Fusse und ist in Fig. 4 nur zum kleinsten Theil zu sehen, nämlich vorn der Uebergang in den Desophagus und rechts hinten ein kleines Stück. Fig. 6, Taf. 1, die Darmicanal und Leber, von der ventralen Seite gesehen, darstellt, zeigt ihn jedoch in seiner ganzen Ausdehnung. Fr ist ein weiter, dünnwandiger Sack, dessen Form wesentlich durch seinen Füllungszustand und die Dimensionen der umliegenden Organe bedingt wird; gewöhnlich ist er, wie überhaupt der Darm, mit aufgenommenen Vahrungsmitteln erfüllt, Resten von Algen, Diatomeen und leider auch Sand, welch letzterer bei der Anfertigung der Schnittserien sich in sehr störender Weise bemerklich macht. Bei dem in Schnitte zerlegten Exemplar war der Darm in seinem vordern Theil ziemlich leer, er enthielt nur etwas Gerinnsel, und man sieht hier die Wand âhnliche Falten bilden wie im Oesophagus (Taf. 2, Fig. 16-20 m).

Eine Einschnürung, die sich etwa in der Mitte des Magens befindet, scheint mir nicht von wesentlicher Bedeutung zu sein, wenirstens konnte ich, trotzdem sie einigermaassen constant aufzutreten scheint, keine wesentlichen Unterschiede in dem Bau der vordern und hintern Hälfte des Magens erkennen. Ungefahr in der Mitte der hintern Halfte des Magens entspringt der $\mathrm{D}$ ünndarm (Taf. 1, Fïg. fo $d_{1}$; Fig. A). Derselhe wendet sich am Boren der Leibeshöble zunächst nach vorn, steigt vor der Herzkammer in die Höhe (Fig. 4, Taf. 1) 
und biegt, dicht unter dem Diaphragma liegend, nach hinten um $\left(d_{2}\right.$, Fig. 4, Taf. 1; Fig. A); er bildet so eine erste, vertical stehende Schleife. Dann wendet sich der Darm nach links (Fig. 4) und läuft am Rande der Eingeweidemasse nach vorn (Fig. 4, $6 d_{3}$ ), sinkt hinter dem Herzen in die Tiefe und verläuft parallel mit $d_{1}$ nach hinten (Fig. $6 d_{4}$ ), steigt hier wieder zur Dorsalseite hinauf und zieht schräg nach vorn unter dem Diaphragma nach der Afteröffnung $\left(d_{5}\right.$, Fig. 4,6$)$, die auf der dorsalen Seite des Anallappens liegt. Am Darmcanal sind zwei Paare von Anhangsdrüsen entwickelt.

Vorn finden sich zwei Speicheldrüsen $(s p d r)$, deren jede eine rundliche, gelappte Masse darstelit, von der der dünne Ausführgang sich bis zur Wand der Buccalmasse verfolgen lässt. Bei dem in Schnitte zerlegten Exemplar waren die Drüsen im Verhältniss viel mächtiger entwickelt; auf den Fig. 8-15, Taf. 1, findet man sie zwischen den verschiedenen Theilen des Darmcanals eingeklemmt.

In den hintern Theil des Magens münden zwei Verdauungs d r üsen (Le ber) von sehr ungleicher Grösse. Die stärker entwickelte ( $h e p_{1}$, Fig. 4,6) mündet dorsal vom Ursprung des Dünndarms durch ein weites Loch in den

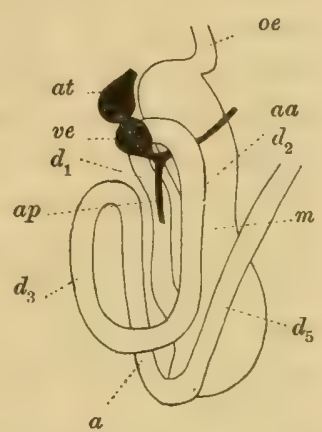

Fig. A. Darm und Herz von Siphonaria pectinata. oe Oesophagus, $m$ Magen, $d_{1}-d_{\overline{5}}$ Darm, ve Ventrikel, at Vorhof, a $a$ Arteria anterior, ap Arteria posterior. Magen, ihre Hauptmasse ist auf der ersten der angeführten Figuren auf der Dorsalseite zu sehen, in der zweiten Figur erkennt man die kleinern, auf der Ventralseite gelegenen Lappen des Organs, die sich zwischen die Darmschlingen eindrängen. Die kleinere Drüse $\left(h e p_{2}\right)$ nimmt das hinterste Ende der Leibeshöhle ein, sie mündet durch einen dünnen, kurzen Gang ventral in den hintersten Abschnitt des Magens; Fig. 4, Taf. 1, zeigt sie von der dorsalen, Fig. 6 von der ventralen Seite. Die Leber erscheint äusserlich aus einzelnen Lappen und Läppchen zusammengesetzt, ich habe versucht, auf der Zeichnung deu Habitus, so gut es mir möglich war, wiederzugeben. Den Bau der Leberzellen übergehe ich hier, da ihr Conservirungszustand ein zu ungünstiger war.

\section{Die Geschlechtsorgane.}

Die Gieschlechtsorgane nehmen den rechts gelegenen kleinern $\mathrm{Ab}$ schnitt der Leibeshöhle eiu, wie es lig. 4, 'Iaf. 1, zeigt. Man bemerkt 
hinten die $Z$ witterdrüse $(z w)$, vor ihr, unter dem Endilarm und zum Theil von der I.eber bedeckt. cine drüsige, aus Schleim-und Eiweissdrüse zusammengesetzte Masse $(s d)$, aus der vorn der Spermoviduct (spoo) entspringt, der in die hintere Flache des vordern rechten Adductorabschnitts eindringt. Ihm dicht angeligert verlâuft ein weit engerer (anal, der Ausführgang des Receptac u l um semin is (rs). Vor dem Receptaculum liegt eine alggeplattete Urüse von rundlichem Lmriss, die Prostata (pr), die durch einen engen Gang in das algerundete Ende eines bohlen, cylindrischen Schlauches (gcl) mündet, der sich dann am liopf, vor der hopf und Fuss tremnenden Furche durch die Geschlechtsöffinung nach aussen iffuet. Ich will ihn Genitalcloake nennen. Eine klarere Uelersicht üler den Zusanmenhang und die Form der einzelnen Theile des Geschlechtsapparats gielıt Fig. 5, Taf. 1, die ihn frei präparirt und auseinandergebreitet zeigt. Oben in der Figur findet man die grosse Zwitterdrüse $(z w)$; etwa im Centrum ihrer untern Flache entspringt der in der Mitte stark aufgetrielsene, gewundene Zwittergang (zucg). Derselbe tritt, nacbdem er einen seitlichen Fortsatz, die Samenblase (sb), entsendet hat, in die aus Schleim- und Fiweissdrüse gebildete Genitalmasse üleer, deren Oberflache vielfach durchfurcht ist isd und ed. Auf der Zeichnung siebt man am untern, in Beziehung auf das Thier vordern Rand der Genitalmasse in der Fortsetzung eines solchen Wulstes den Spernoviduct (spow) entspringen. Fr ist mit dem Gang des Receptaculums ( $r$ ) aus dem Muskel herauspräparirt, und man erkennt, wie er mit diesem in der lähe des Prostataganges in die Genitalcloake $(g c l)$ einmündet.

Yach dieser allgemeinen Orientirung können wir uns zur Schilderung der einzelnen Abschnitte des Genitalupparats an der Hand der abgebildeten Schnitte wenden.

Der erste Schnitt (Fig. 7, Taf. 1) zeigt die Gieschlechtsöffnung gï. sie führt in einen schrag ins Innere vorspringenden dickwandigen, musculösen Schlauch, die Genit alcloake (gch), die sich scharf nach hinten umbiegt. Auf dem abgebildeten Prâparat ist der erste Theil längs geschnitten, während darüler der nach binten sich wendende Theil im Querschnitt getroffen ist; die Communication der bejlen Lumina ist auf den rorangehenden Schnitten leicht nachzuweisen. Der Lichtdruck Taf. 5, Fir. :3, der ein stück eines Horizontalschnittes durch ein auderes Exemplar, das der var. lineolata angehört, darstellt, zeigt elenfalls einen Querschnitt durch den Anfangstheil der Genitalcloake mit seiner stark musculiosen, aus qquer umd längs verlaufonden 
Muskelbündeln zusammengesetzten Wand. Das Epithel ist aus hohen, cylindrischen Zellen gebildet, die wahrscheinlich Wimpern tragen, der Conservirungszustand meines Objectes liess jedoch eine sichere Entscheidung dieser Frage nicht zu. Fig. 8 stellt einen weiter hinten geführten Schnitt dar. Der distale Theil der Genitalcloake ist hier nicht mehr getroffen, sondern nur das hintere, umgebogene Ende mit seinem etwas erweiterten Lumen. Ein paar Schnitte weiter biegt die Genitalcloake wieder nach vorn um und geht, nachdem sich ihr Hohlraum etwas erweitert hat, in den auf der Figur links von ihr gelegenen, mit spov bezeichneten Canal, den Anfang des Spermoviducts, über. Die Längsfaserbündel, die ihn umgaben, verlaufen allein in der ursprünglichen Richtung nach hinten, indem sie sich bald zu einem Retractor der Genitalcloake vereinigen, der bis Fig. 16, Taf. 2, r zu verfolgen ist; dann dringen seine Fasern in die Muskelmasse des Adductors ein. Auf dem Lichtdruck Fig. 3, Taf. 5, ist der Retractor der Länge nach getroffen. Auf der ganz kurzen Strecke vom Uebergang in den Spermoviduct bis zu der Stelle, wo vorn die Biegung nach unten stattfindet, nimmt die Genitalcluake zwei weitere Canäle auf. Zunächst vorn, dicht hinter der Biegung, einen feinen, mit niederm Epithel ausgekleideten Canal (Fig. 7), der zunächst in der Musculatur eingehüllt bleibt (Fig. 8). Hinter dem Anfang des Spermoviducts aber tritt er nach ein paar dicht aneinander gelegten Windungen aus den sich zum Retractor zusammenschliessenden Längsfasern aus und wendet sich medianwärts, um in die Prostat a einzutreten. Diese selbst ( $p r$, Fig. 8-15, Taf. 1, und Fig. 16, 17, Taf. 2) stellt einen dickwandigen, in dorsoventraler Richtung abgeplatteten Schlauch dar, der eine mit der Spitze dorsal gewandte, im Sinne der Conchyliologen linksgewundene Spirale von etwa $1^{1 / 4}$ Windung beschreibt. Bei dem andern ältern Exemplare, nach dem die Fig. 4 u. 5 entworfen sind, war jedoch die Spirale rechtsgewunden, und das dem Ausführgang zugekehrte Ende nach vorn umgeschlagen. Ueber den feinern Bau der Prostatawand kann ich nach meinen Präparaten, der ungenügenden Conservirung wegen, keine befriedigende Auskunft geben. Man kann nur leicht erkennen, dass die Wand der Prostata aus zwei Schichten zusammengesetzt ist, einer innern, dem Lumen zugewandten, ziemlich dünnen, und einer äussern, die an den meisten Stellen viel mächtiger ist. Letztere besteht aus Drüsenzellen von anscheinend birnförmiger Gestalt, mit deutlichem kiern und köruigem, sich in Carmin schwach färbendeın Inhalt; man gewinnt an vielen Stellen den Eiudruck, dass eine Auzahl sulcher Zellen zu einem "Acinus" vereinigt seieu. Die 
innere Schicht zeigt schon bei schwacher Vergrïsserung eine deutlich ausirepragte radiare Streifung, die auch auf den Lebersichtshililern angedeutet ist; auf dünnen schnitten, bei starker Vergriisserung, steht man, dlass sie zum grossen Theil von den halsartigen, innern Abschnitten der Drüsenzellen gehilılet wird, die ebenfalls mit Secretkïrnchen erfüllt sind. \%wischen diesen scheinen sich noch dunne Cylinderzellen mit kleinen, langlichen kernen zu befinden, die, nach vorhandenen Resten zu urtheilen, mit $W$ imperhaaren versehen waren; auch an mit Carmin gefarbten, in toto eingelegten stücken der I'rostata, an denen man die Wand von der aussern flache betrachtet, lassen sich ausser den grossen liernen der Irüsenzellen, die hei hoher Finstellung sichtbar sind, bei tiefer Einstellung noch die kleinen Kerne unterscheiden, welche an den hnoteupunkten eines nicht ganz regelmatssigen, etwas verwaschen gezeichneten Netzwerkes liegen. I hei etwas dickern Schnitten sind die beiden Schichten scharf gegen einander algegrenzt; es scheint hier zwischen beiden Schichten das eben erwahnte Fasernetz zu liegen, Sicheres habe ich jedoch darüber nicht ermitteln kümnen.

Der Ursprung des zweiten Canals, des Stiels des lieceptaculums, ist Taf. 1, Fig. 8 alggebildet. Er entspringt aus einer lirweiterung am Cebergang des Spermoviducts in die Genitalchate, durchdringt den Retractor der letztern und verliuft parallel mit dem Spermoviduct auf seiner dorsalen Seite nach vorn (Fïg. $7 \mathrm{rs}$ ), dann durch den vordern Adductor nach hinten. Fig. 15 tritt er dann unter dem Athemloch aus ihm heraus und lässt sich bis zum Receptaculum verfolgen. Fig. 1s, Taf. 2, liegt er dicht am Receptaculum; ich hahe seine Einmündung nicht hesonders abgebildet, da sie schion auf den Fig. 4 u. 5, Taf. 1, dargestellt ist. Die Wand des Receptaculumstieles ist glatt; sie besteht aus einem einfachen II imperepithel, die Musculatur ist nur schwach entwickelt. Das Receptaculum sellost ist eine dünuwandige Blase; sein Inhalt war an dem in Schnitte zerlugten Exemplare nicht zu hestimmen: über diese Frage und über den liau der $\mathrm{W}$ and werde ich bei der Beschreibung anderer Arten die nuthin...n Angaben machen.

Der spermoviduct (spor) schliesst sich direct an die oben erwahnte Erweiterung an. Er verlatuft, wie schon bemerkt, ventral vom stiel des Receptaculuu seminis, genau wie dieser durch den Adductor und stellt auf dieser Streche ein ziemlich dickwandiges, mit starker Langs- und lingmusculatur versehenes Rohr dar, dessen Lumen von einem etwa 6 - $\varnothing$ Langsfalten bildenden Cylinderepithel ausgrekleidet ist. Dieser eiufache bau erhalt sich his zum Fintritt in die Leilnes- 
höhle (Fig. 17, 18, Taf. 2). Da verdickt sich der ganze Spermoviduct erheblich, und sein Lumen theilt sich in zwei Rinnen. Die Wand der einen gleicht in ihrem Bau vollkommen der $W$ and der Prostata, sie mag daher Prostatarinue heissen; die andere dagegen zeigt grosse Aehnlichkeit mit der Schleimdrüse, ich nenne sie daher Schleimrinne. Auch in dieser hat eine Sonderung der Zellen in Drüsen- und Flimmerzellen stattgefunden, jedoch ohne dass erstere aus dem Epithel herausgetreten wären; es wechseln vielmehr ziemlich regelmässig grosse, farblose Zellen mit grobmaschigem Plasma mit ganz dünnen, fadenförmigen $a b$, die an ihrem verbreiterten Ende die Wimpern tragen. Die Schleim- und Eiweissdrüse, sowie Zwittergang und Zwitterdrüse habe ich bei der vorliegenden Art nicht genauer untersuchen könuen, da die Schnitte hierfür nicht tauglich waren; ich habe in den Fig. 16 -20, Taf. 2, nur die allgemeinen Lageverhältnisse dargestellt. Man sieht in Fig. 17, Taf. 2, den Spermoviduct unten und links von der Schleimdrüse umgeben, ebenso in Fig. 18; Fig. 19 ist der Spermoviduct verschwunden, und an seiner Stelle gewahrt man Windungen des Zwitterganges $(z g)$; daneben liegt links die Eiweissdrüse $(e d)$, darüber und darunter die Schleimdrüse (sd). Schnitte, auf denen die Zwitterdrüse getroffen ist, habe ich nicht abgebildet; ich werde das bei der Beschreibung von Siphonaria stellata var. luzonica nachholen.

\section{Die Blutgefässe.}

Wir wenden uns nun zur Darstellung der Blutgefässe. Werfen wir einen Blick auf Fig. 19, Taf. 2, so sehen wir am medialen Rande des Herzbeutels aus der Kammer ein starkes Gefäss entspringen, das gleich nach seinem Eintritt in die Leibeshöhle eine Anschwellung zeigt. Dicht hinter dieser Anschwellung theilt sich das Gefäss in zwei Theile, einen nach hinten verlaufenden, die Arteria posterior oder abdominalis, welche die im hintern Körperabschnitt gelegenen Eingeweide versorgt (Taf. 2, Fig. $20 \mathrm{ap}$ ), und einen zweiten, die A rteria a nterior oder cephalica, die, zunächst zwischen den Leberlappen eingebettet, durch die erste Darmschlinge hindurchtritt (Fig. 19aa), sich dann dem Boden der Athemhöhle dicht anlagert (Fig. 18, Taf. 2) und so bis zum Rand der Athemhöhle nach rechts und vorn verläuft. Dann wendet sie sich nach unten (Fig. 14, Taf. 1), geht rechts an der Visceralcommissur vorbei und tritt ventral vom Darm durch den Schlundring hindurch (Fig. 13, 12), um sich dort zu verzweigen. $\mathrm{Zu}-$ erst geht unter dem Receptaculum seminis (Fig. 14, 'Taf. 1) ein 
Gefiss nach links (Fig. 15, Taf. 1; Fig. 16, Taf. 2, ( $)$, das sich der Ventralseite des Oesophagus dicht anlagert und nach vorn verliuft ('Taf. 1, Fig. 15-10), weiter lässt es sich nicht mit Sicherheit verfolgen. Darauf gehen etwas weiter nach links zwei Gefässe $\left(\beta_{1}, u, \beta_{2}\right)$ nach vorn $a b$, von denen das medial gelegene $\left(\beta_{2}\right)$ bis zu dem Schlundkopf zu verfolgen ist (Fig. $12-8$, Taf. 1 ); das laterale $\left(\beta_{2}\right)$ scheint schon vorher zu endigen. Ferner entspringen direct neben einander etwa in der Medianlinie zwei nach hinten verlaufende Gefässe $\left(\gamma_{1} u \cdot \gamma_{y}\right)$, die unter den Pedalcommissuren, dicht der Fussmusculatur angelagert, verlaufen (Fig. 13-15, Taf. 1). Fig. 16, Taf. 2, ist einer der letzten Schnitte, auf denen sie mit Sicherheit zu erkennen waren. Auf der lateralen Seite des Spermoviducts, am Ursprung des Anallappens, findet sich Fig. 17 u. 18, Taf. 2, ebenfalls ein mit Blut erfüllter Raum (d), der mit der Arteria cephalica communicirt, wie ich bei zwei Exemplaren nachweisen konnte; ich bin jedoch trotzdem zweifelhaft, ob man ihn als Gefäss ansprechen darf, da ihm eine eigne Wand zu fehlen scheint; es ist immerhin möglich, dass er seine Entstehung einem zufälligen Riss in der Wand der Arterie verdankt, die an dieser Stelle recht dünn ist.

Aus den Verzweigungen der Arterien tritt das Blut frei in die Leibeshöhle: es sammelt sich, nachdem es die Organe umspült hat, in einem Sinus, der besonders deutlich auf der linken Seite, an der Grenze des Athemhöhlendaches auf den abgebildeten Schnitten zu beobachten ist (si Fig. 7-15, Taf. 1; Fig. 16-20, Taf. 2); ich will ihn Pallialsinus nennen. Von ihm treten alle in das Dach der Athemhöhle gehenden Gefässe aus; der Ursprung des zuführenden Kiemenund des linken zuführenden Nierengefässes sind Fig. 20 durch * angedeutet. Vorn am Kopf mündet in den Pallialsinus ein anderer Sinus, der ventral vom Pericard liegt, ich habe ihn auf Fig. 7-18 mit si bezeichnet.

\section{Das Nervensystem.}

Das Nervensystem besteht aus 2 Cerebralganglien, 2 Pedalganglien und 3 Ganglien der Visceralcommissur, von denen ich schon in meiner vorläufigen Mittheilung die beiden äussern als Pleurointestinalganglien, das mittlere als Abdominalganglion bezeichnet hale. Zwischen diesen Gauglien bestehen die typischen Verbindungen; die C'erebralganglien $(\mathrm{cg})$ sind dorsal vom Darm durch eine ziemlich lange Cerchralcommissur (cc) verbunlen; sie ist auf Fig. 14, Taf. 1, zum grössten Theil dargestellt; ihre Lage ist allerdings wie die vieler anderer Theile des schlund- 
ringes durch die starken Contractionen des Thieres und die dadurch bedingten Verschiebungen der benachbarten Organe ziemlich gestört, doch ist ihre Lage dorsal vom Oesophagus deutlich zu erkennen. Die Cerebralganglien sind am besten auf Fig. 10, Taf. 1, dargestellt; von dem rechten entspringt rechts auf der Ventralseite das Cerebropedalconnectiv $(c p)$, das bald mit einem unter ihm gelegenen, vom Pedalganglion nach vorn verlaufenden Nerven verschmilzt, um mit ihm gemeinsam in das vordere Ende des Pedalganglions einzutreten (Fig. 11, 12, Taf. 1, pg). Die nach innen und unten gerichtete Spitze des linken Cerebralganglions (Fig. 10, Taf. 1) ist der Anfang des linken Cerebropedalconnectivs. Es liegt den äusserst kurzen Cerebropleural- und Pleuropedal conn e ctiven (Fig. 12, Taf. 1), welche die drei stark genäherten Ganglien mit einander verbinden, ganz dicht an. Rechts verhält sich die Sache ähnlich, nur ist die gegenseitige Lage der Ganglien eine etwas andere, indem das Pleurointestinalganglion ganz auf die Rückenseite, dicht unter den Boden der Athemhöhle, verlagert ist, während das Cerebralganglion der ventralen Seite genähert ist. Fig. 11 zeigt einen kurzen, dicken, mit einer Rinde von Ganglienzellen versehenen Nervenstrang zwischen Pleurointestinal- und Cerebralganglion, das Cerebropleuralconnectiv, Fig. 12 u. 13 einen ähnlichen Strang zwischen Pedal- und Pleurointestinalganglion, das Pleuropedalconnectiv.

Vom rechten Pleurointestinalganglion geht ein starker Nerv nach hinten, der Anfang der Visceralcommissur (Fig. 14 vi). Man sieht auf der citirten Figur, wie er dorsal von der Arteria cephalica liegt, so dass diese nicht durch den von der Visceralcommissur und den vordern Ganglien gebildeten Ring hindurchtritt. Die folgende Figur (Fig. 15) zeigt den Eintritt der Commissur in das rechts gelegene Abdominalganglion ( $a g)$. Dies Ganglion ist auch noch auf dem Taf. 2, Fig. 16 abgebildeten Schnitt getroffen; auf der medialen Seite entspringt die linke Hälfte der Visceralcommissur, die man Fig. 15, Taf. 1, unter dem Darm zum linken Pleurointestinalganglion verfolgen kann. Die Pedalganglien $(p g)$ sind doppelt unter einander verbunden, durch eine starke vordere (Fig. 14 l $p c$ ) und schwächere hintere (Fig. 16, Taf. 2, $2 p c$ ) Pedalcommis sur. Ein paar Buccalganglien, wie gewöhnlich mit den Cerebralganglien verbunden, liegen an der Ursprungsstelle des Oesophagus (Fig. 8, Taf. 1, bg).

Aus den schon in der Einleitung hervorgehohenen Gründen muss 
ich auf eine erschöpfende Darstellung der peripherischen Nerven verzichten; nur die von den Ganglien der Visceralcommissur ausgehenden Nerven will ich etwas eingehender schildern. Die Cerebralganglieu entsenden eine grössere Anzahl Nerven nach vorn, in den hopf, zu den Augen und in die beiden Falten, zwischen denen die Mundöffnung liegt; auf den Schnitten Fig. 7-9 sind diese Nerven dargestellt. Von den beiden Pedalganglien entspringen die Nerven zumeist auf der lateralen Seite; der Ursprung eines solchen vom rechten P'edalganglion, dicht hinter dem Pleuroperdalconnectiv ist Fig. 14, Taf. I, abgebildet; ein ähnlicher entspringt links (Fig. 13), ein anderer auf derselben Seite, am Hinterende des Ganglions (Fig. 16, Taf. 2). Von jedem P'edalganglion geht ausserdem am hinteru Ende ein ziemlich starker Nerv gerade nach hinten (Taf. 2, Fig. $16 \mathrm{fi} ., n_{9}, n_{10}$ ). Noch einen Nerven muss ich erwähnen, der am vordern Ende les rechten Pedalganglions zugleich mit dem Cerebropedalconnectiv entspringt. Fig. 11 zeigt beide Nervenstränge mit einander verschmolzen, der aus beiden gebildete Faserstrang ist mit $p g$ bezeichnet; ein paar Schuitte weiter nach vorn (Fig. 10) tritt das Cerebropedalconnectiv $c p$ in das Cerebralganglion ein, während darunter der Nerv $(n g)$ sich bis zum hiutern Ende der Genitalcloake verfolgen lïsst, wo er sich verzweigt (Fig. 9 ng). Das rechte Pleurointestinalganglion entsendet dicht neben einander drei starke Nerven, die sich zunächst gemeinsam nach vorn wenden, die zwei lateral gelegenen biegen dann nach rechts um. Der eine davon schwillt am vordern Rande des Athemloches zu einem Ganglion (go Fig. 9, Taf. 1) an, das in dem mit Wimperepithel bedeckten Wulst liegt (os), den wir schon oben als Geruchsorgan kennen gelernt haben. Nerven habe ich von diesem Ganglion nicht ausgehen sehen. Der andere Nerv ist dem eben beschriebenen, auf den zwischen Fig. 9 u. 10 gelegenen Schnitten dicht angelagert, er verlauft jedoch schon hinter dem Ganglion go nach dem Mantelrand zu, auf Fig. y findet man ihn daher schon in die Mantelfalte eingetreten, über dem Athemloch, das der Schnitt tangirt hat $\left(n_{2}\right)$. Hier theilt er sich: ein kleinerer Ast liess sich ein kurzes Stück nach vorn in der Mantelfalte verfolgen, ein stärkerer Nerv verläuft über dem Athemloch nach binten. Dieser ist am innern Rand der Mantelfalte auf allen Fig. 10, Taf. 1, bis Fig. 20, Taf. 2, abgebildeten Schnitten deutlich zu erkenuen, mit Ausnahme der Fig. 11-15, auf denen die betrefiende P'artie des Körpers nicht mit abgebildet ist. Von Strecke zu Strecke giebt er Nerven in die Mantelfalte $a b$; ich konnte ihn bis etwa an das hintere Ende des Athemloches verfolgen. Der dritte Nerv $\left(n_{\xi}\right)$ liegt auf den drei ersten 
abgebildeten Schnitten (Fig. 7-8) am innern Rand der vordern Partie des Adductors; an dessen vorderm Ende geht er in den den Kopf überdeckenden Abschnitt der Mantelfalte über und löst sich dort in mehrere starke, nach dem Rand der Falte sich wendende Nerven auf. Aus dem Abdominalganglion sah ich am hintern Ende drei Nerven entspringen, die alle drei nach hinten verlaufen. Der eine verlässt das Ganglion auf der dorsalen Seite und wendet sich dann mit der Arteria cephalica nach links (Taf. 2, Fig. 17, $18 n_{4}$ ); ich habe ihn bis zum Herzbeutel, an die Umbiegungsstelle der Niere und weiter bis zum Renopericardialporus verfolgen können und schliesse daraus, dass er Pericard und Niere versorgt. Die beiden andern entspringen etwas hinter dem ersten. Der dünnere, dorsal gelegene $\left(n_{5}\right.$ Fig. 17, Taf. 2) kreuzt den Spermoviduct und dringt zwischen ihm und dem Receptaculum in die Genitalmasse ein (Fig. $18 n_{5}$ ); dort lässt er sich noch ein kurzes Stück dem Spermoviduct entlang verfolgen. Der weit stärkere, mehr ventral gelegene $\left(n_{6}\right)$ bleibt auf der rechten Seite, sendet Fig. 18 zwei Nerven nach rechts in den Anallappen, tritt unter dem Enddarm hindurch (Fig. 19, 20) und lässt sich bier am rechten Rand der Leibeshöhle bis in die Gegend des hintern Endes des Athemloches verfolgen, dann tritt er in die Seitenwand des Körpers ein, wo er sich in zwei Aeste spaltet. Der lateral gelegene Ast wendet sich nach aussen und tritt in die Mantelfalte ein. Dort angelangt, verläuft er nach hinten, indem er hier eine ähnliche Lage einnimmt wie der vom Pleurointestinalganglion ausgehende Nerv $n_{2}$ im vordern Theil der Mantelfalte. Von dem linken Pleurointestinalganglion entspringen zwei Nerven, einer auf der linken Seite und einer hinten. Der Ursprung des linken ist Taf. 1, Fig. $14 n_{7}$ abgebildet. Er legt sich ziemlich dicht einem vom Pedalganglion kommenden Nerven an, geht mit diesem nach oben und vorn, um in die Musculatur einzudringen. In den Fig. 10 u. 12 abgebildeten Schnitten ist er zweimal getroffen, einmal in seinem Verlaufe in der Leibeshöhle und dann das bereits in die Musculatur eingetretene Stück. Er durchbohrt den Adductor und gelangt so in die Mantelfalte, wo er sich bis etwa in die Mitte des Körpers verfolgen lässt; Taf. 2, Fig. 16-18 habe ich ibn abgebildet $\left(n_{7}\right)$. Auf Fig. 16 liegt noch ein kleiner, nicht weiter bezeichneter Nerv unter ihm; es ist ein kurzer, nach vorn verlaufender Ast von ihm selbst. Der Verlauf des am hintern Ende des Pleurointestinalganglions entspringenden Nerven geht aus den Fig. 16-20, Taf. 2, hervor, wo er mit $n_{8}$ bezeichnet ist. Er liegt neben den Pedalnerven am Boden der Leibeshöhle und nähert 
sich allmahlich dem linken Rand dersellen; ich konnte ihn da nicht weiter verfolgen.

Die A uge n liegen ziemlich weit vorn an hopfe links und redits von der Mundieffnung in der Haut. Sie sind hei conservirten Thieren in der lienel von aussen nicht sichthar, da sie, wie es scheint, leei Contractionen des Thieres eingestülpt werden können; auf Schnitten sind sie jeulnch stets gut zu erkennen. Fig. 44, Taf. 3, zeigt ein Auge auf dem Grund einer kleinen Hauteinstälpung gelegen. Dassellye hat die Form eines kleinen Bläschens. Der grösste Theil der Wand wird von der Retina gebildet, in der man zwei Schichten unterscheiden kann, eine äussere, die Zellkerne enthalt, und eine innere, deren feinerer Bau völlig durch das schwarze Pigment verdeckt ist. Dies Pigment fehlt nur auf einer ziemlich kleinen, der Haut zugewandten Stelle des Augenllitschens, wo die Retina in die aus ilurchsichtigen Zellen gebildete ,innere Cornea" übergeht. Das Hautepithel, soweit es dieser "innern Cornea" anliegt, ist ebenfalls dünn und durchsichtig und bildet die ,äussere Cornea". Das Innere der Augenblase ist von einer im Leben wahrscheinlich gallertigen, im conservirfen Auge geronnenen „Linse" erfüllt. Die Fintrittsstelle des Sehnerven ist auf dem abgebildeten Schnitt nicht getroffen.

Dic Otocysten liegen in der gewöhnlichen Lage an der Innenfliche der Pedalganglien; sie sind hier, wie bei den meisten andern Arten, die mir zur Verfügung standen, schlecht conservirt und zerdrückt: ich grebe deshall, hier keine Ablildung, sondern verweise auf die Abbildungen von Siphonaria redimiculum ReEve (Taf. 3, Fig. 35 ot), wo sie besser erhalten waren. Ueber Zahl und Form der (otolithen kann ich keine Angaben machen; sie hatten sich vermuthlich bei der Vorbehandlung der betreffenden Stücke mit den verschiedenen Conservirungs- und Färbungstlüssigkeiten aufgelöst, ohne eine Spur zu hinterlassen.

Zum Schluss noch ein paar Worte über Drüsen, die sich an einigen Stellen der Körperoberfläche ausgrebildet haben. Soviel ich mit ilen einfachen, von mir angewandten Färbungsmethoilen ermitteln konnte, sind diese Urüsen kurze Einsenkungen des Hautepithels, deren Zellen zunatchst niedrig bleilen, gegen den Grund des Blindsackchens aber linger werden und sich zum Theil in grosse Drüsenzellen mit klarem, schwach färbbarem Inhalt umwandeln. Die Kerne der Drüsenzellen liegen peripher; sie sind ziemlich gross und rundlich. Ausser ihnen lemerkt man noch kleinere, langliche kerne mehr nach dem Lumen zu, die jedenfalls zwischen die secervirenden Elemente einge- 
schalteten Zellen angehören, deren Form ich jedoch nicht bestimmen konnte. Das ganze, etwa birnförmige Organ ist von einer Hülle von Fasern umsponnen, die höchst wahrscheinlich musculöser Natur sind. Da ich über keinen zur Abbildung geeigneten Schnitt verfüge, habe ich eine nach verschiedenen Präparaten combinirte Zeichnung auf Taf. 2, Fig. 29 gegeben. Diese Drüsen finden sich in ziemlich beträchtlicher Anzahl in der Haut des Kopfes, in den Seitentheilen des Fusses vom Rand der Sohle an bis zur Ansatzstelle der Mantelrinne - und auf der ventralen Fläche des Anallappens.

Drüsen von ähnlichem Bau finden sich in der Mantelfalte, nur weicht ihre Form etwas $a b$, indem die einzelnen Drüsenzellen länger und schmäler sind. Die kurzen Epithelschläuche, in welche die einzelnen Drüsenzellen einmünden, sind in einer Reihe dem Rand der Mantelfalte entlang angeordnet, und zwischen ihnen befinden sich noch andere Drüsen mit stark färbbarem Zelleib; über ihren feinern Bau und ihre Mündungsweise habe ich jedoch nichts Sicheres ermitteln können.

\section{Siphonavia laeviuscula Sow.}

Von der Gestalt des Thieres gilt fast genau das über die vorhergehende Species Gesagte, wie überhaupt fast alle Siphonarien in ihrer äussern Erscheinung nur wenig von einander abweichen. Der einzige, auch in der Form der Schale sich zeigende Unterschied ist der, dass das Thier im Verhältniss höher ist als Siphonaria pectinata, wie schon aus dem Vergleich der einander etwa entsprechenden Querschnitte Fig. 20 u. 25, Taf. 2, hervorgeht. Der innere Bau weist dagegen einige nicht unerhebliche Abweichungen auf. Da ich keine Exemplare secirt habe, kann ich der Beschreibung nur die Taf. 2, Fig. 22-26 abgebildeten Querschnitte zu Grunde legen. Von einem Exemplar habe ich allerdings die Decke der Athemhöhle eingelegt und gefärbt, die Abweichungen von der vorigen Art sind jedoch hier so unbedeutend, dass ich auf eine Wiedergabe dieses Präparates verzichten kann.

So ist ein sich über Dach und Boden der Athemhöhle hinziehendes W imperband vorhanden, unter seinem der Decke der Athemhöhle zugehörigen Theil liegt das zuführende Kiemengefüss, das mit dem das Hinterende des Thieres umsäumenden Theil des Pallialsinus durch ein Gefäss- oder besser Lacunennetz in Verbindung steht. Ebenso ist das Gefässnetz im vordern Theil des Athemhöhlendaches vorhanden, das Blut aus dem überm Kopf gelegenen Theil des 
Pallialsinus in die vordere kiemenvene leitet; auf den Chersichtsbildern Fig. 22 u. 23, Taf. 2 , hale ich diese Gefasse angresleutet.

Die Kieme stimmt in ihrem Ban mit der von Siphomaria pectinata üherein, ein Blick auf die Albililungen (Fig. $25 \mathrm{u}$. 2fi ct) zeigt jedoch, dass die Faltungen und die Anzahl der den einzelnen Blattchen aufsitzenden secundären Blittchen hesonders in dem am Athembeche liegenden 'Theil der Kieme viel beträchtlicher sind als bei dem in Schnitte zerlegten Exemplar von S. pectinata. Das zuführende hiemengefass hake ich schon oben erwähnt; auch das abführende (Fig. 2:5 u. $26 k v_{1}$ ) ist gerade wic bei der andern Art vorhanden.

Die $\mathrm{N}$ iere zerfällt ebenfalls in einen grössern, dem Dach, uml einen kleinern, dem Boden der Athemhöhle angehörenden Lappen, sie weicht nur darin etwas ab, dass die hintere Grenze jenes nicht von dem linken zuführenden Nierengefäss (lzn, Fig. 3, Taf. 1), das auch hier vorhanden ist, gebildet wird; sie erstreckt sich vielmehr über das Gefäss hinaus nach hinten, bis fast an den vordern kand der hieme. Auch ein rechtes zuführendes Nierengefass ist vorhanden; es ist Fig. 26, Taf. 2, bei $r z n$ mit dem „Frenulum" abgelildet, und Fig. 25 stellt es in der Nierenpapille dar, an deren Basis es sich verzweigt. Die vordere Grenze des obern Nierenlappens wird auch hier von der vordern Kiemenvene grebildet, die wieder zwei Muskeln enthält (Fig. $24 k v_{2}, m u$ ). Sie nimmt auch aus der Niere kommende kleinere Gefässe auf; ich hahe auf der angeführten Figur einige (medialwärts von ihr) eingezeichnet. Die hintere Kiemenvene, rig. 2i) u. $26 \mathrm{mit} k v_{3}$ bezeichnet, ist ein starkes Gefäss das den ohern Nierenlappen von links vorn nach rechts hinten durchschneidet. An der Müudung in den Vorhof nimmt sie ein aus dem dorsaleu Vierenlappren kommendes Gefäss ( $n v$, Fig. 25, Taf. 2) auf, in geringer Entfermum davon ein zweites, das ich jedoch nicht besonders ahigetildet habe. Auch aus dem ventralen Nierenlappen geht ein Gefiss hervor $1 \mathrm{nr}$, Fig. 25 u. 26), das aber nit den Kiemenvenen zusammen dirent in den Vorhof mündet; ein Theil des Blutes fliesst jedoch aus de:m ventralen Nierenlappen in das dem dorsalen angehörende Gicfass $n v$, und durch dieses dem Herzen zu. Am Fingang der Athembïhle, dem vordern Theile des Adducturs angelagert, findet sich auch hier das (ieruchsorgan (os) mit seinem Ganglion $(90$, Fig. 23, Taf. 2 ).

Die Ernährungsorgane stimmen mit denen von Siphonaria pectinata überein; ob vielleicht die Radula Alsweichungen zeigt, die für die Unterscheidung der Arten verwendlbar simd, halse ich nicht untersucht, da dies für die Fragren, auf deren lieantwortung es mir 
zunächst ankommt, ohne Bedeutung ist. Einen Schnitt durch den Kiefer habe ich auf Taf. 5, Fig. 5 wiedergegeben; die nöthigen Erläuterungen habe ich schon im voraus bei der Beschreibung der vorangehenden Art gegeben. Hervorheben möchte ich noch, dass die beiden Darmschlingen nicht ganz so weit nach vorn reichen wie bei Siphonaria pectinata; die erste Schlinge ist auf dem letzten der abgebildeten Schnitte (Fig. 26, Taf. 2, $d_{1}, d_{2}$ ) tangirt. Speicheldrüsen und Leber verhalten sich wie bei Siphonaria pectinata.

Beträchtlichere Verschiedenheiten weist dagegen der Geschlechtsa p parat auf. Fig. 22 zeigt einen Schnitt, der durch den vordern Theil der Geschlechtsöffnung gefallen ist. Von hier geht ein stark musculöser Schlauch mit engem Lumen nach innen und hinten: es ist der Penis. Aus seiner Wand treten zahlreiche Faserbündel in die Fussmusculatur ein, die vermuthlich einen Retractor bilden; sie sind Fig. 22 nur angedeutet, auf dem Lichtdruck Fig. 5, Taf. 5, $r$ aber von der folgenden, nahe verwandten Art naturgetreu dargestellt. Nach hinten verschwindet die Musculatur; Fig. 23 ist sie nur noch auf der ventralen Seite mächtig entwickelt; auf der dorsalen sind zahlreiche Syalten ( $p r$ ), Ausläufer des Prostatalumens, vorhanden, gegen das sich der Hohlraum des Penis an der Einmündungsstelle scharf absetzt. Diese selbst habe ich nicht abgebildet, sie liegt ein paar Schnitte hinter dem dargestellten.

Die beiden folgenden Schnitte (Fig. 24 u. 25) fallen ganz in die Prostata $(p r)$, die hier viel complicirter gebaut ist als bei der vorigen Art. Am übersichtlichsten ist noch der Fig. 25 abgebildete Schnitt. Er zeigt, dass die Drüsen (grau angelegt) hier nicht überall entwickelt sind. Ein Stück der dorsalen Wand ist ganz frei davon; auf der in der Figur rechts, im Thier links gelegenen Seite sind sie sehr schwach ausgebildet, während links (in der Figur) ein starkes Polster und unten zwei hohe, bei $\pi$ mit ihren Kanten verschmolzene Falten aus mächtig entwickelten Drüsen zusammengesetzt sind. Nach links von diesen beiden grossen gewahrt man noch eine ganz kleine, wie es scheint, mit Wimperepithel bekleidete Falte $(r)$, die vorn in der, Fig. 24 ebenfalls mit op bezeichneten Furche entspringt und hinter den beiden grossen, zu einem Wulst verschmelzenden drüsigen Falten in die, Figr. 25 mit $\tau_{1}$ bezeichnete Furche übergeht. Sie lässt sich in eine kleine Aussackung verfolgen, die auf der zwischen den algelildeten Schnitten gelegenen Strecke, ungefähr an der auf Fig. 24 mit * bezeichneten Stelle blind endet. Den feinern Bau des Drüsengewehes habe ich auch hier der ungenügenden Conservirung wegen 
nicht studiren kïmnen; er scheint mir nicht wesentlich von dem der vorigen Art verschieden.

Die Furche, in die der Penis mündet, setzt sich noch ein Stück nach hinten fort. Dort münden (Fig. 23, Taf. 2) zwei Canäle, einer mehr dorsal und lateral ( $r s)$, der andere mehr medial und ventral (spor). Ersterer hat ziemlich stark musculöse Wandungen; er durchbohrt den Adductor, und in Fig. 24 sieht man ihn bereits aus diesem heraustreten. Fig. 25 legt er sich der Prostata an, und Fig. 26 finden wir ihn, ziemlich dünn geworden, unter der Eiweissdrüse. Er geht hicr noch ein Stück gerade nach hinten und erweitert sich zum R e ceptaculum seminis, das hier Spermatophoren enthält. Der andere Cunal ist der Spermoviduct. Er verliuft mit dem Stiel iles Receptaculums durch den Adductor, tritt mit ihm in die Leibeshïhle ein; Fig. 25, Taf. 2, zeigt ihn unter dem letztern liegend. Fr erweitert sich hier, indem die Wand drüsig wird, genau in derselben Weise wie bei der vorigen Art, geht so bis an die Medianebene und biegt dann gerade nach hinten um. Auf Fig. 25 ist der quere, durch den Körper verlaufende Anfangstheil getroffen; Fig. 26 zeigt einen Querschnitt, auf dem man deutlich die beiden Rinnen erkennt, die sich wie bei der vorigen Art durch den histologischen Aufhau ihrer Wand unterscheiden. Am hintern Ende trennen sich die Rinnen ganz, die Schleimrinne (sr) geht in die Schleimdrüse $(s d)$ üher, und in die Prostatarinne ( $p r r)$ mündet die Eiweissdrüse $(e d)$ und der $Z$ wittergang, dem seitlich die S amenblase ansitzt. Letztere, auf den Figuren mit $s b$ bezeichnet, war hier nach vorn umgeschlagen, daher ist sie mit Stücken ihres Ausführganges schon auf dem Fig. 26 abgebildeten Schnitt getroffen. Der Zwittergang ist mit reifen (?) Spermatozoen angefüllt; er sowie die Zwitterdrüse weichen nicht von den später zu beschreibenden entsprechenden Organen von Siphonaria luzonica ab, weshalb ich sie hier übergehen kann.

Eine auffallende Abweichung bietet das Blutgefässystem in dem Verhalten der Aorta dar. Während Herz und Herzbeutel gatnz die schon bei der zuerst beschriebenen Art geschilderte Lage einnehmen, weicht die A orta cephalica durch ibren Verlauf in einem wichtigen Punkt ab. Während sie bei Siphonaria pertinata durch die erste Darnuschlinge hindurchtritt, so dass deren beide Schenkel $d_{1}$ und $d_{2}$ sich vor ihr vereinigen, ist dies bei unserer Art nicht der Fall (Fig. B); die beiden Darmschenkel vereinigen sich hinter der Arterie, die nicht ein Stück durch die Eingeweide hindurchiringt, sondern längs der Pericard und Leibeshöhle trennenden Wand nach 
oben (Fig. $25 a a$ ) und dann allerdings wie bei Siphonaria pectinata nach der rechten Seite hinüber verläuft. Hier verzweigt sie sich in ähnlicher Weise wie dort; ich habe die einzelnen Gefässe ziemlich genau verfolgt, muss jedoch hier auf eine eingehende Darstellung derselben verzichten, da die abgebildeten Figuren dazu bei weitem nicht ausreichen, die Zahl der zu diesem Zweck erforderlichen Figuren aber in keinem Verhältniss zur Bedeutung der Sache gestanden hätte.

Das Nervensystem zeigt, soweit ich es untersuchen konnte, dieselbe Zusammensetzung wie bei Siphonaria pectinata; einzelne Theile sind in den Fig. 23-26 abgebildet. So zeigt Fig. 23 das schon oben erwähnte Geruchsorgan mit seinem Ganglion (os u. go), Fig. 24 das linke Cerebralganglion (cg) mit einem Theil der Cerebralcommissur, darunter das linke Pleuralganglion $(p l g)$ und die beiden Pedalganglien $(p g)$; über den Pedalganglien liegt ein Stück der Visceralcommissur (vi), rechts in Zusammenhang mit dem A bdominalganglion $(a g)$, von dem der Herz-

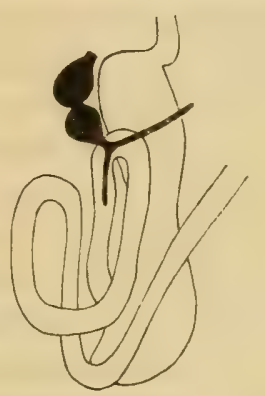

Fig. B. Darm und Herz von Siphonaria laeviuscula. Wegen der Bedeutung der einzelnen Theile vergl. Fig. A, S. 13 . beutel und Niere versorgende Nerv $\left(n_{4}\right)$ ausgeht. Auch einen der vom Abdominalganglion nach binten verlaufenden Nerven habe ich Fig. 25 u. 26 abgebildet $\left(n_{6}\right)$.

Hautdrüsen sind wie bei Siphonaria pectinata am Mantelrand und an der Seite des Fusses und des Kopfes entwickelt, ich habe letztere, um eine Vorstellung von ihrer Vertheilung zu geben, in die abgebildeten Figuren eingezeichnet (Fig. 22-26 dr).

\section{Siphonaria subrugosa Sow.}

Diese Art steht anatomisch der vorangehenden sehr nahe, ich gebe daher hier nur einige Abbildungen vom Geschlechtsapparat, die bei der grossen Aehnlichkeit der beiden Arten das über Siphonaria laeviuscula Angegebene ergänzen können. Fig. 27 u. 28 stellt den Penis mit der Prostata noch im Zusammenhange mit der Geschlechtsïffnung einmal von aussen und einmal von innen gesehen dar; $p r$ ist die Prostata, pe der Penis, von dem auch ein Querschnitt Fig. 7, Taf. 5, alggebildet ist. Der Penis ist ein sehr dickwandiges Rohr mit engem Lumen, welch letzteres mit einem bei dem vorliegenden Exemplar stark macerirten Epithel ausgekleidet ist; sonst besteht die Wand 
aus melufachen Iagen von Ringmuskeln, zwischen denen nan die Querschnitte von mehr längs verlaufenden Faserbiudoln erkonnt. I)as distale Ende des Penis war hei allen untersuchten Exemplaren ausurestiilpt, wie der Fig. 30 ahgebildete Schnitt zeigt; es ragt als ziemlich umfangreiche Papille, an deren Spitze sich bei * das Lunen nach aussen öffnet, in die die Ausführgänge des Geschlechtsaplarats aufnehmende Grube hinein. Während diese bei der vorhergehenden Art nur eine seichte Furche war, ist sie hier durch den ausgestiilpten Penis zu einem ziemlich grossen, blasenförmigen Hohlraum erweitert, in den ausser dem Penis hinten noch der Stiel des Receptaculums und der Spermoviduct cinmünden (wie es Fig. 27 u. 22., Taf. 2 , von Siphonaria laeviuscula dargestellt ist). (Querschnitte durch dic beiden letztern Canäle habe ich Taf. 5, Fig. 6 aligebildet; der oluere, grössere ist der Stiel des Receptaculums, der darunter gelegene dünnere der Spermoviduct. Beide sind mit vermuthlich flimmerndem (ylinderepithel ausgekleidet, das mehrere Längsfalten hilıtet; der Hauptthıil der Wand wird auch hier von Musculatur gebililet, und zwar lient nach innen zu eine Schicht längs verlaufender Fasern, nach ausien dagegen Ringfasern. An der Mündung des Spermoviducts heobachtote ich ein ziemlich dickes Polster von wahrscheinlich einzelligen I)rïsun.

Ausdrücklich hervorheben will ich noch, dass die Aorta cephalica sich hier zur ersten Darmschlinge gerade so verhält wie bei der vorhergehenden, ja auch von der chilenischen Küste stammenden Art.

\section{Siphonaria redimiculum REEVE.}

Von dieser Art hatte ich zwei Exemplare, die ich beide Taf. 3, Fig. 41 u. 42 abgebildet habe. Fig. 41 ist das jüngste Fxemplar, os war nur 21.5 mm lang: das Fig. 42 ahgebildete war schon hedeutend älter und etwas über $8 \mathrm{~mm}$ lang. Zunächst fällt es auf, dass die Thiere in ihrer Gestalt etwas von den seither beschriehenen Arten abweichen, was sich auch in der Form der Schale iussert; die spitze? liegt nämlich nicht nahe der Medianlinie ungefähr in der Mitte des Thieres, sondern links und weit nach hinten, so dass hei der Betrachtung von oben ein Theil des Adductors von dem hier vorspringenden Eingeweidesack verdeckt wird. I)ies Verhalten ist offenhar als eine Andeutung einer spiraligen Aufwindung des Eingeweidesackes aufzufassen.

Da ich die heiden Exemplare gern in unverletztem Zustand schneiden wollte, habe ich nichts präparirt; die Organe der Athemhïhle, 
die in ihrer Lage und Ausdehnung etwas von denen der andern Arten abweichen, habe ich daher nur insoweit darstellen können, als sie bei Betrachtung des Thieres von der dorsalen Seite mit Hülfe einer Lupe sichtbar waren.

Das Dach der Athemhöhle zeigt im grossen Ganzen deuselben Bau wie bei den andern Arten; die Blutgefässnetze im vordern und hintern Theil desselben habe ich allerdings nicht mit derselben Sicherheit wie bei den andern Arten erkennen können, glaube aber nach einigen Beobachtungen, dass sie trotzdem vorhanden sind, sich jedoch, da sie blutleer sind, an den meisten Stellen der Wahrnehmung entziehen.

Die $\mathrm{K}$ i e me $(c t)$ ist in der schon oben geschilderten Weise aus einzelnen Blättchen zusammengesetzt; bei dem ganz jungen Thiere sind es einfache, glatte Falten (Fig. 37, 38, 39, Taf. 3, ct); bei dem ältern sind sie gefaltet und tragen kleine, secundäre Blättchen (Fig. $43 c t$ ). Am hintern Rande, unter dem Wimperband $(w b)$, ist ein $\mathrm{zufüh}$ rendes Kiemengefäss, am vordern ein abführendes $\left(k v_{r}\right)$ vorhanden. Die Gestalt der Kieme im Ganzen weicht jedoch etwas ab: sie ist uicht sichelförmig, sondern nur ganz schwach es-förmig gekrümmt; verglichen mit der Grösse des ganzen Thieres, ist sie schwächer entivickelt als bei den andern Arten. Auch hinsichtlich der Verbindung des abführenden Kiemengefässes mit dem Vorhof findet sich bei unserer Art eine bemerkenswerthe Abweichung: ich konnte nämlich nur eine secundäre Ki emenvene nachweisen. Dieselbe ist auf den Fig. 36 -39 u. 42 mit $k v_{2}$ bezeichnet; Fig. 36 zeigt auch den einen der beiden Muskeln, die sich hier wie bei allen untersuchten Siphonarien in diesem Gefässe befinden $(\boldsymbol{m} u)$. Dies Gefäss entspricht in allem der vordern von den beiden Kiemenvenen, die wir bei den andern Siphonarien finden; von der hintern konnte ich keine Spur erkennen. Es ist mir auch nicht wahrscheinlich, dass sie mir in Folge mangelhafter Füllung mit Blut entgangen sein sollte, denn ich habe bei allen andern untersuchten Siphonarien die beiden Gefässe stets gleichmässig stark mit Blut erfüllt gefunden. Das Fehlen der hintern Kiemenvene steht vielleicht in Zusammenhang mit der verhältnissmässig geringern Entwicklung des sich nach der linken Seite hinziehenden Theiles der Kieme.

Der Bau der Niere war bei dem ganz jungen Exemplar verhältnissmässig noch recht einfach; einiges davon, was in etwas verschwommenen Umrissen durch das Dach der Athemböhle durchschimmerte, habe ich Fïg. 41, Taf. 3, wiederzugeben versucht. Aus 
dieser Figur, in Verbindung mit den Fig. 36-39 abgebildeten Querschnitten, ersieht man, dass die Niere ein einfacher Sack ist, der durch Falten, die grösstentheils von dem Borlen bis zu der Decke herahreichen, in eine grosse Anzahl neben einander liegender, rïlırenförmiger Hohlräume abgetheilt wird. Bei dem altern Exemplar ist das Querschnittsbild wejt complicirter. Ein grïsserer, gemeinsamer Hohlraum, wie ihn bei dem jüngern Fig. 37 u. 38 zeigen, ist nur noch in der Nierenpapille nahe dem Nierenporus vorhanden, wie Fir. 433 erlautert, die eiuen Querschnitt durch ein Stïck des Daches der Athemhöhle mit der Nierenpapille und dem benachbarten Theil der kieme darstellt. Der auf dieser Figur algebildete Schntt hat gerade den Nierenporus getroffen, eine einfache, rundliche (oeffnung mit wulstigen Rändern, in deren Nähe das Lumen der Niere mit einem cubischen Epithel ausgekleidet ist, das den Uebergang zwischen dem Xierenepithel und dem Epithel der Athemhöhle vermittelt. Die Renopericardialpforte ist Fig. 37 von dem ganz jungen Exenplar abgrebildet: sie stellt einen kurzen, quer verlaufenden Canal dar, der mit Wimperepithel ausgekleidet ist.

Auch hier ist am Eingang der Athemhöhle ein Geruchsorga n entwickelt; bei dem grössern Exemplar schimmerte es durch die Decke der Athemhöhle durch und ist Fig. 42, Taf. 3, dargestellt; Schnitte durch dasselbe und das Ganglion zeigen die Fig. 33-35.

Die Form des Darmcanals wird zunächst durch die Taf. :3 abgebildeten Schnitte des ganz jungen Thieres erläutert. Fig. 31 zeigt die an der Mundöffinung gelegene Furche, in welcher der hufeisenförmige Kiefer ( $k$ ) liegt; die beiden Schenkel des Hufeisens erscheinen auf dem Schnitt quer getroffen. Der folgende Schnitt fält schon in die eigentliche Mundhöhle. Von hinten springen die Enden der beiden Stützlsalken der Radula (st), die hier mit einander verwachsen sind, vor; über ihnen liegen die vordersten Reihen der Radulazähne. Einen Schnitt durch den Stützbalken der Radula bei stärkerer Vergrösserung habe ich Taf. 5, Fig. 8 abgebildet. Auf manchen Schnitten erinnert der Stützbalken stark an die Abbildung, die Plate von den Stützbalken von Dentalium dentale giebt. Wie dort ist ein Netz von einer auf der Flächenansicht längsstreifig erscheinenden Sulsstanz vorhanden. Einen protoplasmatischen Belag an dem Rand der Maschen habe ich allerdings uicht erkenuen können, da die Conservirung keine tadellose war; dagegen sind leicht in den Maschen des Netzes Kerne zu constatiren, die entweder in der Mitte der Maschen frei liegen oder dem Netzwerk angelagert sind. Die Maschen sind mit einer homogenen, 
oft durch die Conservirungsmittel geronnenen, farblosen Masse angefüllt, in der zuweilen schwarze Körnchen auftreten.

Betrachtet man einen Schnitt, der in senkrechter Richtung zu den eben beschriebenen geführt ist, wie der von mir abgebildete Taf. 5 , Fig. 8, so wird man belehrt, dass die Aehnlichkeit mit Dentalium keine so bedeutende ist, wie es nach dem einen Schnitt den Anschein hatte. Denu während bei jenem der Stützbalken aus polyedrischen Zellen zusammengesetzt ist, erscheint hier die Substanz, welche auf dem Querschnitt das Netz bildete, in der Form von langgestreckten Zügen, die anscheinend die ganze Dicke des Stützbalkens durchsetzen. Besonders nach dem medianen Rande des Stützbalkens, wo er durch Muskelfasern mit dem gegenüberliegenden zusammenhängt, sind diese unter einander im Allgemeinen parallelen Züge gut zu erkennen. Es ist schwer, sich auf Grund der ziemlich unvollkommenen Präparate, die mir allein zur Verfügung stehen, eine Vorstellung von dem histologischen Aufbau des Stützbalkens zu machen; es ist möglich, dass hier ähnliche Zellen wie bei Dentalium vorhanden sind, nur hätten sie dann nicht die Gestalt eines nach allen drei Dimensionen etwa gleich ausgedehnten Polyeders, sondern stellten prismatische Zellen dar; es ist aber auch nicht auszuschliessen, dass die fein längsgestreiften, faserigen Massen modificirte Muskelzellen vorstellen, zwischen denen die eigentlichen Stützzellen mit ihrem farblosen Inhalt liegen. Die Untersuchung dieses eigenthümlichen Gewebes muss spätern Untersuchungen vorbehalten bleiben; ich theile meine spärlichen Beobachtungen hier nur mit, weil aus ihnen wenigstens das eine hervorgeht, dass die Stützbalken auch bei Siphonaria nicht aus ächtem Knorpelgewebe gebildet sind.

Oesophagus und Magen kann ich übergehen, da ich dem bei den vorhergehenden Arten Erwähnten nichts Neues hinzuzufügen habe; dagegen sind ein paar Worte über den Verlauf des Dünndarms nöthig. Der grössern Anschaulichkeit halber gebe ich als Grundlage für die Beschreibung die nachstehenden Figuren, die, schematisch gehalten, den Darmcanal von Siphonaria pectinata (Fig. A) und von der vorliegenden Form (Fig. C) darstellen. Erstere Figur ist nach Fig. 4 u. 6, Taf. 1, entworfen, Fig. C ist nach ihr, unter Berücksichtigung der Abweichungen, welche die Untersuchung der beiden Schnittserien erkennen liess, construirt. Aus der Vergleichung der beiden Figuren ergiebt sich sofort, dass bei unserer Form, und zwar, wie ich ausdrücklich bemerke, sowohl bei dem grïssern wie bei dem kleinern Exemplar, die zweite, nach vorn gerichtete Darmschlinge $\left(d_{3}, d_{4}\right)$ fitst 
ganz fehlt; sie ist nur durch eine leichte, nach links gerichtete Ausbiegung des Darmstückes $d_{2}$ angedentet, die ich auf Fig. C mit $d_{3 .}$. bezeichne. Auf den Taf. :3 ahgebilideten Querschnitten verrath sich das Vorhandensein dieser Ausbiegung dadurch, dass $d_{2}$, das Fig. 39 nahe der Hedianlinie lag, in Figg. $40 \mathrm{ganz}$ an den linken Rand gerückt ist. Verfolgt man die Serie weiter, so sieht man üher dem Finde des

Fig. A.

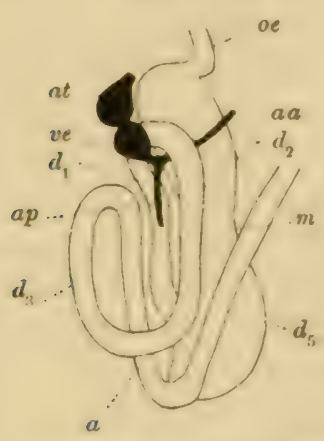

Fig. C.

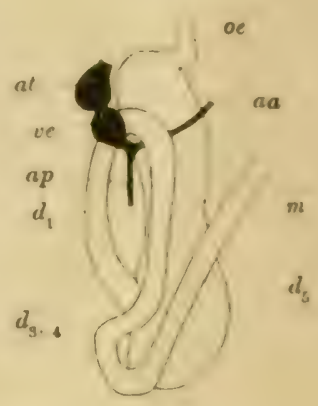

Fig. A. Derm und Herz von Siphonaria pectinata.

Fig. C. Darm und Herz von Siphonaria redimiculum.

oe Oesophagus, $m$ Magen, $d_{1}-d_{5}$ Darm, ve Veutrikel, at Atrium, a Arteris muterior, ap Arteris posterior.

Magens auch die beiden mit $d_{2}$ u. $d_{5}$ bezeichneten Darmquerschnitte mit einander verschmelzen. Diese Umbiegungsstelle des Darmes liegt ebenso wie das blinde Ende des Magens in dem nach hinten vorspringenden, rudimentären Eingeweidesack.

Die beiden Speicheldrüsen sind bei dem jüngern Thier noch ziemlich einfach gebaut; ich habe die Drüsenzellen, da sie sich zu mangelhaft conservirt hatten, nicht eingezeichnet, sondern mich auf die Wiedergabe der Umrisse des ganzen Oryans beschränkt. Dieselhe Methode babe ich aus dem gleichen Grunde bei der Darstellung der Leber anwenden müssen; ich gebe in Fig. 39 einen Schnitt durch die Einmündung der grossen, links und vor der Abgangsstelle des Dünndarms gelegrenen Leber; Fig. 40 stellt dagegen die Communication der kleinen, sich auf der ventralen Seite und hinter dem Pylorus in den Magen öftuenden Leber mit letzterm dar.

Ueber den Geschlechtsapparat der voriiegenden Form hat Struer einige Mittheilungen gemacht. Nach ihm ist eine $\mathrm{Zwitter}$. drüse, ein Receptaculum seminis und ein Penis vorhanden,

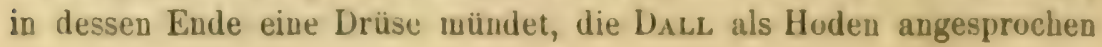


hat. Von den mir vorliegenden beiden Exemplaren besass keines einen völlig ausgebildeten Geschlechtsapparat. Die Anlagen der einzelnen Theile waren im Verhältniss zu der Grösse, die sie bei den andern erwachsenen Siphonarien erreichen, noch ziemlich unbedeutend und die histologische Differenzirung auch bei dem ältern noch wenig vorgeschritten. Ich beginne mit der Beschreibung des jüngern Exemplars.

Das erste, was man vom Geschlechtsapparat gewahrt, wenn man die Schnittserie von vorn nach hinten durchmustert, ist die Anlage des $\mathrm{Pen}$ is. Sie ist eine kleine, von Cylinderepithel ausgekleidete, schlauchförmige Einstülpung, deren Mündung Fig. 32 b pe dargestellt ist. Sie dringt nach vorn zu in die Musculatur ein und zeigt an ihrem blinden Ende eine nach innen und oben umgebogene kurze Aussackung, die von etwas grössern Zellen ausgekleidet ist; es wird wohl die Anlage der Prostata sein (Fig. 32 a pr). Der zweitnächste Schnitt von diesem aus (Fig. 32) tangirt schon das umgebogene Ende, und auf dem darauf folgenden verschwindet die Anlage ganz. An die Mündung der Penisanlage schliesst sich ein ganz kurzes, seichtes Grübchen an, dessen dorsalem Rand ein enger, mit cubischem Epithel ausgekleideter Canal anliegt. Sein vorderes Ende tritt dicht an das Epithel des Grübchens beran, ich war jedoch nicht im Stande, sicher zu entscheiden, ob er hier mündet oder noch blind geschlossen ist. Dieser Canal verläuft auf demselben Weg, den beim Erwachsenen Spermoviduct und Receptaculumstiel einschlagen, durch den Adductor nach hinten und tritt unter dem Athemloch nach links in die Leibeshöhle. Ich will diesen Canal den Geschlechtsgang nennen. Auf den Figg. 33-36, die seine Lage zu den andern Organen erläutern sollen, habe ich ihn mit $g g$ bezeichnet. Bei seinem Eintritt in die Leibeshöhle wird der Geschlechtsgang etwas weiter und entsendet ein kurzes Divertikel medianwärts (Fig. $37 \delta_{1}$ ); kurz darauf verbreitert er sich ziemlich bedeutend (Fig. 37 a gg), und unter der Mitte seiner ventralen Fläche bemerkt man einen kleinen Canal (zwg), der am Beginn der Verbreiterung sich dicht an ihn anlegt, möglicher Weise auch mit ihm communicirt. Beide Canäle lassen sich so, wie es Fig. 37 a darstellt, auf etwa 9 Schnitten $1=90$ u) nach hinten verfolgen, dann endet der erweiterte Geschlechtsgang blind, und der kleine Canal (zwg) bleibt allein übrig (Fig. 38, 39). Ein paar Schnitte hinter den Fig. 39 abgebildeten endet der Canal, der jedenfalls die Anlage des Zwittergangs ist, indem er sich zu einem Blaschen erweitert, dessen Wand eingefaltet zu sein scheint; ich gebe hier keine Abbildung, da das Blaschen durch den Druck der umliegenden Organe stark deformirt ist und deshalb auf den Schuitten 
keine klaren Bilder liefert. Dies Bläschen halte ich für die Anlage der Zwitterdrüse. Nebenstehende Figur (D) soll zum Schluss in schematischer Weise eine Uebersicht über die einzelnen Theile ther Aulage des Geschlechtsapparats gehen; die Buchstabenhezeichnungen sind dieselben wie auf der Tafel. Die Anlagen des Penis, sowie die der Zwitterdrüse und des Zwittergangs sind bein Vergleich mit den Gieschlechtsorganen einer ausgewachsenen Siphonaria schon an ihrer Lage leicht wieder zu erkennen; die grösste $\mathrm{Ab}$ weichung zeigt der mittlere $\mathrm{Ab}$ )schnitt des Geschlechtsapparats, der Genitalgang mit seinem verdickten Ende und dem seitlichen Blindisackchen. Es fehılt nämlich das Receptaculum, wenn nicht das ehen erwahnte Blındsäckchen seine Anlage darstellt, die allmahlich, etwa

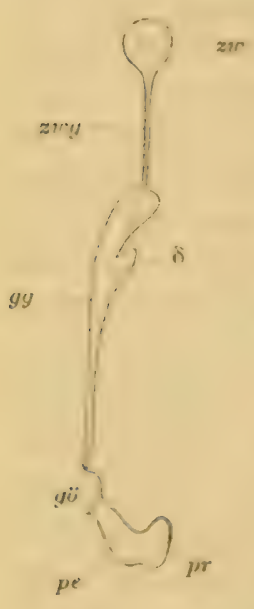
durch spaltung des Geschlechtsgangs, einen gesonderten Ausführgang gewinnen müsste. Das verdickte Ende des Genitalgangs stellt wohl die Anlage der Eiweiss- und Schleimdrüse dar. Bei dem altern Exemplar war das Receptaculum mit seinem Stiel, wie wir unten sehen werden, schon vollkommen seltstandig; /wischenstufen standen mir nicht zur Verfügung, ich muss daher die Frage nach der ersten Anlage des Receptaculums offen lassen; das ohen Angedeutete soll nur eine Vermuthung sein.

Fig. D. Geschlechtsapparat einer ganz jungen Siphonaria redimiculum. zr. Zwitteribüze, zarg Zwitlergang. yg Geschlechlognug. gï Ceschlecht:üfoung, pe Peris, pr Prostata. S Anluge der Receptsculums?

Die Untersuchung des ältern Exemplars ergab theilweise wenig hefriedigende Resultate. Gerade über die Schleim- und Fiweissdrüse, die bei dem erwachsenen Thier - abgesehen von der bei meinen Lxemplaren zumeist mangelhaften Conservirung und schlechten Schnittfahigkeit - complicirte und schwer verständliche Querschnittshilder liefern, batte ich bei dem in Rede stebenden Exemplar Aufklairung zu erhalten gehofft, sah mich aber in meinen Erwartungen durch den Unstand getäuscht, dass der Magen in seinem hintern Theil Sandkörner enthielt. die beim Schneiden an den betreffenden Stellen manches zerstörten.

Die Penisanlage ist, wie man nach der Grïsse des Thieres erwarten kann, in der Entwicklung schon beträchtlich vorgeschritten: sie bat an Grösse zugenommen und ist in Folge dessen aus der 
Musculatur nach dem Kopf $\mathrm{zu}$ in die Leibeshöhle eingetreten. Der distale Theil hat sich dabei ganz auf den proximalen zurückgeschlagen, so dass man auf einem Querschnitt, wie ihn Fig. 9, Taf. 6, darstellt, beide Theile annähernd quer getroffen über einander sieht. Der äussere Theil hat eine stark musculöse Wand gewonnen und documentirt sicb schon dadurch als eigentliches Copulationsorgan; das Lumen engen einige von der musculösen Wand vorspringende Falten ein (auf unserer Figur ist eine derselben so getroffen, dass sie das Lumen auf dem Schnitt vollständig in zwei Hälften theilt). Der innere ist verhältnissmässig dünnwandig geblieben und zeigt nur viele hohe, in das Lumen vorspringende Falten. Im Innern dieser Falten, sowie überhaupt nach aussen von dem Prostataepithel liegt mit Ausnahme einer dorsal gelegenen Stelle, wo das Epithel selbst ziemlich niedrig ist, ein Gewebe, in dem man nur äusserst zahlreiche Zellkerne erkennt; die Structur der Wand erscheint also noch recht verschieden von der, die man sonst bei ausgewachsenen Siphonarien beobachtet. Eigenthümlich verbält sich der auf Fig. 9 mit $x$ bezeichnete Theil der Prostata: er stellt einen Canal ohne innere Falten vor, der dicht hinter dem Uebergang des Penis in die Prostata entspringt und nun an der ventralen Seite derselben nach vorn verläuft, ohne dass er sonst nachweisbar mit dem übrigen Lumen communicirte. Sein blindes, etwas erweitertes Ende bildet den am weitesten nach hinten reichenden Theil der Prostata. Nur der Vollständigkeit halber, denn ich weiss nicht, wie ich ihn deuten soll, erwähne ich einen ganz feinen, mit Cylinderepithel ausgekleideten Canal, der in der Nähe der Mündung aus dem Penis entspringt und sich ein Stück weit in dessen Musculatur nach vorn verfolgen lässt; dann wird er so undeutlich, dass sich sein weiterer Verlauf nicht mehr feststellen lässt; vielleicht kann eine anatomische Untersuchung des erwachsenen Thieres, zu der mir leider das Material nicht zu Gebote steht, über diesen Canal Aufklärung geben.

In demselben Maasse wie bei Penis und Prostata ist auch bei den übrigen Theilen des Geschlechtsapparats die Entwicklung vorgeschritten. Am auffalleddsten macht sich das, wie schon oben erwähnt, dadurch bemerklich, dass hinter dem Penis statt des einfachen Geschlechtsgangs zwei Canäle münden, der Spermoviduct und der Stiel des Receptaculums. Letzterer endet noch vor dem Eintritt des Spermoviducts in die Leibeshöhle blind, ohne eine Anschwellung und ohne dass sich eine besondere Differenzirung in seiner Wand nachweisen liesse; ein eigentliches Receptaculum ist also noch nicht zur Ausbildung gekommen. Im Spermoviduct beginnt in dem 
hintern Theil seines Verlaufs in Adductor eine etwa bis in die Mitte des Lumens vorragende Falte; eine Verschiedeuheit der Wand in den beiden durch die Falte getiennten Halften lasst sich aber hier noch nicht nachweisen. Nach seinem Eintritt in die Leibeshiohle bemerkt man jedoch, dass auf der einen Halfte unter dem Epithel sich Gruppen vou grossen hernen (ke) betinden, wahrend auf der andern die Epithelzellen selbst etwas grösser sind. Ich gebe Fig. 10, Taf. 6 , eine $A$ bbildung des Spermoviducts, welche die betreftenden Verbaltnisse, so gut sie eben auf dem Praparat zu erkennen waren, veranschaulicht. Ich werde wohl kaum fehlgehen, weun ich annehme, dass die grossen herue Eutwicklungsstadien der Drüsenzellen der Prustatarinne (prr) des Spermoviducts angehören, wabrend der übrige Theil der $\mathrm{W}$ and die schleimrinne (sr) umschliesst. Nach einer kurzen Strecke verschwinden diese Kerne an der Prostatarinue, und der Spermoviduct offnet sich zweimal, und zwar zuerst an der Seite der Prostatarime in einen mit stark in das Lumen vorspringenden Falten versehenen Hohlraun, den ich eben wegen dieser Verbindung mit der Prostatarinue für die Anlage der Ei weissdrüse halte (Fig. 53, Taf. 4, ed); dann schliesst sich die Schleimrinne mit einer aus der Eiweissdrüse stammenden Riune $(\varrho)$ ab, um sich nach kurzem Verlauf in eiven der Eiweissdrüse ähulichen kleineru Hohlraum zu ötỉnen, der sich zum grussen Theil nach vorn über die Schleimrinue zurückschlagt (Fig. ¿t-_o, Taf. 4, sd). Dieser Hohlraum ist vermuthlich die Anlage der Schleimdrü se. Unter der Schleimrinue bemerkt man die Anlage des $Z$ witter- gangs (Fig. 53-506, Taf. 4, zwg); er verlauft unter dem Spermoviduct bis dicht vor die Stelle, wo er sich zum ersten Mal offinet, und biegt danu nach links um. Er kommt da in die Gegend, welche bei der Anfertigung der Schnitte aus dem schon oben genanuten Grund beschädigt wurde, und ist da natürlich nicht zu verfolgen; es ist wahrscheinlich, dass er dort, nahe dem Ende der Prostatariune, in deu Hoblraum ed einmündet. Nach hinten lässt sich der Zwittergang gut verfolgen: er liegt da, ähnlich wie auf Fig. 38 von den jungen Exemplar dargestellt, zwischen Enddarm und Magen, nur etwas weiter nach rechts und beginnt schon sich in Windungeu zu legen. Er mündet dann in die Zwitterdrüse, welche links an der vou den anderu Arten her bekannten Stelle liegt und schon den typischen Bau zeigt, den ich bei den folgenden Arten naher schildern werde. Deutlich als Eier erkeubbare Zellen sind aber auf diesem Stadium noch ziemlich selten; die Elemente, welche den grïssten Theil des Organs einnehmen, scheinen Entwicklungsstadien von Spermatozoen zu sein. 
Die grossen arteriellen Gefässe verhalten sich bei unserer Art zu der Darmschlinge nicht wie bei den beiden vorhergehenden Arten, sondern wie bei Siphonaria pectinata, d. h. die Arteria cephalica tritt durch die Darmschlinge hindurch, wie die Schnitte Fig. 37 u. 38, Taf. 3, und in schenatischer Weise die Textfigur C (S. 32) es zeigen; sie läuft dann unter dem Boden der Athemhöhle nach rechts, wo sie sich in ähnlicher Weise wie bei den seither betrachteten Arten verzweigt.

Nach hinten geht ausser der grossen Arteria abdominalis, die dicht am Herzen entspringt, noch ein ganz schwaches Gefäss weiter nach rechts von der Aorta ab; es verläuft links vom Magen nach hinten.

Das N ervensystem zeigt die schon bekannte Zusammensetzung aus neun Ganglien, die hier bei dem ganz jungen Thier noch ziemlich übersichtlich angeordnet sind. Fig. 32 zeigt die beiden Cerebral ganglien, das rechte oben mit dem Anfang der Cerebralcommissur, das linke unten mit dem Ursprung eines Nerven. Fig. 33 zeigt die beiden B u c calganglien $(b g)$, einen Querschnitt durch den vordersten Theil des Geruchsorgans (gs), das Pleurointestinalganglion $(p l g)$ rechts und das Cerebropleuralconnectiv ( $c p l$ ) links, sowie die beiden Cerebropedalconnective $(c p)$. Fig. 34 hat ebenfalls noch das Geruchsorgan, jedoch an der Stelle, wo es ins Athemloch einbiegt, getroffen; dann sieht man die beiden $\mathrm{Pleurointestinalganglien}$ und die beiden Pedalganglien ( $p g)$. Der folgende Schnitt (Fig. 35) zeigt dieselben Ganglien; er tangirt die hintere Kante des Geruchsorgans, und dorsal von den Pedalganglien bemerkt man die Otoc ys te n $(o t)$, kleine Bläschen mit niedrigem Epithel ausgekleidet, die nur hier einigermaassen genügend conservirt waren. Fig. 36 endlich zeigt das letzte Ganglion, das A bdominalganglion $(a g)$, und über dem Fuss die hintern Enden der Pedalganglien. Auch einige Nerven have ich in die Schnitte eingezeichnet und, soweit es thunlich war, mit Bezeichnungen versehen, die mit den bei Siphonaria pectinata angewandten übereinstimmen; ich verweise daher, um Wiederholungen zu vermeiden, auf das dort Gesagte.

\section{Siphonaria aspera KRAUSS.}

Das 'Thier zeigt nicht die äussere Asymmetrie wie die vorangehende Art, sondern nähert sich in dem Aussehen mehr Siphonaria pectinatr L., ist jedoch nicht so stark abgeflacht. Fs ist die einzige Art, die eine etwas lebhaftere Färbung zeigte; während bei Siphonaria 
redimiculum REEVE und Siphonaria subrugosa Sow. die Färbung ein eintöniges (irau war, das nur am Mantelrand regelmassig alternirende helle Flecken unterbrachen, zeigt die vorliegende Art am kopf und an den Seiten des Fusses zahlreiche unregelmassige schwarze Flecken auf der Grundfarbe, einem düstern Graubraun, das rein nur an der Ventralseite des liopfes, auf der Fussohle und in der Mantelrinne auftritt. Auch am Mantelrand sind die schwarzen Flecken vorhanden; ich habe sie Fig. 45, Taf. 4, auf den kleinen Stück der Mautelfalte, das über das Athemloch wegzieht, dargestellt. Man erkennt auf der Zeichnung, dass die farblosen Partien vorspringende Zacken bilden, wahrend die pigmentirten Theile meist eingezogen sind. Es hat den Anschein, als ob diese Zacken mit den Rippen der Schale in Beziehung ständen, denn sie sind im Allgemeinen stark entwickelt bei stark gerippten und schwach entwickelt bei schwach gerippten Arten.

Bei der Schilderung des innern Baues brauche ich nur auf zwei Organsysteme eivzugehen, die wesentliche $A$ bweichungen von den seither betrachteten Arten darbieten und die sich ahnlich bei einer andern Art finden, über die ich hernach noch Einigres mitzutheilen habe. Es ist der an Dach der Athemhöhle gelegene Organcomplex, besonders die Niere und die Geschlechtsorgane.

Die Abweichungen des erstern sind ziemlich sering. Fig. 45, Taf. 4, welche das Dach der A themhöhle, von der Innenseite gesehen, darstellt, zeigt beim Vergleich mit Fig. 3, Taf. 1, die ein entsprechendes Präparat von Siphonaria pectinata L. darstellt, dass der Hauptunterschied in der viel grössern Ausdehuung des dorsale n Nierenlappens besteht. Er tritt bei unserer Art über die vordere Kiemenvene hinaus betrachtlich nach vorn in den Theil des Athemhöhlendaches hinein, der bei den anderu Arten von dem Gefässnetz eingrenommen wird; dies ist in Folge dessen bei Siphonaria uspera auf einen schmalen Streifen reducirt. Nach binten reicht die Niere, wie wir allerdiugs schon bei andern Arten, z. B. Siphonaria laeviuscula ReEve, subrugosa Suw. und redimiculum REeve, fanden, bis zum abführenden Kiemengefass. Auch lezüglich der Mündung der hintern hiemenvene halse ich eine kleine Abweichung zu erwahnen, die ich bei einem Tutalpraparat beobachten, allerdings auf der Schnittserie durch ein anderes Exemplar nicht unzweifelhaft wiederfinden konnte; sie gabelt sich namlich noch innerhalb) der Niere vor dem Eintritt in das abführende Kiemengefass. Die Nierenpapille ist bei unserer Art ziemlich klein, auf ihrer spitze liegt wie gewöhnlich der Nierenporus (renpo). Der Theil der Niere, der auf dem Boden 
der Athemhöhle liegt, gleicht in Form und relativer Ausdehnung ganz dem von Siphonaria pectinata. Ebenso ist das W imperband (Fig. 51, Taf. $4, w b)$ und das Geruchsorgan vorhanden, letzteres ist jedoch zufällig auf keinem der abgebildeten Schnitte getroffen.

Die Geschlechtsorgane zeigen in ihren rein mänulichen Theilen einen von den andern Arten ziemlich abweichenden Bau. Ich habe die im vordern Abschnitt des Körpers gelegenen Theile Fig. 46, Taf. 4, schwach vergrössert dargestelit. An die Geschlechtsöffnung, welche die gewöhnliche Form und Lage besitzt, schliesst sich eine Art Atrium von ganz geringer Ausdehnung an, in das vorn ein ziemlich dicker Canal $\left(p r_{1}\right)$ einmündet, der nach längerm Verlauf zu einem grössern drüsigen Körper $(p r)$ anschwillt, von dem, in der Fortsetzung des Canals $\left(p r_{1}\right)$, ein dünner Schlauch $(f l)$ abgeht. Der Canal $\left(p r_{1}\right)$ ist der Stiel der Prostata, er besitzt auf dem Querschnitt (Taf. 4, Fig. 47-49) ein ziemlich complicirt gestaltetes Lumen, das durch Falten der Wandung eingeengt wird. Der im Lichtdruck (Taf. 6, Fig. 12) wiedergegebene Schnitt geht durch eine Stelle, wo der Canal gebogen ist, ähnlich wie Fig. 46 rechts von der Bezeichnung $p r_{1}$, daher ist er auf dem Schnitt dreimal getrofĩen. Die Wand des Canals zeigt annähernd die schon bei den vorhergehenden Arten beschriebene und von Siphonaria subrugosa Taf. 5, Fig. 7 pr mit abgebildete Structur, ein Epithel und darunter ein von Fasern durchzogenes Lager von Drüsenzellen; unsere Figur, die allerdings in erster Linie der Darstellung des Penis dienen soll, giebt auf der linken Seite, wo die Schnittrichtung günstig ist, den Habitus des Gewebes, soweit es bei der geringen Vergrösserung möglich ist, wieder.

Gegen das Ende des Canals wird die Wand ventralwärts dünn (Fig. $49 p r_{1}$ ), dann mündet er in die umfangreiche Prostata. Die eine Rinne, die dorsale in Fig. 49, erhält sich ein Stück weit in der Wand der Prostata und bildet dann, indem sie sich abschnürt, den Anbang $f$, den ich als Flagellum bezeichne, ohne damit für seine morphologische Bedeutung etwas präjudiciren zu wollen. Er ist mit Wimperepithel ausgekleidet; darüber liegt eine lockere Muskelschicht, deren Dicke die Höhe des Epithels nur wenig übertrifft. Zwischen den Muskelu liegen Zellen, die den Drüsenzellen der Prostata ähneln, jedoch kleiner sind. Die Prostata selbst, deren hinter dem Abgang des Flagellums gelegenen Abschnitt Fig. 50 im Querschnitt darstellt, weist im Innern ein sehr complicirtes Faltensystem auf. Das Gewebe der Wand ist leider recht mangelhaft erhalten; es zeigt jedoch deutlich den dem Lumen zugewandten gestrichelten Saum, das darunter liegende 
Gewebe scheint mir aus zerfallenen Drüsenzellen zu bestehen, wie ich sie bei den andern Arten in der Prostata beschrieben habe. Eine der Furchen ist besonders ausgezeichnet: ihre Wand hilden verhältnissmässig sehr grosse Zellen, deren Kerne fast ungefirbt bleihen und ein oder mehrere stark gefärbte Kernkörperchen enthalten. Sie erinnern sehr an die von HALLER aus der Penisrinne von Siphonaria gigas LEss. beschriebenen und abgebildeten Zellen (9, tab. 3, tig. 27 u. 28).

Hinter dem Prostatastiel mündet ein stark musculöser Schlauch, dessen Mündung in das Atrium Fig. 48, Taf. 4, bei pe dargestellt ist; es ist der Penis. Auf diesem Schuitt schon bemerkt man zwei ins Innere vorragende Falten, die noch besser auf einen genau quer geführten Schnitt hervortreten, den ich Fig. 12, Taf. 6, abbilde. Der Verlauf der Muskelfasern in der Wand und in den Falten, die das Lumen bis auf einen schmaleu on-förmigen Spalt einengen, ist gut sichtbar; man bemerkt auch ein unten aus der Wand sich alozweigendes Faserbündel, das in die Musculatur des Fusses eintritt und wahrscheinlich als Retractor fungirt. Nach hinten zu wird die Wand des Penis dünn und bedeckt kappenartig die Enden der beiden Falten. Einen Schnitt nahe an diesem Eude stellt Fig. 49 dar. Vom Epithel waren nur sehr spärliche Reste erhalten.

Etwas mehr nach aussen zu münden ebenfalls zwei Canale, ein langer, stark gewundener von vorn, der Stiel des Receptaculums (rec) und ein anderer (spov), der Spermoviduct, von hinten (Fig. 46, Taf. 4).

Auf dem Schnitt Fig. 47, Taf. 4, ist bei $r s_{\text {,.. }}$ die Mündung des Receptaculums getrofien, von da geht der Canal im Bogen vor dem Prostatastiel nach oben, wo er sich mehrfach hin- und herwindet;

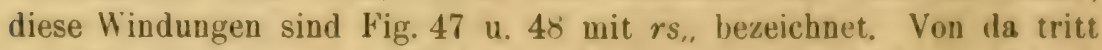
der Canal neben dem Penis berab und in den Adductor binein (Fig. $48 \mathrm{rs}$,), wo er wie gewöhnlich mit dem Spermoviduct nach hinten verläuft. Fig. 50 zeigt ihn in der Leibeshöhle; er verläuft schray nach links, um in das Receptaculum ( $r s$, Fig. $50 \mathrm{u}$. 51) zu münden. Die Wand des Receptaculumstiels ist in Folge der geringern Entwicklung der Musculatur beträchtlich dünner als bei Siphonaria laeviuscula und subrugosa. Das Receptaculum selbst ist eine weite Blase, deren Wand stellenweise noch mit hohem Cylinderepithel leedeckt ist; ihr Inhalt besteht aus Spermatophoren. Diese sind langlich walzenfirmige Körper mit langem fadenartigen Anhang. Sie sind ziemlich spröde; ein Versuch, ein Knäuel derselben zu entwirren, missglückte mir des- 
halb. Ihre Farbe ist gelblich, nach den Schnitten, die sich überall auf der Serie im Receptaculum finden, ist der dickere Theil mit einer dünnern, der fadenartige Theil mit einer ziemlich dicken, hornigen Hülle versehen; letzterer hat im Querschnitt etwa die Form eines Linsendurchschnitts. Der Inhalt der Spermatophoren war zu einer krümlichen Masse zerfallen, da die Conservirungsflüssigkeit durch die Wand anscheinend nicht genügend hatte einwirken können. Auch im Stiel des Receptaculums bemerkte ich Spermatophoren.

Der Spermoviduct tritt, wie schon oben erwähnt, von hinten zu der Geschlechtsöffnung; seine Mündung ist Fig. 47 mit spov bezeichnet. Der ganze Raum, in den die vier Canäle einmünden, zeigt starke Falten, die zum Theil möglicher Weise für den Weg, den die Geschlechtsproducte einzuschlagen haben, von Bedeutung sind; ihre Untersuchung versprach jedoch bei dem Contractionszustand des Thieres, da jedenfalls auch andere, zufällige Falten vorhanden sind, keinen Erfolg. Der Spermoviduct geht zunächst mit dem Receptaculumstiel als enges Rohr mit musculöser Wand nach hinten bis unter das Athemloch. Dann wendet er sich nach links in die Leibeshöhle und macht dort eine Schlinge nach vorn, so dass er Fig. 49 dreimal getroffen ist, einmal im Adductor und zweimal in der Leibeshöhle. Hier vollzieht sich auch die Differenzirung seiner Wand und die Spaltung in zwei Rinnen. In dem dorsal gelegenen, nach hinten verlaufenden Schenkel der Schlinge haben beide Rinnen schon ihre charakteristischen Wandungen erhalten. Einen noch etwas weiter nach hinten geführten Schnitt habe ich bei stärkerer Vergrösserung auf 'Taf. 6, Fig. 11 wiedergegeben. Schon auf den ersten Blick kann man die beiden Rinnen, die jetzt medial gelegene Schleimrinne $(s r)$ und die lateral gelegene Prostatarinne ( $p r r)$ unterscheiden. Einzelheiten des histologischen Aufbaues sind allerdings nicht leicht zu erkennen, da die Photographie eben nicht, wie die Zeichnung, schöner zu werden pflegt als das Präparat; doch wird der Leser an der Hand der Beschreibung wohl die gröbern Verhältnisse erkennen; auf Feinheiten einzugehen verbietet ohnehin die mangelhafte Conservirung. Die Schleimrinne zeigt einen ziemulich einfachen Bau: ihre Wand besteht aus hohen Zellen mit hellem Inhalt, zwischen denen man dünne Fäden bemerkt, die sich gegen das Ende hin verbreitern; denselben Elementen begegneu wir auch in der Schleimdrüse; ich werde sie bei der folgenden Art, die besser erhalten ist, schildern. In der Prostatarinne treten die beiden schon mehrfach erwähnten Schichten, auf dem abgebildeten Schnitt besonders deutlich an der dorsalen und medialen Wand, scharf 
getrennt hervor. Die innere, dem Lumen zugekehrte Schicht zeigt senkrecht auf der 'Tremnunerslinie stehemde feine Streifen, die atn freien Ende verbreitert siud; auf demselhen sitzt, bei starker Vergrösserung erkenular, ein Büschel von Wimperhaaren. Die Zwischenraume zwischen den Streifen sind mit einer sich schwach tingirenden, trüb erscheinenden Masse erfüllt, die den grössten Theil der aussern Schicht ausmacht. Auf dünnen Schnitten und auf dickern beim Wechsel der Einstelluug beobachtet man, dass diese \%wischenraume überall mit jener äussern Schicht in Zusammenhang stehen, dass also die beide trennende Membran siebartig durchlöchert sein muss. In Folge dessen verschwindet ja auch die scharfe Trennungslinie überall da, wo der Schnitt nicht genau senkrecht zur Wand geführt ist, wie es unsere Abbildung am obern Ende der lateralen Wand der Prostatarinne bei * zeigt: die vorber scharfe Grenzlinie löst sich in einzelne Fasern auf, was mir wahrscheinlich macht, dass sie von einem Netz von solchen gebildet wird. Die aussere Schicht ist sehr mangelbaft erhalten, nach deu Befunden bei andern Arten schliesse ich, dass sie aus Drüsenzellen zusammengesetzt ist; in den dunklen Punkten, welche man auf dem Lichtdruck sieht, erkennt man zuweilen grosse Kerne. Trotzdem habe ich gerade dieses Präparat zur Darstellung gewählt, weil es am scharfsten die Zusammensetzung der imnern Schicht aus zweierlei Elementen zeigt, von denen die einen sicher in die Irüsenschicht herabreichen und meiner Ansicht nach die ausführenden Theile der I)rüsenzellen sind, wăhrend ich die audern für Wimperzellen halte, wie sie auch sonst im Drüsenepithel von Mollusken beobachtet worden sind.

Verfolgt man den spermoviduct weiter nach hintell, so öffnet sich die Prostatarinue, indem sie, wie Fin. 50, Taf. 4, darstellt, mit der Eiweissdrüse in Communication tritt; die Schleimrinne erweitert sich nach der lateralen seite hin $\left(s l_{1}\right)$ und setzt sich endlich in die $s \mathrm{chleimdr}$ ü se fort. In das bintere Ende der Prostatarinne mundet der $Z$ wittergang ein. Allem Anschein vach ist auch eine samenblase vorhanden, doch konnte ich dies leider nicht sicher feststellen, da in Folge der schlechten schnittfahigheit des (objects die serie an dieser Stelle lückenhaft ist.

Die Form der Darmwindungen ist eine ahnliche wie bei Siphonaria pectinatu $1_{\text {. }}$ : es sind ebenfalls zwei nach vorn gerichtete Schleiten vorhanden; durch die erste $\left(d_{1}, d_{2}\right)$ tritt die Arteria anterior (Fig. 50, Tiff. 4), die Arteria posterior verzweigt sich gleich bei ihrem Crsprung, vielleicht sind auch zwei Eingeweidearterien vorhanden; man kann das auf deu Schnitten durch das ganz blutleere, plattgedrückte. 
Gefäss nicht entscheiden. Die zweite Darmschlinge $\left(d_{3}, d_{4}\right)$ ist Fig. 51 tangirt. Auch Speicheldrüsen und Leber verhalten sich ähnlich wie bei Siphonaria pectinata. Die grössere vordere Leber mündet mit einer weiten, ausgebuchteten Oeffnung vor dem Pylorus links, die kleinere, hintere dagegen ganz am Hinterende des Magens durch einen kurzen Ausführgang.

Den Schlundring habe ich bei einem Exemplar, so gut es an dem Spiritusmaterial ging, herauspräparirt; ich habe in der Anordnung der Ganglien keine Abweichungen von den andern Arten beobachten können. Bei dem in Schnitte zerlegten Exemplar waren die Ganglien so zerdrückt und gegen einander verschoben, dass ich die Untersuchung aufgab. Gut waren an dem herauspräparirten Schlundring die Otoconien zu beobachten: in jeder Otocyste lag eine grössere Anzahl kugliger oder ellipsoidischer Körperchen, deren Durchmesser ich bei dem grössten runden zu $16 \mu$, bei den kleinern ovalen zu $11 \times 9 \mu$ bis $9 \times 6 \mu$ bestimmte.

\section{Siphonaria stellata Helbling var. luzonica ReEve.}

Die Exemplare dieser Art, die mir zur Verfügung standen, waren in histologischer Beziehung in den meisten Organen besser erhalten als die im Vorhergehenden beschriebenen; in Folge der Conservirung (wahrscheinlich in starkem Alcohol) waren sie jedoch ausserordentlich stark contrahirt, was ihre Untersuchung auf Schnittserien - präparirt habe ich keine - sehr erschwerte. Nach meinen Untersuchungen schliesst sie sich sehr nahe an die vorangehende Art an; ich kann mich daher in der Beschreibung kurz fassen.

Wie bei dieser erstreckt sich die Niere nach vorn über die vordere Kiemenveue hinweg, in der ich aber nur den langen Muskel nachweisen konnte, der kurze scheint zu fehlen. An dem in sagittaler Richtung geschnittenen Exemplar konnte ich die Gablung der hintern Kiemenvene innerhalb der Niere, wie ich sie schon bei der vorhergehenden Art erwähnt habe, nachweisen. Auf einer Querschnittserie kunnte ich auch die Innervirung der Kieme, wenigstens der rechten, über dem Athemloch gelegenen Theils feststellen, es liessen sich zwei Nerven von dem unter dem Geruchsorgan gelegenen Ganglion bis in die Kieme verfolgen.

Das Verhältniss der Aorta zum Larm, sowie die Art der Aufwindung desselben siud wie bei Siphonaria aspera; ebenso verhalten sich die Anhangsdrüsen des Darms, Speicheldrüsen und Leber. Auch 
die bei derselben Art beschriebene duppelte Eingeweidearterie, resp. die Theilung der einzigen dicht hinter ihrem Ursprung konnte ich feststellen.

Auch beim Geschlechtsapparat finden wir dieselben Theile wieder wie bei Siphonaria aspera, den P'enis, die Prostata, deren Stiel allerdings bei der vorliegenden Form bedeutend kürzer ist, so dass sie näher am Kopf liegt, von der Prostata entspringend ein Flagellum, ferner das Receptaculum mit seinem stark gewundenen Ausführgang, den Spermoviduct mit seinen Anhangsdrüsen, '/wittergang mit Samenblase und die Zwitterdrüse. Da die histologische Erhaltung hier zum Theil genügend war, so trage ich einiges nach, was ich bei den andern Arten übergehen musste.

Zunächst gebe ich Taf. 6, Fig. 13 ein Stück eines Querschnitts durch die Wand der Prostata wieder. Ith habe eine Stelle ausgewählt, wo dieselbe ziemlich dünn war, weil hier der Bau verständlicher ist als an den Stellen, wo die Wand durch die mächtige Entwicklung der Drüsenschicht verdickt ist. Die Abbildung zeigt, den Lumen zugewandt, zunïchst einen Saum von Wimperhaaren $(w h)$, darunter eine Schicht von hier ziemlich niedrigen Zellen, deren kierne bei $k$ zu suhen sind; darunter liegen die Drüsenzellen nit ihren grossen, stark tingirten Kernen bei $K$, von erstern geschiedeu durch das schon mehrfach erwähnte, hier im reinen Querschnitt als scharfe Linie erscheinende Netzwerk. Die Drüsenöttnungen sowie die Gruppirung der Drüsenzellen zeigt dieser Schnitt leider nicht deutlich, letzteres ist besser auf Schnitten durch dickere Stellen der $W$ and zu sehen, ich habe eine solche jedoch nicht besonders abgebildet.

Auch der Bau der Schleimdrüse war hinreichend erhalten, so dass ich aus diesem Organ ein paar Zellen abbilden kann. Sie geben zugleich eine Vorstellung von dem Bau der Schleimrinne des Spermoviducts, die ja von den gleichen Zellen ausgrekleidet ist. Fig. 52, Taf. 4, zeigt, dass die Drüsenzellen Cylinderzellen sind, mit farblosem Inhalt und basalstandigem Kern, in dessen Umgebung der Inhalt gewöhnlich etwas trüb und dadurch dunkler erscheint, zwischen ihnen liegen andere, auf dem Schnitt fadenförmig erscheinende Zellen, die sich dunkler tingiren und an ihrem verbreiterten, freien Ende Wimpern tragen. Sie sind durch die dicken Drüsenzellen stark zusammengepresst; das freie Ende erscheint auf Schnitten parallel zur Obertlache des Epithels meist sternförmig im Querschnitt zwischen den secernirenden Elementen, und die kerne liegen in der Regel in der Nähe dieses Endes. Aehnlich ist der Bau der Eiweissdrüse, doch sind hier die 
Zellen dicht mit Schollen einer sich in Carmin blass rosa färbenden Substanz erfüllt, und aus diesem Grund sind vielleicht die Wimperzellen dazwischen nicht zu erkennen, ich glaube wenigstens nur an einigen Stellen etwas davon bemerkt zu haben. Fig. 14, Taf. 6, habe ich ein Stückchen der Eiweissdrüse abgebildet.

Das Receptaculum war wieder mit Spermatophoren gefült, deren Inhalt sich auch hier nicht gefärbt hatte, jedoch soweit conservirt war, dass man seine Zusammensetzung aus dicht zusammengepackten Fäden erkennen konnte. Die Wand der Blase zeigte an einigen Stellen ein schönes Cylinderepithel, dessen Zellen fast homogenes Plasma und schwach färbbare Kerne mit einem kleinen Nucleolus besassen; an andern Stellen war die Wand ganz dünn zusammengedrückt und keine Zellen mehr zu erkennen.

$\mathrm{Zwittergang}$ und Samenblase waren bei den untersuchten Exemplaren mit Sperma erfüllt.

Einen Schnitt durch die Zwitterdrüse bilde ich Fig. 15, Taf. 6, ab. Das Organ zeigt auf dem Durchschnitt aussen eine Rinde, die aus einzelnen Haufen von Eizellen besteht; nach innen zu findet man Spermatozoen und Bildungsstadien von solchen, durch eine sehr feine bindegewebige Membran zusammengehalten. Aus der Vergleichung einer grössern Reihe von Schnitten ziehe ich den Schluss, dass es sich gabelnde Schläuche sind, die von der Mündung des Zwittergangs aus divergiren. Sie enthalten nur die männlichen Geschlechtsproducte; wie sich die peripheren Eihaufen zu ihnen verhalten, habe ich nicht feststellen können; das Wahrscheinlichste ist mir nach meinen Präparaten, dass sie den äussersten Enden der spermabildenden Schläuche aufsitzen; einen unzweifelhaften Uebergang zwischen beiden habe ich allerdings auf keinem Schuitt beobachten können.

\section{Abschnitt II.}

Ein Ueberblick über die Anatomie der im Vorhergehenden beschriebenen Siphonaria-Arten, noch mehr aber die Vergleichung der Resultate der vorliegenden Untersuchung mit den Ergebnissen, zu denen Arbeiten anderer Forscher über Angehörige derselben Gattung geführt haben, zeigen, dass im innern Bau in manchen Punkten beträchtliche Abweichungen eintreten, trotz der geringen Unterschiede in der Körperform -- auf die Structur der Schale gehe ich hier nicht ein -, die 
sich nur auf grössere oder geringere Verschiedenheiten in der Höhe und auf eine grössere oder geringere Abweichung des Apex der Schale nach hinten und links beschränkt.

Auf den folgendeu Seiten sollen dio wichtigsten Organsysteme nach einander durch die einzelnen Arten verfolgt werden, und ich beginue hier mit den Organen der für die Siphonarien so charakteristischen Athemhöhle, und zwar zunachst mit den Athmungsorganen.

Da finden wir zunächst die hieme; doch ist das Gefissnet\%, das in diesem ()rgan entwickelt ist, nicht das einzige, für das die Bedingungen gegeben sind, die wir bei einem respiraturiscben liefassnetz voraussetzen müssen; auch der vordere Theil des A themhiohlendachs enthält ein Gefässnetz, das, wie Fig. 1, Taf. 5, zeigt, sehr blutreich ist. Wenn auch die Gefässe nicht wie bei einer typischen Pulnouatenlunge in die Athemhöhle vorspringen, so steht es doch einerseits mit einem venöses Blut enthaltenden Pallialsinus in Verbindung, der ja auch der Kieme das Blut zuführt, und andrerseits mündet es in die vordere Kiemenvene, die arterielles Blut direct in die Vorkammer führt. Aehnlich verhält es sich bei Siphonaria pectinata ausserdem noch mit dem zwischen der Niere und der linken Halfte des abführenden Kiemengefasses gelegenen Theil des Athemböhlendaches, der bei den ambern Arten noch von der Niere eingenommen wird. Da Siphomaria nach dea Angaben vou Hutrun (5) und Texison-Woress onon Hutrus citirt, die Arbeit selbst, in den Transactions of the Royal Society of Tasmania, war mir nicht zugänglich) öfters Luft zu athmeu scheint, so dïrften wohl die namhaft gemachten Stellen auch Gelegenheit haben, ihre respiratorische Function auszuủben.

Siphonaria besitzt also im vordern 'Theil des Athembihlendaches ein als Lunge fungirendes, wenn auch nicht ganz in dur typischen Form ausgebildetes Organ, obgleich der Theil, den frühere Beobachter der Lunge angesprochen haben, jetzt als Niere erkannt worden ist.

\section{Die Kieme.}

Wir wenden uns jetzt zur K i me. Sie zeigte bei den Siphonarien, die meiner Untersuchung zu (irunde lagen, wenig Verschiedenheiten. Was zunichst Gestalt und Ausdehnung der hieme als Ganzes angeht, so zieht sie stets in querer Richtung in einem nach vorn offenen liogen vom Athemloch nach dem gentenuberliesenden Rand der Athemhihle (Taf. 1, Fig. 3; Taf. 4, Fig. 45); nur Siphonaria redimiculum weicht insofern etwas ab, als der Bogen nur sehr flach ist und die hieme 
mehr die Gestalt eines S-förmig schräg von vorn nach hinten ziehenden Streifens bekommt (Taf. 3, Fig. 41 u. 42). Der Vergleich der letztern Figur mit den beiden oben citirten lehrt, dass der Unterschied hauptsächlich durch eine viel schwächere Entwicklung des linken, nach vorn umbiegenden Theils der Kieme bedingt ist; bei Siphonaria redimiculum macht er etwa nur $1 / 5$ des ganzen Organs aus, während er bei den andern Arten etwa $1 / 3$ darstellt. Bei dem ganz jungen Exemplar von S. redimiculum scheint er noch gar nicht ausgebildet zu sein (Fig. 41), denn die Kieme endet eine ziemliche Strecke vom linken Rand der Athemhöhle entfernt (Fig. 39, Taf. 3, stellt bei ct ihr linkes Ende dar). Sehr stark gebogen ist die Kieme nach HALLER bei Siphonaria gigas Less. $(9$, tab. 2, fig. 11 u. 14); dabei ist ihre Breite im Verhältniss zu ihrer Länge viel unbedeutesider als bei den von mir untersuchten kleinern Arten. Bei Siphonaria ionasi DKR. ist die Kieme nach NoвRE, soweit ich seine Beschreibung ohne Abbildung verstehe, wohl ähnlich wie bei S. pectinata. Siphonaria tristensis Sow. schliesst sich, nach der Zeichnung DaLl's zu urtbeilen, in der Form der Kieme wohl am nächsten an Siphonaria redimiculum an, das ganze Organ bält sich jedoch dichter an dem Adductor und scheint ausserdem im Verhältniss zur Grösse des Thieres bedeutender entwickelt zu sein; allerdings scheint mir die Figur dafür nicht ganz maassgebend, da das theilweise abgelöste Dach der Athemhöhle im Verhältniss zur Grösse des übrigen Thieres etwas zu gross gezeichnet ist.

Bedeutender weichen die Angaben HutTon's über Siphonaria australis QUOY \& GAIMARD ab, wonach zwei Kiemen vorhanden sein sollen, eine an der Decke und eine am Boden der Athemböhle. Erstere stimmt nach Beschreibung und Abbildung (5, tab. 15, fig. 2) ungefähr mit der von Siphonaria aspera Kkauss überein, sie ist nur schwächer gebogen. Eine zweite, an Borlen der Athemhöhle gelegene Kieme, die allerdings weniger entwickelt sein soll als die erste, ist meines Wissens ausser von Hutron noch von keinem andern Beobachter gesehen worden. Es scheint mir deshalb nicht unmöglich, dass eine Täuschung durch das ventrale Wimperband vorliegt; es wäre jedoch auch möglich, dass die Kieme ebenso wie die Niere und das Wimperband auf die ventrale Fläche der Athemhöhle übergeht; ohne eine erneute Untersuchung der von HUTTON beobachteten Species wird sich die Sache kaum sicher entscheiden lassen. Auf der Ablildung von Siphonaria dimensis Quoy \& GaImari, (1, tab. 25, fig. (i) ist die Kieme als schmales, fast gerades und quer durch die Athemhöhle verlaufendes Band dargestellt; die Biegung ist also noch viel schwächer als bei 
der eben erwähnten Art. Auffallender als dies wäre eine Eigenthümlichkeit in der relativen Lage von Niere und hieme; als erstere betrachte ich namlich ein hinter der hieme gelegenes, als "Organ de viscosité" bereichnetes ()rgan. Ich glaube, dass es den durch das Dacb der Athemhöhle durchschimmeruden ventralen Nierenlappen vorstellt, dessen hinteres Ende über die Kieme hinausragt. Auffallend ist auch, dass Lacaze-Di:Tuizks (6, p. s!l) die hieme „au dessus du corps rénal" liegen lasst, nach der bei uns üblichen Orientirun: des Thieres, also vor der Niere, wahrend sie in Wirklichkeit dahinter liegt; es ist vielleicht ein Druckfehler, „au dessus" statt „au dessous".

Die Structur der Kieme ist bei allen Siphonarien die gleiche, sie ist aus grössern und kleinern, etwa dreieckigen Blattchen zusammengesetzt, die gefaltet sind und mebr oder weniger stark entwickelte secundäre Lamellen an den Seiten tragen. Bei den ganz jungen Thieren stellen sie einfache, ungefaltete und unverzweigte Lamellen dar (Taf. 3, Fig. 37, 38 u. 39).

Die Grösse der Blăttchen variirt ziemlich bedeutend, am kleinsten sind sie im Allgemeinen am linken Ende der hieme; sie nehmen von da an Grösse zu, dann in der Nachbarschaft der Niereupapille wieder $a b$, um in dem vor dem Athemloch gelegenen Theil der Kieme wheder eine betrachtliche Grösse zu erreichen. Ausserdem sind überall zw ischen den grössern ein oder mehrere kleinere Blattchen eiugreschaltet. Die einzelnen Blattchen stehen am dichtesten am rechten Fude der hieme; grösser werden die Zwischenräume zwischen ihnen nach dem linken zu. Jedes Blattchen trigt, wie auch HALLFr für seine Art angiebt und fig. 14, tab. 2, und tig. 25, tab. 3, abbildet, an dem vordern Kand ein abführendes, am hintern ein zuführendes Gefass; erstere münden alle in ein am Vorderrand der hieme verlaufendes abführendes hiemengefäs, und letztere stammen aus einem an Hinterrand befindlichen zuführenden Kiemengefâss. Was ich als abführendes Kiemengefäss bezeichne, setzt sich nach Hallek's Nomenclatur aus drei Theilen zusammen, dew rechts gelegenen Theil der vordern Kiemenvene und den beiden Aesten der hintern Kiemenvene (9, tig. 11 u. 14, tab. 2); ich habe aber aus practischen Gründen fur das Gefass eine einheitliche Bezeichnung gewahlt und auch den Nanen "Samuelgefiss", den ich in meiner vorlautigen Mittheilung gebraucht hatte, fallen lassen. Das abführende Kienuengefass war bei allen von mir untersuchten Siphonarien deutlich zu erkennen, nur in der Nachbarschaft der Nierenpapille schien es immer etwas undeutlich. Auch die übrigen Beobachter hal,en es, soweit sie ihr Augenmerk auf die 
Kiemengefässe richteten, beschrieben und abgebildet, so DALL bei Siphonaria tristensis Sow. (2, fig. 7, tab. 5) und HuTton bei Siphonaria australis (5, fig. 3 u. 4, tab. 15).

Das abführende Kiemengefäss steht mit der Vorkammer des Herzens in der Regel durch zwei Gefässe in Verbindung, die vordere und hintere secundäre Kiemenvene, wie ich sie jetzt nennen will („abführende Kiemengefässe" in meiner vorläufigen Mittheilung). Die vordere liegt bei Siphonaria pectinata, laeviuscula, subrugosa und redimiculum am vordern Rand der Niere; ebenso verhält sich Siphonaria gigas Less. nach HALLER. Bei Siphonaria aspera Krauss und stellata Helbling var. luzonica Reeve durchsetzt sie die Niere quer. Charakteristisch für das Gefäss waren bei allen von mir untersuchten Arten Muskelfaserbündel, die aus der Vorhofsmusculatur stammen und eine Strecke weit in dem Gefäss verlaufen. Es sind meist zwei vorhanden; beide inseriren an der dorsalen Wand der Niere, der eine ziemlich nahe dem Herzen, der andere auf der rechten Seite des Thieres, nicht sehr weit vom Ende des Gefässes. Bei Siphonaria stellata Helbling fand ich nur einen Muskel. Von den andern Beobachtern wird er nicht erwähnt. Wie sich das in Rede stehende Gefäss bei den übrigen Siphonarien verhält, konnte ich aus den Angaben der schon mehrfach citirten Beobachter nicht erseben, da die vordere Kiemenvene selbst da, wo das abführende Kiemengefäss erwähnt oder abgebildet wird, nicht mit Sicherheit zu erkennen ist.

Die hintere Kiemenvene durchsetzt bei den Arten, wo sie überhaupt nachzuweisen ist, stets die Niere und entspringt etwa in der Mitte des abführenden Kiemengefässes, so bei Siphonaria pectinata, laeviuscula, subrugosa, aspera und stellata var. luzonica; ebenso verbält sich Siphonaria gigas (9, tab. 2, fig. $14 h k v)$ nach HALLER und Siphonaria tristensis nach DALL (2, tab. 5, fig. 7). HutToN (5) erwähnt weder im Text noch in der Tafelerklärung die Gefässe; auf seiner fig. 3, tab. 15, scheint er das hintere dargestellt $\mathrm{zu}$ haben, vielleicht auch beide; ich kann das, da ich die Art aus eigner Anschauung nicht kenne, aus der Figur nicht sicher entnehmen.

Bei Siphonaria redimiculum habe ich keine hintere Kiemenvene gesehen; ich halte es auch, wie schon erwähnt, nicht für wahrscheinlich, dass ich sie übersehen haben sollte, weil sie blutleer war, denn die scbwächere Entwicklung der linken Hälfte der Kieme lässt das Fehlen eines ihr Blut aufnehmenden Gefässes verständlich erscheinen; die vordere genügt dann eben für die ganze Kieme. 
Bei einer Art (S. luzonica) konnte ich die Innervirung eines Theils der lieme und zwar des rechten Endes beobachten: es waren zwei Nerven vorbanden, die von dem unter dem Geruchsorgan gelegenen Ganglion ausgehen.

Besteht in den Angaben über den Bau der Kieme eine ziemlich erfreuliche Uebereinstimmung bei den verschiedenen Autoren, so weichen sie doch in ihren Ansichten über die morphologische Bedeutung des von uns seither einfach als "Kieme" bezeichneten Organs weit von einander $a b$. Eine Entscheidung zwischen den verschiedenen Ansıchten, die für die Beurtheilung der verwandtschaftlichen Bezichungen von Siphonaria zu andern Gastropoden von der grössten Bedeutung ist, muss sich vorwiegend auf vergleichend anatomische Betrachtungen stützen, das ist jedoch nicht möglich, wenn wir uns, wie wir es hier $\mathrm{zu}$ thun beabsichtigen, auf die Gattung Siphonaria beschränken: bei der Einförmigkeit des Baus, den die Kiene bei den Siphonarien aufweist, finden wir von dem Weg, auf dem das Organ seine jetrige Gestalt erreicht hat, fast nichts als den einen Endpunkt, an dem alle Arten angelangt sind, und ein Punkt genügt nicht, um die Richtung einer Linie festzulegen. Ich muss daher jetzt auf die Erörterung der morphologischen Bedeutung der Kieme verzichten, da ich den $/ \mathrm{u}$ sammenhang nicht durch Vorführung von Material, das andere Gastropoden uns liefern, unterbrechen kann; im folgenden Abschnitt werde ich Gelegenheit haben, diesen Gegenstand ausführlicher zu behandeln. Ich gehe jetzt zur Betrachtung der Niere über.

\section{Die Niere.}

Die Niere ist stets aus zwei Lappen zusanmengesetzt, von denen der eine das Dach, der andere den Boden der Athemhïhle einnimmt; an der Stelle, wo der Herzbeutel in die Athemhöhle vorspringt, gehen sie ohne scharfe Grenze in einander über. Der ventrale Lappen zeigt in Form und Ausdehnung kaum Unterschiede zwischen den einzelnen Arten, ich habe ihn nur von Siphonaria pectinata abgebildet, ungefahr die gleiche Gestalt und Lage hat er bei den andern Arten. Elsenso verhält sich nach DALI. Siphonaria tristensis; bei Siphonaria australis ist er auf HutTon's Zeichnung $(5$, tab. 15, fig. 3) ziemlich klein dargestellt, ebenso bei Quoy u. Galmard $(1$, tab. 25, fig. 6 e), wo sein hinteres Ende, hinter der Kieme durch das Dach der Athemböhle hindurchschimmernd, dargestellt ist. LACAZE-DUTHEas (6) erwahnt den untern Lappen nicht; NuBre (7) vergleicht den ventralen Lappen, 
den er irrthümlich für die ganze Niere hält, mit einer Lanzenspitze; was er für den Ausführgang hält, ist jedenfalls die ventrale Hälfte des Wimperbands. Bei der von HaLler untersuchten Siphonaria gigas ist der untere Lappen verhältnissmässig ausgedebnt $(9$, tab. 2 , fig. $12 \ln l$ ).

Hat über die Deutung des untern Nierenlappens kaum je ein Zweifel bestanden, so ist der obere um so mehr Gegenstand der Controverse gewesen. Bei den von mir untersuchten Exemplaren hatte der obere Nierenlappen eine ziemlich verschiedene Ausdehnung. Am kleinsten war er bei Siphonaria pectinata, wo er noch nicht einmal den von der Kieme und der vordern Kiemenvene eingeschlossenen Raum ganz einnahm (Taf. 1, Fig. 3); bei Siphonaria laeviuscula und subrugosa war dies dagegen der Fall, ebenso bei Siphonaria redimiculum, wo der zur Verfügung stehende Raum in Folge der geringern Grösse der Kieme allerdings auch kleiner ist (Taf. 3, Fig. 42); am weitesten dehnt er sich aus bei Siphonaria aspera und stellata, wo er sich vor der vordern Kiemenvene noch über einen Raum ausbreitet, der etwa halb so gross ist wie der $z$ wischen Kieme und vorderer Kiemenvene eingeschlossene (Fig. 45, Taf. 4). Stets liegt an dem dem Athemloch genäherten Ende der Kieme bei den erwachsenen Siphonarien eine Papille, die bei Siphonaria aspera verhältnissmässig klein ist; auf ihrer Spitze findet sich der Nierenporus. Diese Nierenpapille ist stets durch eine Falte, das Frenulum, das zwischen den Kiemenblättern an der Decke der Athemhöhle entspringt, an dieser befestigt; das Frenulum gleicht ganz einem mittelgrossen Kiemenblatt, nur trägt es an seinem Rand ein starkes Gefäss, das sich in der Niere verzweigt, das rechte zuführende Nierengefäss. Ein zweites zuführendes Nierengefäss fanden wir ganz links, wo es gemeinsam mit dem zuführenden Kiemengefäss aus dem Pallialsinus entspringt. Die abführenden Nierengefässe waren schwieriger nachzuweisen; sie münden, wie ich bei der Beschreibung der einzelnen Arten mitgetheilt habe, in die Kiemenvenen und das abführende Kiemengefäss. Stets konnte ich eine entwickelte Renopericardialpforte nachweisen; sie liegt hinter der Mündung der Kiemenvenen, senkrecht zur Längsaxe des Körpers.

Quoy u. Gamari) (1[?]), Dall (2) und, soweit ich seine Ausführungen verstehe, auch NoBke (7) betrachten den obern Nierenlappen als Lunge, eine Ansicht, die schon HutTon (5) und LACAZE-Duthiers (6) widerlegt haben. Ganz abweichend würde sich Siphonaria gigas LEss. verhalten. Bei dieser Art glaubt HaLLeR eine vollständige Trennung 
des obern Lappens in zwei Hälften beobachtet zu haben, von denen die rechts gelegene eine rechte, die linke mit dem untern Lappen eine von ersterer völlig getrennte linke Niere bilden soll. Bei der Wichtigkeit, die der Sache zukommt, citire ich hier die uns interessirenden Stellen wörtlich. Zunächst lesen wir p. 11: „Die rechte Niere ist eine schöne acinöse Drüse mit einem kurzen Ausführungsgange. Dieser spaltet sich nach hinten zu und geht in die zwei Lappen der rechten Niere über (fig. 11, 14 rn). Der eine dieser Lappen eudet nach hinten an jener Stelle, wo die hintere Kienenvene in die der kieme anliegende Anastomose übergeht. Diese's ist der lảngere Lappen. Der vordere, nach links dem Pericard zuziebende Lappen stösst beinahe an das Pericard, und zwar zwischen dem Austritt der beiden Kiemenvenen (fig. 13 rechts). Eine Mündung in das Pericard, einen Nierentrichter, habe ich an der rechten Niere nicht auffinden können. Doch wäre es inmerhin möglich, dass eine solche unter dem Austritt der beiden Kiemenvenen sich in reducirtem Zustand befindet. Wenigstens sehe ich dort zwei kleine Oeffinungen." Ueber die Mündung der rechten Niere sagt Haller: "Man wird da (d. h. auf der citirten fig. 14, tab. 2) erkennen, dass an jener Stelle, wo in der Nähe des rechtsseitigen Endes der Kiemenreihe die grössten Kiemen liegen, unter der Kiemenreihe sich ein kleiner, jedoch sehr deutlicher Höcker vorfindet (fig. $14 \alpha$ ), bis zu welchem der Ausführungsgang der rechten Niere zu verfolgen ist. Dieser Höcker verbindet sich dann durch eine Falte (fig. $14 \beta$ ), welche zwischen den Einzelkiemen gelegen ist, nit der Kiemenarterie: Querschnitte liessen deutlich erkennen, dass eine der grïssten venösen Lacunen zwischen denen, welche zwischen den Acinis der rechten Niere so zahlreich lagern, durch diesen queren Gang mit der Kiemenarterie direct in Verbindung steht (fig. $34 v$ ) und sımit das venöse Blut aus die-er Niere direct in die Kiemenarterie entleert wird. Ein Querschnitt weiter nach rechts zeigt, dass der Nierengang (fig. $34 \mathrm{ng}$ ) durch jene buschriebene Papille (fig. $33 w$ ), welche aus Nierengewebe gebildet wird, nach aussen mündet." Der Abschnitt über die linke Niere lautet (p. 12): „Anders verhalt sich die linke Niere. Diese besteht aus einem compacten untern, nach hinten der ganzen untern und hintern Pericardwand sowie dem Kiemenhöhlenborlen aufliegenden Lappen (fig. 12, $13 \mathrm{lnl}$ ) und dem schon beschriebenen obern Nierenlappen (fig. 11, $14 \ln l$ ). Diese beiden Lappen bangen an der hintern Pericardwand mit einander zusammen; hier vereinigen sich ihre Sammelgange. Der Ausführgang mündet in form eines kurzen, kraftigen Fortsatzes an der linken Seite des P'ericardiums, diberdeckt 
von einem Muskelbündel (welches auf fig. $13 m$ durchschnitten wurde), in die Kiemenhöhle. Führt man durch dieses Mündungsstück, welches am Kiemenhöhlenboden fest angewachsen ist, Sonden ein, so wird man bei vorsichtiger Behandlung die eine $(a)$ in das Lumen der linken Niere, die andere in die Mündung der Niere in das Pericard $(b)$ leicht einzuführen im Stande sein. Somit ist der Gang des Nierentrichters der linken Niere sehr kurz und zweigt sich vom Endgang der Niere ab. Die Trichtermündung befindet sich in der linken Ecke des Pericards, unweit von der Herzkammer entfernt." Das Resultat seiner Untersuchungen fasst HALLER in den Worten zusammen: „A u s diesen Untersuchungen resultirt somit, dass S. gigas paarige Nieren besitzt, wenngleich es sich auch nicht leugnen lässt, dass die rechte Niere in Rückbildung begriffen is t."

Das Ergebniss der Arbeit HaLlen's steht somit in Widerspruch mit den Resultaten meiner Untersuchungen, welche die Existenz einer einzigen Niere lehrten, wie es auch alle andern frühern Untersucher angenommen hatten.

Form und Lage der Niere von Siphonaria gigas stimmt allerdings ganz mit dem überein, was ich bei Siphonaria laeviuscula beobachtete; auch die Nierenpapille mit ihrem Frenulum hat HALLER beschrieben und abgebildet (fig. 14, tab. $2 \alpha$ und $\beta$ ); die auf ersterer gelegene Oeffnung kommt nach ihm allerdings nur der rechten Niere zu. Eine weitere wichtige Uebereinstimmung besteht in dem Verhalten des Gefässes, das durcb die Falte $\beta$ aus der Kiemenarterie (nach meiner Nomenclatur zuführendes Kiemengefäss) in die Niere eintritt; es ist offenbar die von mir als rechtes zuführendes Nierengefäss beschriebene Ader. Haller hält es für ein abführendes Gefäss, und ich neigte Anfangs auch zu dieser Ansicht, ich habe sie aber aufgegeben, denn es scheint mir nicht wahrscheinlich, dass das Blut in diesem Gefäss eine andere Richtung haben soll als in den dicht daneben entspringenden zuführenden Gefässen der Kiemenblättchen; ausserdem habe ich ja andere Gefässe beschrieben, die in die Kiemenvenen zum Theil dicht an ihrem Uebergang in das Atrium münden und somit sicher Blut aus der Niere herausfübren; directe Beobachtungen hat natürlich HALLER so wenig wie ich anstellen können. Nach meiner Auffassung würde also nur ein Theil des Bluts die Kieme passiren, ein anderer durch die Niere dem Herzen zuströmen; ein dritter Theil des Blutes kann noch ausserdem durch das Gefüsnetz im vordern Theil der Athemhöhle gehen, ohne Kieme oder Niere zu passiren. Auch die 
pericardiale ()effinung der vou mir beschriebenen Renopericardialpforte scheint HaLLeE gesehen zu haben, bält sie jedoch für reducirt, eine Ansicht, zu der man bei der von ihm angewandten Untersuchungsmethode leicht kommen kaun, da der Canal immer sehr eng und der Trichter nur klein zu sein scheint. Suweit lassen sich unsere beiderseitigen Befunde ganz gut vereinigen, anders aher ist es mit der Oeffnung und dem Renopericardialporus dẹr "linken" Niere und mit der Trennung der Nieren durch die hintere Kiemenvene. Ich habe die Gegend, wo die linke Nierenöffinung nach HaLllk liegen soll, auf meinen sämmtlichen Serienschnitten wiederholt sorgfaltig durchgesehen, ohne eine in die Athemhöhle führende Mündung der Niere anzutreflen. Ich habe auch einige Präparate von dem Dach der Athemhïhle gemacht, und da habe ich allerdings ein Loch vor dem linken Ende der Kieme gefunden, durch das man wenigstens in die obere Niere gelangen konnte; es führt aber nicht in das Lumen, sondern in Bluträume und ist der gemeinsame Ursprung des linken zuführenden Nierengefässes und des zuführenden Kiemengefässes; selbstverständlich mündet es nicht in die Athemhöhle, sondern in den Pallialsinus. Ebensowenig konnte ich den von HaLLER angegebenen linken Renopericardialporus finden. Was die Trennung der Niere durch die hintere Kiemenvene anlangt, so könnteu allerdings einzelne Schnitte (wie Fig. 26 , Taf. 3) den Auschein erwecken, als theile das Gefäss das Nierengewebe vollständig, andere Schnitte, wie Fig. 19, 20 u. 25, Taf. 2, zeigen dagegen unzweifelhaft, dass das Nierengewebe über dem Gefäss in innigem Zusammenhang steht. Die hintere Kiemenvene trennt die Continuität des obern Nierenlappens hier ebensowenig, wie es die voriere bei Siphonaria aspera und stellata thut, wo sich ja bekanntlich die Niere über sie hinwey nach vorn erstreckt. Bei Siphonaria redimiculum liess sich sogar die hintere Nierenvene gar nicht nachweisen, und bei dem ganz jungen Thier lässt sich auf der Schnittserie ohne Schwierigkeit feststellen, dass die Niere ein einheitliches Lumen besitzt. Wären zwei Nieren vorhanden, so müssten sie, da sie ja den primitiven Zustand darstellen, gerade bei jungen Thieren mit aller Deutlichkeit zu beobachten sein. Es war mir leider nicht möglich, Siphonaria gigas zur Nachuntersuchung zu erhalten, obgleich Herr Graf Halı,ER sich in liebenswürdigster Weise bereit erklärt hatte, mir Exemplare dieser Art zur Verfügung zu stellen, falls sich solche noch unter dem von der Corvette „Vittor Pisani" gesammelten Material finden sollten; zu meinem Bedauern war dies jedoch nicht der Fall. Dass die Widersprüche in unsern beiderseitigen Angaben in der specifischen Ver- 
schiedenheit der von HALLER und mir untersuchten Formen begründet sein sollten, will mir nicht wahrscheinlich dünken, denn solche fundamentalen Unterschiede dürften wohl kaum innerhalb einer Gattung vorkommen, die gerade mit Bezug auf die Organe der Athemhöhle eine gewisse Einförmigkeit zeigt. Ich fürchte, dass der verdiente Anatom hier das Opfer einer Täuschung geworden ist: die „Ausführgänge" der beiden Nieren erinnern in ihrem Verlauf verdächtig an die von mir beschriebenen zuführenden Nierengefässe.

Am hintern Rand der Kieme, das zuführende Gefäss bedeckend, verläuft ein aus hohem Flimmerepithel gebildetes $W$ imperband; ganz links schlägt es sich hinter dem Pericard auf den Boden der Athemhöhle um und zieht, auf einer ziemlich starken Falte liegend, dem hintern Kiemenrand entlang wieder nach dem Athemloch zu, wo es in der Nähe des Afters endet. Der einzige von den frühern Beobachtern, der die am Boden der Athemhöhle liegende Hälfte wenigstens richtig erkannt hat, ist HALLER; HUTTON zeichnet etwas an den hintern Rand der ventralen Kieme, was man darauf beziehen kann, wenn nicht die ganze ventrale Kieme in Wirklichkeit nur ein stark entwickeltes Wimperband ist. NOBRE hat die Falte für den Ausführgang der Niere gehalten.

\section{Die Circulationsorgane.}

Das $\mathrm{Herz}$ liegt in dem geräumigen Herzbeutel auf der linken Seite des Körpers. Ich fand stets den Vorhof wach rechts oben und vorn, die Kammer nach unten und hinten gerichtet. DALL zeichnet bei Siphonaria tristensis das Herz mit seiner Längsaxe parallel dem Körper $(2$, tab. 5 , fig. $7 h$ ) den Vorhof nach vorn und die Kammer nach hinten; HalLer giebt für seine Art an, dass der Vorhof rechts, die Kammer links liegt, aus der Zeichnung geht ferner hervor, dass der Vorhof etwas nach vorn liegt. In die Vorkammer münden die beiden Kiemenvenen aus dem Dach der Athemböhle und mit ihnen Gefasse aus dem obern und untern Nierenlappen; der Ventrikel legt sich der Medialwand des Herzbeutels an und entsendet von dort aus seine Gefässe in den Körper. Die Anordnung dieser Gefässe war bei den von mir untersuchten Arten etwas verschieden. Bei Siphonaria pectinata entsprangen zwei Gefässe nit ziemlich stark erweiterter gemeinsamer Wurzel aus dem Ventrikel, eine Arteria posterior, die nach hinten in die Eingeweide geht, und eine Arteria anterior, die sich nach links wendet. Ebenso verhalten sich Siphonaria lae- 
viuscula und subrugosa. Bei Siphonaria redimiculum beobachtete ich ausser der Arteria posterior noch ein kleines, von der Arteria anterior nach hinten dem Magen entlang verlaufendes Gefäss. Bei Siphonaria aspera und stellata theilt sich die Arteria posterior gleich bei ihrem Ursprung, so dass zwei Eingeweidearterien vorhanden sind. Von Siphonaria australis hat HutTon die vordere Arterie gezeichnet; NoBrE giebt eine Abbildung des Herzens (fig. 6) mit einer starken Arterie, von der zwei schwächere nach hinten abgehen, ein Verhalten, das sich dem bei Siphonaria aspera beschriebenen nähert. Bei Siphonaria gigas erwähnt HaLLer zwei Arterien, die aus einem gemeinsamen erweiterten Abschnitt, den er als Bulbus arteriosus bezeichnet, entspringen.

Einige interessante Thatsachen ergeben sich, wenn wir die Lage der Arterien, besonders der Arteria cephalica zu andern Organen ins Auge fassen. Aus der Beschreibung der einzelnen Arten ist dem Leser schon bekannt, dass der Darm nach seinem Abgang von dem Maren eine nach vorn gerichtete Schlinge beschreibt. Bei Siphonaria pectinata, redimiculum, aspera, stellata, sowie nach Hutros bei Siphonaria australis geht nun die Kopfarterie unter dem dorsalen, zurücklaufenden Schenkel der Schlinge hinweg, so dass sie durch die Schlinge nach der rechten Seite hinübertritt, wie am besten Fig. A und C, S. 32 illustriren; bei Siphonaria laeviuscula und subrugosa dagegen geht sie dicht vor dem vorderu Ende der Schlinge nach rechts hinüber, ohne also die Schlinge zu durchsetzen (Fig. B, S, 27). Wie sich die andern Arten in dieser Beziehung verhalten, geht aus der Literatur nicht hervor.

Der zweite Punkt betrifft die Beziehungen des vordern Theils der Aorta anterior zum Nervensystem. 'Zuerst hat v. JiIERING diesem Gegenstand seine Aufmerksamkeit geschenkt. Er giebt (3, p. 204) für Siphonaria lineolata ${ }^{1}$ ) D'ORB. an, dass die Pedalarterie zwischen Peialund Parapedalcommissur, über letzterer, hindurchzieht. Dann hat Bouvier $(8$, p. 3) eine nicht näher bestimmte Siphonaria untersucht und gefunden, dass die Arteria anterior wie bei Limnaeus unter der Visceralcommissur und über den beiden Pedalcommissuren hinwegzieht. Ich habe die Angaben des französischen Forschers bei den von mir untersuchten Arten bestätigt gefunden; das Gefäss geht zwischen Abdominal-

1) Diese Art ist möglicher Weise mit der auch von mir untersuchten S. pectinata var. lineolata Krarss identisch, die Beschreibung der Geschlechtsorgane passt allerdings wieder nicht. 
und Pleurointestinalganglion ventral von dem beide verbindenden Stück der Commissur nach links und dann über das rechte Pedalganglion nach vorn. An dem direct vor den Pedalganglien gelegenen Theil entspringen stets zwei kleine Gefässe, die unter den Pedalganglien nach hinten verlaufen, ich habe sie mit $\gamma_{1}$ und $\gamma_{2}$ bezeichnet (Taf. 1, Fig. 13-15; Taf. 2, Fig. 24; Taf. 3, Fig. 34).

\section{Die Ernährungsorgane.}

Der Dar m c an a l gliedert sich in Schlundkopf, Oesophagus, Magen, Dünndarm und Enddarm. Auf eine Vergleichung der wichtigsten Theile des Schlundkopfs, des Kiefers und der Radula gehe ich hier nicht ein, weil die Unterschiede des erstern bei den einzelnen Arten, soweit ich sie kenne, nur sehr geringfügig sind; die eingehende Behandlung der Radula hätte aber nur systematisches Interesse und würde hier zu weit führen. Ein paar Worte will ich nur über die beiden Speicheldrüsen bemerken. Ihre Form war auf den von mir untersuchten Arten eine sehr wechselnde, selbst die einzelnen Individuen einer Art gleichen einander in dieser Hinsicht nicht. Es kommt dies daher, dass die einzelnen Theile der beiden Drüsen meist überall in die Zwischenräume $z$ wischen den benachbarten Organen eingedrungen und bei den Contractionen des Thieres deformirt worden sind. Bei Siphonaria pectinata habe ich sie in situ abgebildet, sie waren hier rundlich; als mehr oder weniger längliche Gebilde stellen sie Quoy u. GatMaRD, DaLL, HutTon und HaLler dar.

Als $\mathrm{O}$ es ophagus fasse ich das kurze, meist stark gewundene Rohr auf, das vom Schlundkopf aus nach dem Boden der Leibeshöhle herabsteigt. Dort geht es in einen weiten, etwas hinter der Mitte leicht eingeschnürten Sack über, den ich als Magen bezeichue; an dessen hinterm Ende münden die beiden Mitteldarmdrüsen ein, und hinter der Mündung der linken entspringt der Darm. Ich habe diese Theile des Darmcanals auf Taf. 1, Fig. 6 von Siphonaria pectinata abgebildet; die andern Arten verhalten sich im Wesentlichen ebenso. Auch Hutron schildert diesen Theil des Darms von Siphonaria australis ähnlich. DALL und HALLER finden bei den von ihnen untersuchten Arten im Ganzen ähnliche Verhältnisse, nur liegt nach DALL und mehr noch nach HALLER die Einschnürung viel weiter nach hinten, als ich es bei meinen Arten gefunden habe; sie deuten auch ihre Befunde etwas anders und fassen nur den kleinen, hinter der Einschnürung gelegenen Theil als Magen auf, während sie den davor gelegenen Theil 
als eine besundere Differenzirung des Vorderdarms betrachten. Achnlich sieht Nonke die Verhältnisse bei Siphonaria jonasi I)kk. an : nach seiner Zeichnung war der vor der Einschnürung gelegene Thril leer und wohl in Folge davon so dünn. Ich hahe zwischen beiden Abtheilungen nie einen Unterschied in der Structur der Wand nachweisen können: beide hatten auch stets den gleichen Inhalt, der aus Resten von Algen und Diatomeen, häufig mit Sand vermischt, bestand, ich hielt es deshalb für richtiger, den ganzen erweiterten Darmtheil als Magen zu bezeichnen.

Der eigentliche Darm ist ziemlich eng. Er entspringt stets auf der linken Seite und übertrifft das Thier an Länge bedeutend, weahalb er sich in Schlingen leagt. Bei den meisten Arten sind zwei Schlingen vorhanden (vergl. die schematischen Figg. B, S. 2 2 , und C, S. 32). I)er Darm wendet sich vom Pylorus aus nach vorn $\left(d_{1}\right)$, in der Nihe des Vorderendes des Magens biegt er nach oben und hinten um und verlauft über die Leber hinweg bis zum Enddarm nach hinten $\left(d_{2}\right)$, dann wendet er sich wieder nach links und vorn $\left(d_{3}\right)$, ehe er jedoch soweit wie das erste Mal vorgedrungen ist, kehrt er wieder um $\left(d_{4}\right)$ und erreicht, am Boden der Leibeshöhle verlaufend, den Fuddarm $\left(d_{5}\right)$, in den er allmählich obne scharfe Grenze übergeht. So verhielten sich von meinen Arten Siphonaria pectinata, laeviuscula, subrugısa, aspera und stellata. Genau ebenso verhalten sich nach HutTon Siphonaria australis und nach Nonre Siphonaria jonasi; bei Siphonaria tristensis ist nach Dalc die erste Darmschlinge $d_{1}, d_{2}$ zienlich kurz. Complicirter sind die Windungen bei Siphonaria gigas, indem der Darm sich von dem Pylorus aus nicht gleich nach vorn weudet, sondern zunïchst ein Stück gerade nach hinten geht: dann bildet der Iarm auf der von mir mit $d_{4}$ bezeichneten Strecke, kurz vor dem Liehergang in den Enddarm, noch eine in die Leher eingeschlossene, nach hinten offene Schleife. Auch der Enddarm weicht bei dieser Art, alggesehen ron seiner eigenthümlichen Pigmentirung, durch seine Form und Verlindung nit dem übrigen Darm ab. Einfacher ist dagegen der Darm von Siphonaria redimiculum: hier fehlt die zweite I/armschlinge, resp. sie ist nur durch ein kurzes, S-förmig gebogenes Stïck angedeutet (Fig. C, S. 32). Noch einfacher ist der Darm bei Siphonaria diemenensis nach Qcor u. GammaRI): hier scheint der Zeichnung nach der Enddarm genau quer zu verlaufen und schliesst sich gleich vorn an das vordere Ende der von mir mit $d$, bezeichneten Darmstrecke an; die ganze Zeichnung (1, tab. 25, fig. 4) macht mir übrigens den Eindruck, als ob sie etwas schematisch gehalten sei. 
Die Leber ist von allen frühern Beobachtern gesehen und richtig gedeutet worden; Angaben über ihre Mündung finde ich jedoch nur bei Hutton, der von mehreren ,hepatic ducts" spricht, und Haller, der die Mündung der linken grössern, aus einem grössern und einem kleinern Lappen zusammengesetzten, und der rechten, ebenfalls aus zwei Lappen bestehenden Leber genau beschreibt. Ich hatte in meiner vorläufigen Mittheilung irrthümlich die linke Leber als die einzige angegeben, habe jedoch nachträglich bei meinen sämmtlichen Arten auch die zweite kleinere nachweisen können. Ihre Mündung liegt jedoch mehr ventral und weiter nach hinten, als es bei Siphonaria gigas der Fall ist, so dass ihre Lage auf der rechten Seite nicht so klar hervortritt.

\section{Die Fortpflanzungsorgane.}

Eine unerwartete Verschiedenheit zeigte der Geschlechtsapparat bei den einzelnen Arten. Allen gemeinsam ist der Besitz einer Zwitterdrüse. Von den frühern Beobachtern haben Quor u. GAIMARD die Zwitterdrüse beobachtet, aber für das Ovarium gehalten; Dall scheint mir die Zwitterdrüse ganz übersehen zu haben - was bei der Präparation von ungenügend conservirtem Spiritusmaterial leicht möglich ist, da sie dann fest mit der Leber verklebt ist und sich von ihr auch im Aussehen kaum unterscheidet - denn was er als "ovary" bezeichnet ( 0 , fig. 3 , tab. 5), ist sicher die Schleim- und Eiweissdrüse; die "small spiral mucus gland" am hintern Ende ist wahrscheinlich ein Stück des Zwittergangs. Zuerst haben v. JHering, bald darauf auch Stcder und Hutton nachgewiesen, dass der vermeintliche Eierstock Eier und Sperma zugleich producirt, also eine echte Zwitterdrüse ist. Auch HALler wies bei Siphonaria gigas eine Zwitterdrüse nach und bildet einen Schnitt durch das Organ (tab. 2, fig. 22) al). Nach ihm sind getrennte Follikel vorhanden, die Eier resp. Sperma produciren. Ich habe bei Siphonaria stellata ähnliche Bilder auf Schnitten bekommen wie HaLt.ER, aber nicht mit Sicherheit entscheiden können, ob die weiblichen getrennt von den männlichen in den Zwittergang münden oder ob sie etwa nur periphere Aussackungen der letztern bilden. NовкE stellt sich, jedenfalls mit Unrecht, wieder auf den von Quor u. Gaimarid vertretenen Standpunkt.

Aus der /witterdrüse geht ein stark gewundener, oft strotzend mit Sperma gefüllter, ziemlich dünnwandiger $\mathrm{Zw}$ it te rga $\mathrm{ng}$ ab, den auch Quoy u. Gaimarn, HoTton, Nobre und Hallekr abbilden; auch DaLL hat ihn wohl, wie ich ohen äusserte, gesehen und als Schleim- 
drüse beschrieben. Drüsen, wie sie HaLLfer abbildet, konnte ich bei meinen Arten nicht finden; die gelhen Concretionen in den Zellen habe ich allerdings an einigen Stellen auch gefunden.

Bei den von mir untersuchten Arten konnte ich auch eine am Zwittergang ansitzende $\mathrm{S}$ a $\mathrm{m}$ en bla se nachweisen; ausser bei v. JukRIN(t, der eine Vesicula seminalis erwihnt, finde ich jedoch in der Literatur nichts darüber. Sie ist möglicher Weise bei allen Arten vorhanden, aber, weil sie meist in der Schleimdrüse eingebettet liegrt, bei der Präparation seither übersehen worden.

Der Zwittergang mündet damn bei allen Siphonarien in ein mebr oder weniger rundliches, drüsiges Organ, das von verschiedenen Beobachtern verschieden gedeutet worden ist. (Quox u. GaimainI) bilden es ab und bezeichnen es als Uterus ( $l$, fig. 5 , tal). 25); Dat. hat es ebenfalls gesehen und als Ovarium gedeutet; v. JnEkisi erwähnt eine Eiweissdrüse und meint damit wohl jedenfalls das in Frage stehende Organ. HutTox unterscheidet in ihm zwei Theile, einen hinter der Mündung des Zwittergangs gelegenen, ,albumen gland“ ( $g$, fig. ?, tab. 15), und einen davor befindlichen, den er als "swollen portion of

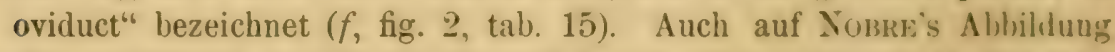
der "weiblichen Geschlechtsorgane" ist ein lï̈rper gezeichnet, den man für diese Drüsenmasse halten muss. Haller konnte hei Siphonuria gigas ebenfalls diesen Abschnitt nachweisen; er unterscheidet darin eine Eiweissdrüse mit einem eigenthümlichen Anhang, üher sie verläuft in zwei Schlingen der ,weibliche Geschlechtsgang", der sich dann vor der Eiweissdrüse noch einmal stark verdickt und zusammenknäuelt. Am Beginn der verdickten Stelle mündet die Fiweissilrüse in den weiblichen Gang. Der verdickte Theil desielben zeigt ein hohes Cylinderepithel (fig. $36 \mathrm{ep}$.), darunter liegen lange, nach aussen hin zusammengeschlängelte, tubulöse Drüsen, in denen zwei Arten von Zellen, nach HatLER's Ansicht verschiedene Secretiousstadien, beobachtet wurden.

Ich konnte bei meinen Arten, soweit sie ausgrebildete Geschlechtsorgane hatten, drei Theile unterscheiden: 1) den drüsigen Theil des Spermoviducts, 2) die Eiweissdrüse und 3) die Schleimalrüse.

Der Spermoviduct ist ein ziemlich gerade von vorn nach hinten verlaufender Canal (nur bei Siphonaria pectinata war er etwas gewunden), dessen Lumen durch eine starke, von der dorsalen Seite herabhängende Falte in zwei Rinnen geschieden wird. Die beiden Rinnen unterscheiden sich wesentlich durch den Bau ihrer Wand, wie ich des nähern bei der Beschreibung von Siphonaria aspera dargelegrt 
habe; ich nannte die eine, weil ihre Wand die grösste Aehnlichkeit mit der Wand der Prostata hat, Prostatarinne, die andere, weil sie sich ähnlich zur Schleimdrüse verhält, Schleim rinne. An ihrem hintern Ende geht diese Schleimrinne in die Schleindrüse über, ein Organ, das aus stark abgeplatteten, wie die Blätter eines Buchs neben einander liegenden Tubulis zu bestehen scheint, deren Wand mit einem charakteristischen, bei Siphonaria stellata näher beschriebenen Epithel bedeckt ist.

Die Eiweissdrüse ähnelt in den gröbern Verhältnissen ihres Baues der Schleimdrüse sehr, besonders auf Schnitten sind sie nur an der Verschiedenheit der zelligen Elemente, wie ich ebenfalls bei Siphonaria stellata geschildert habe, zu unterscheiden. Sie mündet von der Seite der Prostatarinne in den Spermoviduct.

An der vordern Seite der Drüsenmasse wendet sich der Spermoviduct nach rechts, um in den Adductor einzutreten. Dabei verliert er die Falte, die sein Lumen in zwei Rinnen theilte und in Verbindung damit schwinden auch die Drüsenzellen, um einem einfachen Epithel Platz zu machen. Man kann ihn, da seine Wand jetzt vorwiegend von Muskelfasern gebildet wird, als musculösen Theil dem drü sigen gegenüberstellen. Aehnliches haben, soweit sich aus ihren Angaben ersehen lässt, Quor u. GaImard bei Siphonaria diemenensis und Nobre bei Siphonaria jonasi gefunden, doch giebt keiner dieser Autoren an, dass der Canal eine Strecke weit im vordern Theil des Adductors verläuft; DALL zeichnet ihn sogar deutlich ausserhalb (fig. 3, tab. 5). Auch HUTTON hat bei Siphonaria australis die "swollen portion of oviduct" sich in einen Gang von ähnlicher Gestalt und Lage wie der Spermoviduct meiner Arten umwandeln und in die Musculatur eintreten sehen; da er jedoch ein besonderes Vas deferens beschreibt, so deutet er ihn als Oviduct. Bei Siphonaria gigas, die nach HALLER ebenfalls ein Vas deferens besitzt, setzt sich der dicke, drüsige Theil les Geschlechtsgangs, der nach seiner Lage offenbar dem Spermoviduct der von mir untersuchten Formen entspricht, bis zur Mündung in die Geschlechtsöffnung fort.

Gewöhnlich mündet der Spermoviduct neben dem Copulationsorgan in die gremeinsame Geschlechtsöffnung auf der rechten Seite, bei Siphonaria tristensis dagegen mündet der Spermoviduct mit dem Stiel des Receptaculums zusammen in eine kleine, von der Geschlechtsöffinung aus nach hinten gerichtete Aussackung, die Dald als Uterus bezeichnet. Bei den Arten, die ein besonderes Vas deferens besitzen sollen, verhält sich die Mündung des ()viducts ähnlich wie im ersten 
Fall; so öfnet sich der Oviduct bei $S$, australis nach HurTos in dic gemeinsame Geschlechtsïffnung. Der weilliche Geschlechtsgang hei Siphonaria gigas mündet nach HAı,L:k an derselben Stelle, nur scheint die Grube, welche die beiden Geschlechtsöftnuugen sonst einschliesst, hier kaum ausgebildet zu sein. Bei Siphonaria lineulata I' (ORB. sind nach v. Jnerivg , ,lie Leitungswege eine Strecke weit getrennt, treten schliesslich aber wieder in einer Geschlechtscloake zusammen".

Ich will hier gleich das Receptaculum anschliessen. Is besteht aus einem längern und kürzern Stiel und einer Blase, in der ich in einigen Fällen Spermatophoren nachweisen konnte. Der Stiel verläuft in seinem distalen Ende parallel neben dem Spermoviduct, ebenfalls im Adductor. Gewöhnlich ist er dünner und weniger musculis als der Spermoviduct, nur bei S. laevinscula und subrugosa verhalt er sich umgekehrt. Nach meinen Untersuchungen mündet er bei Siphonaria laeviuscula, subrugosa, redimiculum, aspera und stellatu direct in die gemeinsame Geschlechtsöttnung, bei den drei zuerst genannten Arten hinter der Münlung des Penis, neben dem Spermoviduct, bei den beiden letzten aber vor dem Spermoviduct, nachden er zuvor mehrere Windungen in der Leibeshöhle beschriehen hat. Aehnlich wie ich beschreiben (Qcoy u. Gamand und Hutron das Receptaculum, erstere als „vessie propre i plusieurs mollusques pulmonés". DALL zeichnet es auffallend kurzgestielt, STUDER und v. Jhering erwähnen nur seine Existenz, ohne es zu beschreihen. Die von HaLler untersuchte Art soll auch hier von den andern abweichen; das Receptaculum ist eine ganz kurz gestielte Blase, die in den dicken drüsigen Theil des Geschlechtsgangs dicht vor seinen Windungen einmündet.

Ganz abweichend verhält sich Siphonaria pectinata. Allerdings geht auch hier der Spermoviduct mit dem Stiel des Receptaculums durch den Adductor hindurch auf die Geschlechtsöflinung zu, beide Canäle treten aber wieder in die Leibeshöhle hinein und vereinigen sich zu einem einzigen Schlauch, der eine sehr starke Laings- und Ringmusculatur erhält und durch einen nach hinten verlaufenden Retractor unter dem Athemloch am rechten Rand der Leibeshöhle an dem Adductor befestigt wird. Diese Genitalcloake, wie ich sie nannte, mündet an der Stelle, wo auch bei andern Arten die Geschlechtsöffnung liegt, aus.

Auch in den rein männlichen Theilen des Genitalapparats herrscht eine gewisse Verschiedenheit. Die einfachsten Verhältnisse beobachtete ich bei Siphonaria laeviuscula, subrugosa und vielleicht redimiculum. 
Hier mündet am vordern Rand der gemeinsamen Geschlechtsöffnung ein Schlauch mit sehr stark musculösen Wänden, der Penis, der gewissermaassen den Ausführgang einer Prostatadrüse mit sehr complicirt gestaltetem Lumen darstellt. Die Wand der Prostat a drü se zeigt einen sehr charakteristischen Bau, den ich mehr oder weniger deutlich bei allen von mir untersuchten Arten wiederfand. Von Siphonaria redimiculum habe ich allerdings keine geschlechtsreifen Thiere vor mir gehabt, ich bin aber geneigt, aus der Anlage zu schliessen, dass die in das Ende des Penis mündende Drüse, die auch Studer erwähnt, bei dem ausgebildeten Thier nicht sehr viel von der bei den andern Arten beschriebenen abweichen wird. Den kleinen, vom Lumen des Penis aus in dessen Wand eindringenden Canal, den ich schon oben erwähnt habe, müssen wir allerdings hier ausser Betracht lassen, ich finde auch bei keiner andern Art etwas ähnliches beschrieben. Nach der Abbildung, die Dalı, giebt, zu urtheilen, könnte auch Siphonaria tristensis hierher gehören, doch stimmt mir die Beschreibung nicht recht, selbst wenn ich davon absehe, dass DALL offenbar irrthümlich die Prostata als Hoden angesprochen hat, denn es soll ein "very large and stoute penis" vorhanden sein, der eingeschlossen ist in ein "preputium, consisting of two spirally coiled muscular layers". Etwas Derartiges habe ich aber bei keiner meiner Arten gesehen, auch sonst in der Literatur keine ähnliche Angabe gefunden; die Sache scheint mir daher doch einer erneuten Untersuchung bedürftig.

Eine höhere Differenzirung zeigen Siphonaria aspera und stellata var. luzonica. Das Copulationsorgan besteht hier aus zwei getrennten Theilen, einem rein musculösen und einem drüsigen, die neben einander gemeinsam in die Geschlechtsöffnung ausmünden. Der rein musculöse, den ich als Penis bezeichne, hat im Innern zwei einander gegenüber stehende musculöse Falten, der drüsige dagegen zerfällt in 3 Theile, den Stiel, die eigentliche Prostata und das Flagellum. Sie zeigen alle in ihrer Wand die subepithelialen Drüsen, ein Abschnitt der eigentlichen Prostata war jedoch durch besonders grosse, eigenthümliche Zellen ausgezeichnet, über die ich aber wegen mangelhafter Frhaltung leider keine nähern Angaben machen kaun. Ganz ähnlich ist wohl das Copulationsorgan von $S$. diemenensis zusammengesetzt, wenn man die jedenfalls zutreffende Annahme macht, dass die von Quroy u. Gamari als Hoden und Vas deferens bezeichneten Theile in Wirklichkeit Prostata resp. Stiel sind. Das Flagellum würde allerdings dann fehlen, aber die Figuren können doch im grossen Ganzen 
richtig sein, und nicht ,figures, which, seem to owe a grood deal to the imagination of the artist", wie DAL, meint.

Bei den bis jetzt angeführten Arten ist kein Vas deferens vorhanden, für zwei wird ein solches aber in der Literatur angegehen: zuerst von HuTTux für Siphonaria australis und dann für Siphonaria gigas von HaLl.ER. Bei der erstern Art soll es von der „swollen portion of the oviduct" entspringen und in die Prostata eimmünlen. Ich muss gestehen, dass mir letztere Angabe etwas verdachtig scheint und mich vermuthen lässt, dass vielleicht eine Verwechslung mit dem Flagellum vorliegt, dessen Ende manchmal bei meiner Siphonaria stellata der Drüsenmasse fest anliegt, ohne dass jedoch eine Communication der Lumina stattfande. Was mich allerdings an dieser Annahme wieder irre machen könnte, ist der Umstand, dass es, der Zeichnung nach zu urtheilen, mit Spermoviduct und Receptaculumstiel durch die Musculatur zu verlaufen scheint, was ich bei dem Flagellum nie beol)achtet habe, doch bei der verschiedenen Lage, in der ich es sonst angetroffen hale, nicht für unmöglich erklären darf. Bei Siphonaria gigas entspringt es aus dem „weiblichen Gang", ehe er die Windungen auf der Eiweissdrüse macht und verliuft direct nach der männlichen Geschlechtsöffinung, wo es neben dem verhailtnissmassig kleinen Penis mündet (fig. 19, tab), 2). Diesen ,männlichen Gang" hat HALLER nicht auf Schnitten untersucht, dagegen hat er den P'enis genau beschrieben und abgelililet. Ir ist in seinem dicksten Theil ein wesentlich drüsiges (Organ, wie der alggebildete Quer-chnitt (fig. 27, tab. 3) lehrt, seine Wand ist zum Theil dünn, zum Theil stark verdickt. Der verdickte Abschnitt der Wand begrenzt theilweise eine Rinne, die „Penisrinne" $r$, die mit ausserordentlich grossen \%ellen ausgekleidet ist; daran schliesst sich die nach dem Lumen zu concav vorspringende drüsige $W$ and des Penis, die aus tubulösen, unter einem Cylinderepithel gelegrenen Urusen zusammengesetzt ist, ahnlich wie die Wand des "weiblichen Geschlechtsgangs". Nach der Spitze erstreckt sich die Penisrinne nicht, sie bört vorher pliitzlich auf: nach der Mündung zu verstreicht sie allnahllich, ehenso wie die drïsige Wand, die sich jedoch andrerseits lis zur Spitze des Penis erstreckt. Der der Mündung zugewandte Theil des I'nis ist nach dem Verschwinden der Rinne und der Drüsenwand nur mit Cylinderepithel ausgekleidet.

Die Discussion dieser von den verschiedenen Beolachtern über den Geschlechtsapparat der einzelnen Arten gemachten Angaben ist kein sehr viel Erfolg versprechendes Lnternehmen. Ausser HaLLi:R, 
der aber eine Form untersucht hat, die von den andern vielleicht gerade in diesem Organsystem weit abweicht, hat keiner meiner Vorgänger Angaben über den Bau der einzelnen Abschnitte gemacht, was für eine sichere Identificirung derselben von der grössten Wichtigkeit wäre, und dann scheint mir selbst die Darstellung der gröbern anatomischen Verhältnisse nicht über jeden Zweifel erhaben. Ich hale ja auf den vorhergehenden Seiten schon an verschiedenen Stellen meine Bedenken geäussert, womit ich allerdings keinen weitern Vorwurf gegen die betreffenden Autoren erheben will, hat doch mich selbst mancher missglückte Versuch belehrt, dass die kleinen SiphonariaArten in conservirtenı Zustand für die Präparation sehr ungünstige Objecte sind, deren Untersuchung ohne Anwendung der Schnittmethode kaum weit führen kann.

$\mathrm{Z}$ witterdrüse, Zwittergang und vielleicht auch die S a menblase kommen wohl allen Siphonarien zu, dann fangen aber die Verschiedenheiten an. Zunächst ist Siphonaria gigas auszuscheiden, wo sich der Zwittergang in zwei Theile spalten soll, einen männlichen und einen weiblichen Gang. Bei den andern mündet der Zwittergang in den drüsigen Theil des Spermoviducts, der Schleimund Eiweissdrüse aufnimmt und mit ihnen die compacte Drüsenmasse bildet. Aus dieser geht der musculöse Theil des Spermoviducts neben dem Stiel des Receptaculums zur Geschlechtsïfnung. Das einfachste und wohl auch primitivste Verhalten scheint mir das bei Siphonaria laeviuscula, subrugosa und vielleicht auch redimiculum $\mathrm{zu}$ sein, wo beide Canäle neben einander hinter dem Copulationsorgan ausmünden, das hier in zwei hinter cinander gelegene A bschnitte, einen musculösen Penis und eine Prostatadrüse, differenzirt ist. Bei Siphonaria aspera und ähnlichen ist insofern eine hïhere Entwicklungsstufe erreicht, als beide Abschnitte sich fast vollkommen von einander getrennt halen und nur an ihrer Mündung \%usammenhlïngen. Wie der Bufund bei Siphonaria pectinata zu erklären sein wird, lïsst sich schwer sagen; die Genitalcloake kann dadurch entstanden sein, dass der Fnialsschnitt eines der neben einander mündenden Canäle sich mächtig entwickelt und die Mündungen der andern, eventuell unter Rückbildung der äussern Theile, aufgenommen hat; vielleicht ist aber auch die Genitalcloake eine viollige Yeubildung, die von der geneinsamen Gieschlechtsïflinung aus entstanden ist; wir können diese frage nicht sicher heantworten, da uns \%wischenformen fehlen, die vielleicht verwandte Arten oder jüngere 
Lintwicklungsstadien aufweisen: das eine glaube ich aber bestimmt annehmen zu dürfen, dass das Verhalten kein primitives ist.

Noch weniger passt Sighonaria gigas zu den ülorigen. Wenn maun auch nach dor Lage annehmen darf, dass der "weibliche Geschlechtsgang" dem Spermoviduct und das von Hatder als I'enis bezeichnete Oryan dor sonst als l'rostata gredeuteten I riise entspricht, so sind doch andrerseits im feinern Bau der Wand beider Organe Unterschicele vorhanden, über die man sich nicht so ohne weiteres hinwegsotzen lann. Ëne ernente Untersuchung des Geschlechtsapparats der Siphonarien an auch für feinere histologische Cntersuchungen ausreichend conservirtem Material scheint mir sehr wünschenswerth zı sein, dat auch mein Material in dieser Hinsicht den Anforderungen nicht genügte.

Aus der Entwicklung der Geschlechtsorgane hahe ich zwei stallien untersuchen können und schon oben ausführlich beschrichen; is ist leider eine Art, von der mir keine erwachsenen Thiere zu Gebote standen, Siphonaria redimiculum. Ich habe auch dort gleich die Deutung der einzelnen Theile versucht, so dass ich hier nielit melhr darauf zurückzukommen brauche; allgemeinere Schlüsse aus den dort niedergelegten wenigen Beobachtungen zu ziehen, scheint mir nicht rathsam.

\section{Das Nervensystem.}

Die Angalıen über das Nervensystem sind in der Literatur recht spärlich. Die beste Beschreibung und Abbildung verdanken wir HAL.LER, ler die grosse Siphonaria gigas untersucht hat. v. JnEmovi lat dats Xervensystem von Siphonaria lineolata besclirieben, aber nicht ahyebildet; eine ziemlich schematische Abhildung gieht HoTTus; die Beschreilungen der andern Autoren sind so allgemein gehalten, dass ich sie hier übergehen kann. Die Mittheilung liorvikl's äher das Verhalten der Arteria anterior zu Visceralcommissur und Schlundring habe ich schon oben berủcksichtigt.

Ich habe bei meiuen Arten das Nervensystem nur auf Schnittserien untersuchen können, da ich für diesen \%weck nicht sovicel Material opfern konnte, wie bei der sichwierigkeit der Praparation an den kleinen, stark gehärteten Thieren erforlerlich grewesen wäre. Diese von mir angewandte Untersuchungsmethoule ist aher sehr zeitraubend und führt trotzdem in manchen fallen nicht eimmal zum Ziel, da die Nerven und Ganglien durch die Contractionen der alsterhenden Thiere fast stets verlagert, an einatnder grepresst ouler sonst unkenntlich 
gemacht werden. Ich habe daher nur die wichtigsten Nerven, die von den Ganglien der Visceralcommissur ausgehenden, verfolgt.

Der Schlundring besteht aus drei Paaren von Ganglien, den Cerebral-, den Pedal- und den Pleurointestinalganglien (Commissuralganglien, v. JHering; Pleuralganglien, Haller). Dieselben sind durch die bekannten Commissuren resp. Connective verbundeu, die Pedalganglien durch zwei, eine vordere und eine hintere, die Pedalund die Parapedalcommissur. Zwischen den beiden Pleurointestinalgauglien liegt die kurze Visceralcommissur, die rechts ein A b d o m in a lganglion (hinteres Eingeweideganglion) enthält. v. JHERing hat das Abdominalganglion nicht gefunden, Huтton hat die Cerebropleuralconnective übersehen, ebenso die zweite Pedalcommissur, auch beschreibt er nur zwei ,parieto-splanchnic ganglia", beide auf der rechten Seite; es sind offenbar rechtes Pleurointestinal- und Abdominalganglion; das linke erwähnt er nicht, hat es aber gezeichnet. Wie gewöhnlich sind auch zwei Buccalganglien (vordere Eingeweideganglien, Haller) vorhanden, von denen zwei Connective zu den Cerebralganglien führen; aus der sie verbindenden Commissur entspringt nach Haller und v. Jhering ein Nerv.

Ich gehe nun zu den peripherischen Nerven über und werde mich hier auf diejenigen beschränken, die ich selbst auf meinen Schnitten habe untersuchen können, im Wesentlichen die von der Visceralconmissur und ihren Ganglien ausgehenden Nerven. Das rechte Pleurointestinalganglion entsendet drei Nerven, von denen einer den vordern und einer den hintern Theil des Mantels versorgt. Der dritte ist nur kurz und endet unter dem Geruchsorgan am Eingang der Mantelhöhle mit einem ziemlich grossen Ganglion, vou dem ich einige Nerven zur Kieme verfolgen konnte.

Haldar beschreilst nur zwei Nerven, einen vordern und einen hintern. Ersterer innervirt den Mantel und den vordern Theil des Genitalapparats, der hintere die Kieme und den Vorhof des Herzens. Jic Alweichungen zwischen unserm Angaben sind jedoch hier nicht so gross, wie sie scheinen: der zum Geruchsorgan gehende und der hintere Mintelnerv, die ich beschrieben habe, liegen nämlich so dicht an einander, dass man sie erst auf Schnitten tremnen kann; sie beide stellen wohl zusammen rlas vor, was Harduk als den hintern Nerven bezeichnet. Auch der 1). 22 crwälnte, mit Ganglienzellen versehene "Nerv. trunc." unter ciner lalte (n), die er wie ich für das Geruchsorgan hailt, ist wohl nichts anderes als dieser hintere von beiden Nerven, wenn es auch aus der Beschreilumg nicht ganz klar hervor- 
geht. Nur bezüglich des vordern hesteht eine Verschiedenheit: ich hale zu den Geschlechtsorganen gehende Aeste nicht finden kinnen. Von dem Abdominalganglion sah Harder wie ich drei Verven algehen, die, wie ich chenfalls fand, Geschlechtsorgane, Niere und Endilarm versorgen; ausserdem sollen sie nach H.at.En Theile der Leber versorgen, was ich nicht hatre nachweisen kïmnen, loch für wahrscheinlich halte. Dagregen sah ich einen Ast in den hinter der Athemhöhle grelegenen Theil der Mantelfalte eintreten, wo or nach hinten verlief. Vom linken Pleuralganglion sah ich zwei Nerven entspringen, einen am linken Rand, der cinem Peslalnerven dicht anlagert und nach dem Mantelrand verläuft - es ist offienhar der von HaLLek mit $s$ bezeichnete Mantelnerv - und einen andern am hintern Ende, der neben dem Pedalnerven an Boden der lecileshöhle nach hinten und links verläuft; ich kann ilın in keinem der von HALLer beschriebenen Nerven wiedererkennen. Von den hei Siphonaria gigas beschriebenen eigenthümlichen Darmuerven hahe ich bei meinen Arten keine Spur finden können.

Von Sinnesorganen konnte ich an der Innenfliche der Pealalganglien ein paar () tocyste n mit zahlreichen Otoconien nachweisen: auch Halier, Nobre, HutTon und v. Jueisisa erwähnen sie. Fermer sind deutliche Augen wohl bei allen Arten vorhanden und nur wegen ihrer versteckten Lage von einigen Autoren wie HrTTos, TExisonWorns (nach Hotros) und Noвke übersehen worden; ich kommte bei Siphonaria laeviuscula auch den Opticus nachweisen.

Ueber frühe Entwicklungsstadien hat IIтTux einige Angaben gemacht, bezüglich deren ich auf das Original verweise: als besonders wichtig hebe ich hervor, dass ein freischwinmendes Veligerstalium mit nautiloider Schale und Leckel vorhanden ist. Das Thierchen wird auf diesem Stadium durch einen links gelegenen Adductor in der Schale festgehalten; hei der weitern Entwicklung soll die Schale ah)geworfen werden.

\section{A bschnitt III.}

Wir kommen jetzt zur Erörterung der letzten und wichtigsten Frage, der nach den Verwandtschaftsheziehungen und der davon ahhängenden systematischen Strellung der Siphonarien. Fs ist gegenwärtig kein Zweifel, dass die Verwandten von Siyhonaria nur hei den Pulmonaten oder bei den Tectiluranchien zu suchen sind; zu 
diesem Resultat ist jeder der neuern Beobachter, die das Thier untersucht baben, gekommen, und das geht aus seiner ganzen Organisation auch so klar hervor, dass eine nähere Begründung überflüssig ist. Als wesentlichster Unterschied zwischen den Tectibranchien und den Pulmouaten, speciell deu Basonmatophoren, die hier zunächst in Betracht kommen, ist aber die Thatsache anzusehen, dass erstere in der Athemhöhle, die mehr oder weniger weit geöttinet ist, ein Ctenidium, eine typische Kieme, besitzen, während bei diesen das Ctenidium fehlt und auf der Wand der Athemhöhle ein respiratorisches Gefässnetz zur Entwicklung kommt. Dabei ist noch die Athemhöhle bis auf eine kleine, meist auch verschliessbare Oeffinung abgeschlossen.

Wir haben also zunächst nach dem morphologischen Werth der Kiene von Siphonaria zu fragen. Darüber finden wir drei verschiedene Ansichten vertreten: 1) die Kieme von Siphonaria ist der Molluskenkieme, dem Ctenidium, nicht homolog, sondern eine Neubildung, entstanden durch die Anpassung an eigenthümliche Lebensbedingungen; 2) die Kieme von Siphonaria entspricht einer Reihe von Cten idien, und jedes der "Kiemenblättchen" ist einem ganzen Ctenidium homolog; 3) die ganze Kieme von Siphonaria entspricht einem einzigen Ctenidium, wie wir es bei den übrigen Prosobranchiern und den meisten Tectibranchien uuzweifelhaft in der Kiemenhöhle finden.

Für die erste Annahme hat sich von den Autoren, die Siphonaria als Pulmonaten in Anspruch nehmen - das sind Quoy u. GaImari), I. . I L, Studer, Hutron, Lacaze-Duthiers, Nobre und Bouvier - nur IlutToN direct ausgesprochen, indem er (5, p. 342) schreibt: „evidently they (d. i. die Kiemen) are adaptive in origin and not homologous with the gills of other Mollusca"; auch DALL ist dieser Meinung, ganz unzweifelhaft geht dies auch aus einem an mich gerichteten Bricf hervor, in dem er kurz seine Meinung über diese Frage darlegt; dass LAciaze1) THE mit Gadinia zusammenstellt und ihre Kieme als ,première ébauche d'une branchie" bezeichnet; die andern Autoren treten dieser Frage überbaupt nicht näher.

I) ¿weite Ansicht ist erst kürzlich von HALLER aufgestellt worden, lor Sijhonaria mit Umbrella und Thylodina zusammengestellt und diesen Formen, wie überhaupt allen Pleurobranchien, eine Kienenreihe ähnlich derjenigen der Chitonen zuschreibt.

Für die dritte Möglichkeit hat sich zuerst v. Jusand entschieden, indem or Siphonaria zu den Steganohranchien stellte, direct neben die Pleurobranchilen, und auch ich hahe diese Ansicht über die Kiene 
in meiner vorlaufigen Mittheilung, ohne sie allerdings naher zu begründen, anfgestellt. Whe ich die begründung hier versuche, müchte ich zuerst einige Bemerkungen über die P'allialorgane der Tectibranchien üherhaupt vorausschicken, die ich durch einige Zeichmungen auf Tafel 4 näher erlautere; dieselben machen keineswegs Anspruch auf Vollstindigkeit, sonderu sollen nur einige Thatsachen vorführen, die mir für die Vergleichung mit Siphonaria von hesonderer Wichtigkeit zu sein scheinen; vielleicht kann ich hei einer andern Gelegenheit die Athemhöhle der 'Tectibranchien einmal ausführlicher bearbeiten.

Zum Ausgangspunkt wähle ich das Dach der Athemhöhle von Bulla striata Broci. Ich habe dasselbe abprijparirt und von der Innenseite in Fig. 60), Taf. 4, dargestellt. In der vordern linken (auf das Thier bezogren) Ecke liegt das II erz in dem Iferzheutel, der Ventrikel (ve) nach unten und vorn, das Atrium (at) wach oben und hinten gerichtet. Hinter dem Herzen liegt die Xiere (ren); sie hesit»t einen trapezförmigen Lmriss, die kürzere Grundlinie liegt dem Hır\%beutel, die längere dem Hinterrand der Athemhöhle an. Am rechten Schenkel der Niere erhelst sich eine Membran, welche bis zum Herzen nach vorn verläuft und sich dann schräg nach rechts und vorn wendet; sie trägt die Kieme (ct), die, wie schon Varssizar, allerdings bei einer andern Art (14), richtig beschreibt, aus Falten dieser Membran besteht, die balı nach der einen und bald nach der andern Seite vorspringen. Der nach vorn gerichtete, zum grössten Theil festgewachsene Ramd der hieme trägt die $\mathrm{Kiemenvene,} \mathrm{der} \mathrm{nach} \mathrm{hinten} \mathrm{gerichtete} \mathrm{das}$ zuführende Kiemengefäss; letzteres habe ich auch an meinen Prïparaten gut ohne Injection erkennen können und dither eingezeichnet. Die Nierenöfung hat Varssizke nicht beschriehen; sie limet, wie aus meiner Fig. 60 hervorgeht, auf einer kleinen Papille, die an der hintern rechten Ecke der Niere hinter der lieme vorspringt.

Ganz ähnlich verhalten sich die Organe des l'allialcomplexes bei Scaphander lignarius, nur erscheinen sie, wie ein Versleich unserer Fig. 59) mit ti0 zeigt, in der Richtung von hinten nach vorn mehr zusammengeschoben, so dass alle Organe im Verhaltniss zur Breite viel kürzer sind als bei Bulla. IDie Kiene ist wieder ähnlich grehaut wie lee Bulla; um eine Vorstellung von der complicirten Faltum gehen, bilde ich Fig. 18, Taf. 6, cinen Schnitt ab, der senkrecht z.u den Falten etwa durch die hreiteste Stelle der Kieme gefuhrt ist. Die Ni e renöf $\mathrm{n}$ ung liegt auch an rechten Nierenrand hinter der lieme nahe dem zufiihrenden Kiemengefass; ich hate sie Fig. 19, Taf. 6, auf einem Querschnitt abgebildet. 
Etwas abweichend verhält sich Acera bullata. Während Kieme und Herz sich im Allgemeinen wie bei den beiden andern Arten verhalten, hat sich die Ni e re über die Insertion des abführenden Kiemenrands hinaus weit nach rechts ausgebreitet, so dass sie bis nahe an den Mantelrand reicht (Fig. 62). Die Nierenöffnung liegt wie bei den beiden andern Arten hinter der Kieme auf einem kleinen, sich auf dieselbe erstreckenden Fortsatz (Fig. 62 u. 61 renpo).

Die Anatomie von Gastropteron meckeli hat VAYssì̀e in einer schönen Monographie ausführlich beschrieben, und ich würde mich auf die Anführung seiner Angaben hier beschränken können, wenn nicht ein eigenthümlicher Zufali den französischen Gelehrten bei dem Aufsuchen des Nierenporus auf falsche Bahn geleitet hätte. VAYssière fand nämlich einen $\mathrm{schwarzen} \mathrm{Punkt}$ vor dem After, dorsal von der Kieme, der direct der Wand des BoJanus'schen Organs aufsass; nach längerer Maceration glaubte er darin Oeffnungen zu erkennen, und es lag nahe, den schwarzen Punkt für die Nierenöffnung zu halten. Ich habe die Sache auf Schnittserien nachuntersucht und dabei feststellen können, dass der schwarze Punkt mit der Niere nichts weiter $z u$ thun hat; es ist ein kleines Bläschen mit schwarz pigmentirter Wand, das durch einen äusserst engen Canal mit der Epidermis in Verbindung steht (Fig. 17, Taf. 6); was es eigentlich bedeutet, habe ich noch nicht ermitteln können. Die Nierenöffnung liegt ganz hinten in dem Winkel, den die Membran, welche die einzelnen Kiemenblättchen trägt, mit der Körperwand bildet; sie kann daher erst sichtbar werden, wenn man den freien Theil der Kieme nach oben klappt. Bei meinen conservirten Exemplaren war sie bei der Betrachtung von aussen kaum zu erkennen, dagegen lasst sie sich auf Schnitten sehr gut nachweisen (Fig. 57, Taf. 4, renpo). Die Kieme ist, wie VAyssìne zutreffend beschreibt, halb gefiedert. Auf einer Membran, die vorn die Kiemenvene, hinten das zuführende Kiemengefäss trägt, sitzen gefaltete Lamellen, in denen das Blut circulirt; ich habe Fig. 58 einen senkrecht $z u$ den einzelnen Kiemenblättern geführten Schnitt abgebildet, der die Membran (me) und die darauf sitzenden Blätter $(b l)$ schön zeigt; letztere tragen an ihrem freien Rand die abführenden Gefässe $(k v)$, die weiter vorn in die Kiemenvene münden; das hintere Ende dieses Gefässes ist schon bei $k v$ getroften.

Doppelt gefiederte Kiemen kennen wir von den Pleurobranchiden. Nach Lavazri-Duthers (11) lildet die Kieme lier eine horizontale, dreieckige Membran, deren Lasis am Körper befestigt ist, während die Spitze frei bleibt; auf ihrer obern und untern Seite ent- 


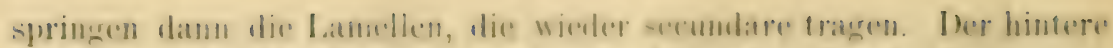

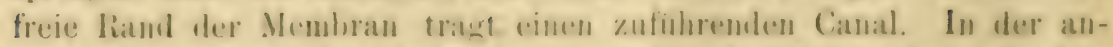

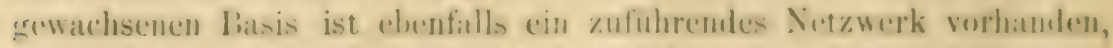

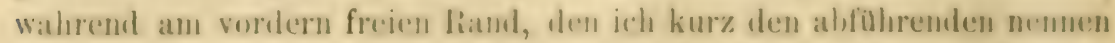
will, die liemenvene zum Ilermen verbuft (fig. 1, tab). У). Ibie An-

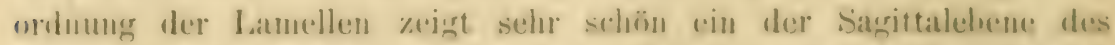

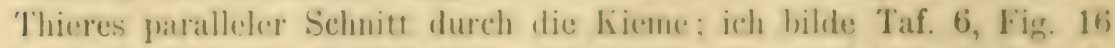
rinen soldhen durch die Kiemenspitze cines kloinen (Oseanius al). Die: Niere mündet nach LACAZE voru, unter der lassis der Membran (11, tab. 10, fig. 2 j).

Achnlich gebaut ist nach VArssit:re (16) die lieme von Thylodina, nur scheint sich, wie ich aus den Abbilnhugen schliesse, der bei J\%mrobranchus nach a ussen igerichtete ahführende Raud nach oben onewandt zu haleen, so dass jetzt die Iatmellen nicht mehr eine dorsale und eine ventrale, sondern eine mediale und eine laterale Reihe hilden.

Fast genatu ebenso verhalt sich der hintere Theil der Kieme von

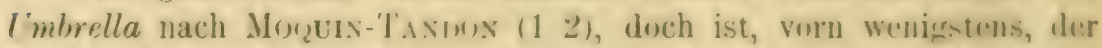
ahführende Rand ventral grawandt (tal). 1, fig. (i), und ausserilem setot sich die baterale Reihe der Kiemenblattchen kopfwarts his äher die Medianlinie des liöpers in der zwischen Fuss und Mantel gelongnen Furche fort (tal), 4, fig. 3). Auch an diesem Theil liest ras zuführome. Gefiss dorsal, das ahführenule, die kienenvene, ventral. An der stelle, wo der freie, doppelt gefiederte Theil der kieme in den einfach \&orfiederten iilsergeht, münlen beide Kiemenvenen in den Vorhof. fiwas hinter dieser stelle münlet unter der hieme die Niere aus 112 , Iah. 1, fig. $6 a)$.

Vergleicht man diese verschienlenen Arten mit einamber, sn zeigt

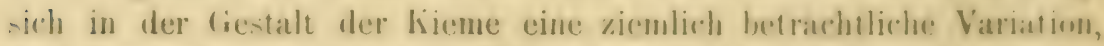

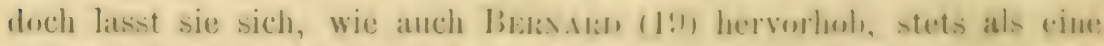
gewrihnlich etwa dreieckige Falte: de- Interguments auffis-on, dir mit ciner seite, lor liasis, von der kiorperwanl entsprinest uml am molern,

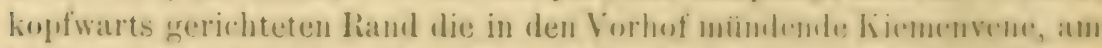
hintern, analwarts gewanden das zuführemle liomengrefies trant. Dne In-ertionsstelle dierex Falte berderankt sich jeoloch nicht allein anf

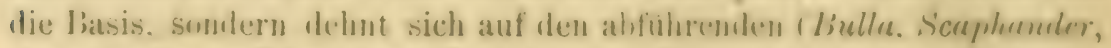
Acera) oder zufïhrenden (fiastropterone. I'leurobranchislen, I'mbrella,

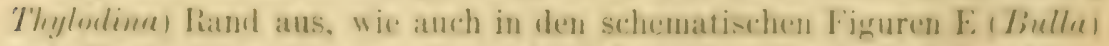

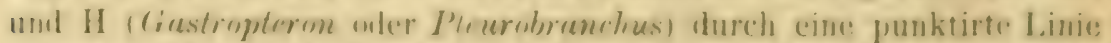

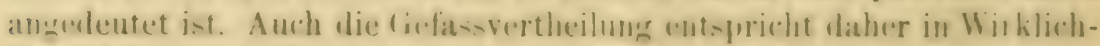
keit nicht gnenau dem angenommenen schema, indem die liemenvene 
beim Austritt aus (lem Herzen sich gabelt (Fig. E); wie dieses Verhalten phylugenetisch zu erklären ist, müssen spätere Untersuchungen lehren: ('s kanu in der Aushildung einer zweiten Kiemenvene an der Nierenhasis seincu Grund haben, ehenso gut aber anch durch eine Verschiehung des Herzens dem Verlauf der Kiemenvene entlang zu Stande kmmmen. Bei Gastropteron und den Pleurobranchiden ist es das zuführente liemengefäss, das ein ahnliches Verhalten zeigt. Auch die

Fig. E.

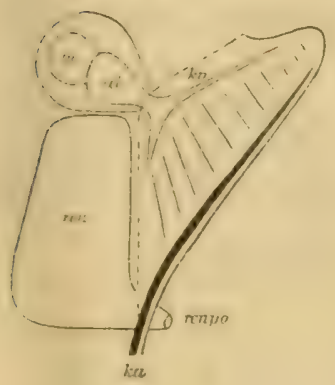

Fig. H.

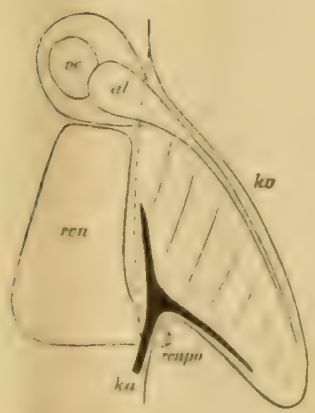

Fig. F.

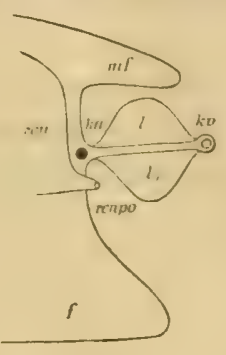

Fig. J.

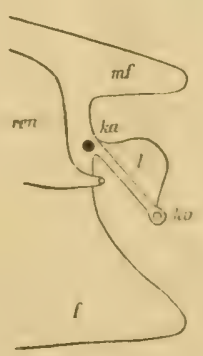

Fig. $\mathbf{G}$.

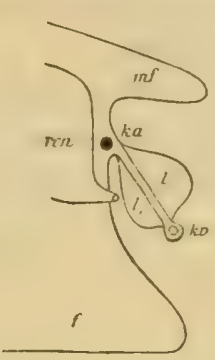

Fig. $\mathbf{K}$.

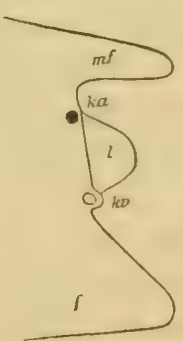

Fig. E. Anordnung der Pallialorgane, Herz, Niere und Kieme bei Bulla.

Fig. F. Quersehnitt durch die Gegend der Nierenmündung bei Pleurubranchiden.

Fig. G. Vesgl, bei Umbrella, es ist der hintere freie Theil der Kieme getroffen.

Fig H. Asurdnumg der Pullialurgane leei Giastropteron. Denkt man sich die Nierenwilnung weitor mach vorn greriickt und din Kieme doppelt gefiedert, so hat man die Anordnung der betreffenden Organe bei den Pleurobranchiden.

Fig. J. Schnitt durch die Gegend der Nierenmündung bei Gastropteron.

Fig K. Schnitt durch den vordern, in der Mantelfurche angewachsenen 'Theil der Kieme bei Umbrella.

at Vorhof, $f$ Fuss, ka zufiihrendas Kinmengefiss, ko abfïhrendes Kiemangefiss, ᄂ. I, Kiernenblätlben, $m f$ Mautuliales, ren Niere, renpu Nierenjorus (wegen Mangel as

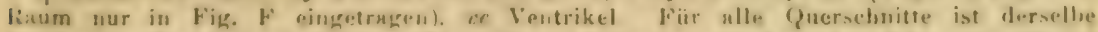
Limriss zu firunde gelogt, whne Rür-ksicht suf die verschiedene Ausbililung ies Fusses bei den verschiedenen Formen. 


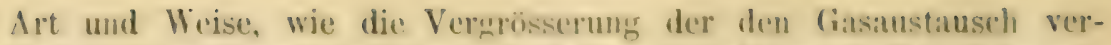
mittehden Oberflache in leeden Fallen erreidht wird, ist eine verschiedene: hei bulla, scaphemeler etc. ist die ganzo Membran zwischen den beiden Gefassen, wie wir uhen sihen, ahwechsednd nach unten und when sefaltet; hei den I'leurobranchiden ditgewen heibt sie zirmlich glatt und ist anf ihren beiden seiten mit alterniremden fienlerblattrhen hesetzt. Auch Gastropteron zejgt den letztern Tyjus, jedowh unt der . lhweichung, ditss nur auf der nach atusen und oben gewandten Flache der Membran die Lamellen zur Aushildung kommen, und die Lamellen sind ihrerseits nicht gefiedert wie bei I'leurobranchus, sondern nur grefaltet.

Beide Arten der Oberflachenvergrïsserung, die „F i ederung" wie die "Faltung g6, lassen sich leicht als Monlificationen der rinen gemeinsamen, schou oben angenommenen Anlage erklaren. Die Haut-

Fig. L.

2

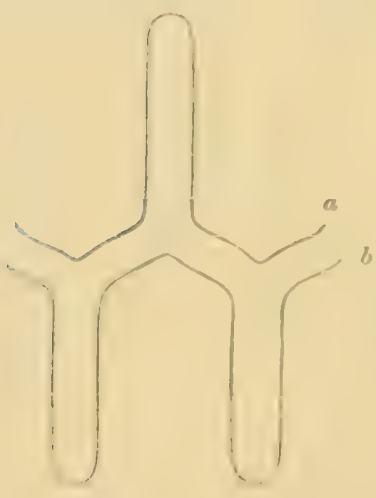

1

3

Fig. L. Schems der gefiederten Kieme.

Fig. M. Schema der gefalteten Kiemo.

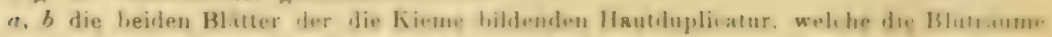
einschliessen; 1, 2, 3 die sogenanuten Kiemenblüttchen.

falte, welche die hieme, im frumb genommen, darstellt, leesteht ja als solche aus zwei Blittern. $a$ und $b$, Fig. I, und $M$, zwischen dencm die Blutfüssigkeit circulirt. Dies findet, wie anch Li:ksakn, ansführt, in der Weise statt, dass an den Kanten des Blattes je ein grrisserer Blutraum die Zu- resp. Alfuhr des Blutes ühernimmt, während sich $z$ wischen ibnen ein Netz von kleinern Blutraumen aushildet, das den 
eigentlich respiratorischen Theil vorstellt. Die Leistungsfähigkeit des Organs steht nun in geradem Verhältniss zur Grösse der Oberfläche, welche die in dem respiratorischen 'Theil der Kieme enthaltene Blutmasse dem sauerstofthaltigen Medium darbietet, und diese kann bei geringer Entwicklung der die Bluträume durchsetzenden Trabekel der Summe beider Oberflächen des respiratorischen Theils gleichgesetzt werden. Fine Vergrösserung der mittlern, die respiratorische Oberfläche bildenden Theile der beiden Blätter ohne gleichzeitige Verlängerung der zu- und abführenden Gefässe, welche die Höhe der Leistung nicht oder yar ungünstig beeinflusst, hat aber zur Folge, dass sich in der Mitte Falten ausbilden und zwar, soweit mir bekannt, meist so, dass die von beiden Blättern gebildeten Falten mit einander alterniren. Drei derartige Falten zeigt die schematische Figur L, die den einfachsten Fall des bei Pleurobranchus ausgebildeten Typus darstellt. An einer solchen Kieme kann man dann zwei Reihen von Falten oder La mellen (Kiemenblättchen) unterscheiden, die den beiden Seiten einer dünnen Membran, der Axe aufsitzen.

Steht die Axe in horizontaler Richtung von dem Körper ab (Fig. F), so dass die Kiemenblättchen auf beiden Seiten gleichen Raum zur Verfügung haben, so ist ihre Zahl auf beiden Seiten gleich, wie man aus VAyssière's Angaben über die Pleurobranchiden des Marseiller Golfes cntnehmen kann (17); neigt sie sich dagegen in einer oder der andern liichtung, so dass sich eine Seite mehr oder weniger der Körperwand anlegt, so ist auf letzterer die Zahl der Kiemenblättchen eine geringere, wie z. B. bei Thylodina, sie können sogar auf der letztern ganz fehlen, wie bei Gastropteron.

Der Kieme von Thylodina entspricht nach Lage und Bau vollkummen der hinter der Mündung der Kiemenvenen gelegene Theil der Kieme von Timbrella; für den vordern Theil der Umbrella-Kieme aber finden wir bei Thylodina kein entsprechendes Gegenstück. Er scheint larlurch als eine Neubildung entstanden zu sein, dass die laterale livihe der Kiemenbliattchen sich über den vordern Rand der eigentlichen Kieme auf den Boden rer Mantelrinne ausgedehnt hat, und in Verbindung damit hat sich eine lesondere, von vorn in das Her\% eintretende Kienenvene ausurebildet. Diese Annahme scheint mir wenigstens mit Rücksicht auf das Verhalten von Thılodina plausibler als die, dass im vordern Theil die Kiemenaxe nach Räckbildung der medialen Kiemenhlätchenreihe mit der Seitenwand des Körpers in grösserer Ausdehrumgr verwachsen sei; diese Auffassung würde die Lagre des fraglichen Kiemenalsschnitts vor dem Herzen und die Ausbildung der 
zweiten Kiemenvene nicht erklaren, falls man nicht noch ausserdem eine Verlatgerung des Herzens nach hinten annehmen wollte.

Ohne auffallige Verinderung der Form, Anzahl und Groisse der Falten einer doppelt grefiederten Kirme kann eine wesentliche Vergrösserung der Oherfliche erreicht werden, wenn sich an der Bildung einer respiratorischen Iamelle nicht nur das eine Blatt, z. B. auf Fig. I. das Blatt $b$, an der Bildung der Lamelle 1 betheiligt, sondern jede Lamelle durch die gleichmässige Faltung beider Blätter gehildet wird, wie Fig. M (S. 74) zeigrt; es ist dies in schematischer Darstellung das Verhalten, das wir bei Bulla, Scaphander und Acera gefunden hahen und dem wir, wie ich in Bestätigung einer Angahe von Bransak1, hier nachtragen will, auch bei Aplysia loggegnen. Von einer Axe kann hier nicht mehr die Rede sein, der ganze respiratorische Theil ist e in e gefaltete Membran. Das hat Brennars $(19$, p. 24!1) mit Recht hervorgehoben; er geht jeloch zu weit, wenn er die Existenz einer Axe, eines „support branchial" ülerhaupt hei Tectibranchien leugnet, denn bei Gastropteron und den Pleurobranchilen ist er sicher vorhanden, wie ich selhst bestätigen konnte, eloenso nach Varssilikes und Monum-Tanoron's Beschreihung hei I'mbrella und Thylodina. I) Aese Axe kann allerdings ihrerseits noch gefaltet sein, wie wenirstens meine Schnitte von Grastropteron zeigen, und ebenso kïnnen sich die einzelnen Lamellen verhalten.

Wir kommen nun zur Kieme vom Siphonaria. Sie besteht aus einer Reihe von gefalteten, häufig secundïre Iamellen tragemilen Blattchen, die in ihrem Bau und ihrer Lage zwischen dem zufihhrenden und abführenden Gefäss gatnz den Kiomenblättchen von I'mbrella oder Pleurouranchus entsprechen. Sie entspringen allerilings nicht von einur Axe, sondern direct von dem Dach der Athemhöhle, ahnlich wie die vorderu Kiemenb]ättchen von ['mbrella von der Seite des Kürpers. Meines Erachtens ist dieser Interschied aher nicht schwer zu erklären: die hiene von Siphonaria lisst sich z. B. aus der inppelterefienderten Kieme leicht ahleiten, wenn man eine Reslurtion der kiemenblattchen auf einer Seite der Axe und Verlöthung der letztern mit der Interlage anuimmt.

Vebrigens besitzt auch ein anderer (Opisthobranchier, Lobiger, nach Mazzarela eine ähnliche kammförnige Kieme wie eine junge Siphonaria.

Lasst sich so die Kieme von Siphonaria nach ihrom Bau leicht an die Kieme der Pleurolnanchiden resp. Umbrellen anschliessen, so ist andrerseits ihre Lage eine ganz ähuliche wie bei den Tectibranchien 
mit gut ausgebildeter Athemhöhle, wie besonders eine Vergleichung des Daches der Athemböhle von Bulla (Fig. 60, Taf. 4) mit einem entsprechenden Präparat von Siphonaria zeigt (vergl. aspera, Fig. 45, 'Taf. 4). Diese Aehnlichkeit ist noch etwas grösser bei Siphonaria redimiculum, wo das linke Ende der Kieme nicht so stark entwickelt ist. Besondere Erwähuung scheint mir hier die Uebereinstimmung in der Lage der hieme zur Niere, speciell der Nierenmündung bei Siphonaria und diesen Opisthobranchiern zu verdienen. Geht man von dem Mantelrand aus, so liegt der Nierenporus stets dicht hinter der Kieme, bei Formen mit ausgebildeter Athemhöhle, wo beide Organe in dem Dach derselben liegen, also links von der Kieme, so bei Bulla, Acera, Scaphander (Fig. 59-62, Taf. 4; Fig. 19, Taf. b), sonst unter derselben, so bei Gastropteron (Fig. 57, Taf. 4), Umbrella (12, fig. 6, tab. 1 a), Pleurobranchus (11, fig. 2, tab. 10 \%). Bei Acera und Bulla liegt die Nierenmündung sogar auf einer kleinen Papille, die sich über die liieme hinüberlegt (Fig. 61 u. 62), ganz ähnlich wie bei Siphonaria, wo dieselbe ja einem Kiemenblättchen anliegt. Die Unterschiede in der Anordnung der das Dach der Athemhöhle eiunehmenden Organe bei Siphonaria einerseits und den meisten Cephalaspideen andrerseits scheinen mir hauptsächlich in einer Verlagerung des Herzens nach links und einer Verlängerung der Kieme nach derselben Seite zu bestehen. Der Abstand des Vorhofs von der Kieme wird dadurch vergrössert, und in Folge dessen hat eine Sonderung der das Blut dem Herzen zuführenden Gefässe in der Weise stattgefunden, dass sich jetzt zwei Abschnitte unterscheiden lassen, einer, der vom Herzen vor oder in der Niere nach dem ausführenden Rand der Kieme hin verläuft und bei allen Siphonarien durch die secundären Kiemenvenen gebildet wird, und einer, der am ausführenden Rand selbst liegt, das ausführende Kiemengefäss. Als ein Zeugniss für diese Wanderung des Herzens nach links ist es vielleicht aufzufassen, dass sich der Vorhofsmusculatur angehörende Muskelfasern in der vordern Kiemenvene befinden. Diese Verschielung des Herzens scheint mir bedingt durch den mit der eigenthümlichen Lehensweise verknüpften, relativ vollständigen Abschluss der $\Lambda$ themhöhle nach aussen; der den Porus tragende Theil der Niere musste im Interesse der Fuuction in die Nähe des Athemlochs rücken, während das Herz cher in dem entfernteren Theil der Athemhöhle liegen konnte. Die Fintstebung z we ier secundärer Kiemenvenen scheint, wie ein Vergleich von Siphonaria redimiculum mit den andern Arten lehrt, in der zunehmenden Ausbildung der patelloiden form begründet zu sein, dem dabei dehnte 
sich die Athemhöhle besonders nach hinten und links ans, und in dieser Richtung verlangert sich auch der links von der Nierenpapille gelegene Theil iler hieme, dessen lilut speciell ron dem hintern Gefass dem Herzen zugeführt wird.

Die Ausilehnung der Niere am Dach der Athemhöhle scheint mir für die Vergleichung von keiner hesomblern II ichtigkeit zu sein, dat sie sowohl bei den verschiedenen siphonarien als auch bej den verschiedenen Tectibranchien mannigfachen Varrationen unterlient; ich erinnere nur an Siphonaria pectinata und aspera, sowie fíalla striala und Acere bullata (Fig. 1, Taf. 1; Fig. 45, Taf. 4; Fig. lit u. (il, Taf. 4). Grïssere Beachtung verdient viclleicht der Umstand, dass ein Theil der Niere auf dem Boden der Athemhirhle lient, was ich bei keiner der andern Formen gefunden habe.

Die Lehereinstimmung, welche die lieme von Siphonariu leesonders mit Bezug auf ihre Lage zu den andem Oratnen der Athemhöhle mit den hiemen der Tectibranchien zeigt, scheint mir den Schluss zu rechtfertigen, dass wir es hier mit homologen Grganen zu thun haben, eine Ansicht, die noch unterstiitzt wird durch die An der Innervirung: sie ist hei Siphonaria die greiche wie bei den meisten Tectilsanchien: die Nerven entspringen von dem am lingang der A themhöhle gelegenen Ganglion (Kiemenganglion, li anglion of actorium), das mit dem ersten Ganglion der Visceralcomnissur in Verbindung steht und von einem charakteristischen sinnesepithel bedeckt wird.

Es erhel,t sich nun die Frage, wie die lieme in beiden fallen zu deuten sei. Meines $\mathrm{W}$ issens ist noch kein beyründeter \%weifel darüber erhuben worden, dass die hieme der Bulliden eine echte Kieme, ein Ctenidium sei und somit der I'rosoloranchierkieme homolong. I)as beweist ihre Innervirung von einem liemenganglion ans, dats

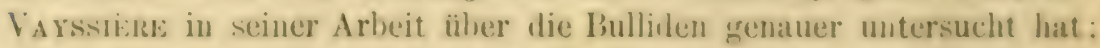

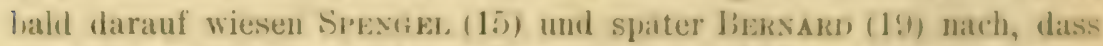
über diesem (banglion sich ein Sinneseppithel befinde. SPExGEa deutetr das Ganglion mit dem Epithel darüler als Geruchsorgan und erklarte es für homolog den bei den verschiedensten Mollusken verbreiteten, mit der kieme in Verbindung stehenden Sinnesorganen, der P'seudobranchie der Monotocardier und den "Kiemenganglien" der Diotocardier, wemn wir uns auf die Prosoloranchier heschrinken wollen. LikinAkn dagegen giebt nur die flomolorie mit den K iemenganglien der loioforardier zu, dem die l'seudobranchie uicht direct lomolog sein soll. lis ist hier nicht der Ort, 
auf diese Frage näher einzugehen; für unsern Zweck genügt es, dass feststeht, dass die Kieme der Cephalaspideen ebenso von einem „Branchial"-Ganglion und Geruchsorgan innervirt wird wie die Kiemeu der niedern Prosobranchier, es beweist das, dass sie ebenso gut wie jene ein Ctenidium ist.

Etwas anders liegen die Dinge bei Umbrella und den Pleurobrancheu. Hier weicht die Kieme in ihrem Bau etwas ab, und es fehlt auch das Geruchsorgan bezw. das Kiemenganglion, doch ist bei L'mbrella am ausführenden Kiemenrand ein Nervengeflecht entwickelt, das von einem Nerven versorgt wird, der vom rechten Ganglion der Visceralcommissur entspringt, das in seinem vordern Theil jedenfalls dem Pleurointestinalganglion von Siphonaria entspricht. Von diesem Nervennetz konnte Bernard Fasern zu kleinen, zerstreuten Epithelinseln verfolgen, die wie das Epithel des Geruchsorgans aus Sinnesund Wimperzellen bestanden. BERNARD hält, wie mir scheint mit Recht, dieses Nervennetz mit den Epithelinseln für ein gewissermaassen diffuses Geruchsorgan. Dieses Verhalten der Innervirung gestattet allerdings keinen sichern Entscheid in der Frage, die durch HaLler (9) aufgeworfen wurde, ob nämlich Umbrella und die Pleurobranchiden eine einzige Kieme oder eine Kiemenreibe, ähnlich wie die Chitonen, besitzen. Ich habe aber schon oben bei der Vergleichung der Kiemen der einzelnen Tectibranchier unter einander nachzuweisen gesucht, dass eine principielle Uebereinstimmung in dem Bau ihrer Kiemen besteht und dass trotz der anscheinend grossen Verschiedenheiten die doppelt getederten Kiemen der Pleurobranchen und die gefalteten der Bulliden sich unter Annahme eines in beiden Fällen nur wenig verschiedeuen Entwicklungsprocesses, einer Faltenbildung, aus der gleichen Anlage ahleiten lassen. Ferner konnte ich die bei allen Tectibranchiern im II esentlichen gleiche Lage der Kieme in Bezug auf andere Organe, specicll die Nierenmündung, feststellen, und aus diesen Gründen schliesse ich, dass das Respirationsorgan der in Frage stehenden Formen ein e in $\mathrm{ziges}$ Ctenidium ist.

Diese Erwägungen gelten in noch böherm Grade für Siphonaria, wo wir ja noch ein wohlausgebildetes Geruchsorgan in typischer Lage finden; ich halte mich also zu dem Schluss berechtigt, dass die Kieme von Siphonaria ein echtes Ctenidium ist und nicht eine secumbiare Xeubildung in Anpassung an die eigenthümliche Jebensweise. Darlurch scheint mir aber eben der leweis erbracht, dass Siphonarin ein 0pisthobranchier ist und kein P'ulmonate.

Andere Organsysteme sind für die Beurtheilung der Verwandt- 
schaft nicht so gut zu verwerthen, la sie keine für die ()rinumgen lesonders charakteristischen Merkmale liofern obler mocere liemutnisse dariber noch nicht so ansgohreitot umb ge-ichert sind, dass sich eine ausführliche Veregleichung verlehnte, ich will dexhalb hier nur auf das Nervensystem und die Geschlerhtsorgane eingehen.

Das Nervensystem stoht, worauf llatek mit Rerht anfmerkSam macht, dem Xervensystem der Embrollen, hesomlers Thyludina, am nächsten, nur ist die Vorkïrzung der Commissuren und Connective nicht so weit vorgeschritten. Es simol wie dort zwei Cerehral-, zwei Perlal- und zwei liucealganglien sowie drei Ganglien der Viscraalcommissur vorhanden. I)ie beilen Cerchralganglien sind bei Thylomlina allerdings durch eine der Pedalcommissur angelagerte Subcereloralcomnissur verbunden, die hei Siphonaria nicht nachgewiesen werlon komnte, dagegen ist bei beiden eine zweite Pedalcommissur (Parapedal(commissur) vorhanden und zwischen den beiden liuccalganglien geht ein Nerv von der Commissur ab). Auch die Lehereinstimmung zwischen den Ganglien der Visceralcommissur ist recht gross, wie sich bei der Vergleichung der von ihnen abgehenden Nerven zeirt. Das rochte: Ganglion vou Thylodina entspricht dem I'leurointestinalganglion von Siphonaria, es versorgt wie dieses die rechte Seite des körpers mit der lieme; ein "Kiemenganglion" wie hei Siphonaria ist allerding voll VArssil:Re $(16,17)$ nicht beobachtet worlen und wird wie bei I'mbrella fehlen. I)as mittlere Ganglion versorgt die Geschlechtsorgane, wie das Abdominalganglion von Siphomaria; Nerven, die in die rechte Seite des Körpers eintreten, und solche, die Her\% und Niere versorgen, werilen nicht angegeben. Das linke Ganglion, dem linken Pleurointestinalganglion der Siphonarien entsprechend, entsendet wie dieses Nerven in die linke Seite des Kïrpers.

Finden wir im Nervensystem eine grosse leberrinstimmung mit den Umbrellen, so zeigen die Geschlechtsorgane Anklinge an dio Bulliden. Eine Vergleichung in Finzelnen kitnn ich allerdings hier nicht durchführen, da wir, trotz dor schömon Intersuchumeren von Mazzakefal und Anleren, den Geschlechtsilpparat bei zu wenigen Formen genau gemug kennen; ich muss mich desbalh auf die Vergleichung der gröhern anatomischen Verhaltnisse beschranken, zumal

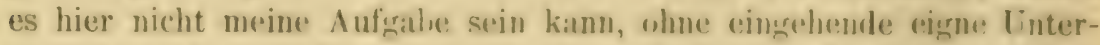
suchungen in eine Discussion dioser ziemlich verwickelten firage einzutreten.

Wie bei den Cephalaspirleen und Anaspideen zerfallt dor ausführende zwittrige Theil des Geschlechtsapparats in zwei Theile, 
einen engen 'Zwittergang und einen weitern Theil, der die Schleim- und Eiweissdrüse aufnimmt. Dieser letzte Theil ist bei den Bulliden sehr kurz („cloaque sexuel“, VAYSSIÈRE), bei Siphonaria dagegen stellt er den langen Spermoviduct vor und besitzt eine drüsige Wand; in dieser Hinsicht erinnert Siphonaria an Acera bullata und die Aplysien, bei welchen dieser Abschnitt („grande condotto ermafrodisiaco", MAZZARELLI [21, 22]) ebenfalls sehr lang ist. Das Receptaculum seminis scheint mir nach Bau und Function der "poche copulatrice“(VATssirère) oder der SWAMMERDAM'schen Blase (MAZZARELLI) der übrigen Tectibranchien zu entsprechen, sein Inhalt, Spermatophoren, deuten wenigstens darauf hin. Wie es sich jedoch mit den Homologien der von mir beschriebenen Samenblase verhält, kann ich nicht sicher angeben; vielleicht entspricht sie dem bei Philine und Doridium vorhandenen Anhang des Zwitterganges.

Ohne engern Zusammenhang mit dem übrigen Geschlechtsapparat ist das Copulationsorgan, mit alleiniger Ausnahme von Siphonaria gigas und pectinata. Es besteht wie bei der Mehrzahl der Opisthobranchier aus einem musculösen und einem drüsigen Abschnitt, der erstere zerfällt aber nicht, wie es bei den Bulliden Regel ist, in einen eigentlichen, vom Ausführgang der Prostata durchbohrten Penis und eine Penisscheide, sondern er stellt entweder ein einfaches musculöses Rohr dar, in das sich die Prostata öffnet, oder er mündet als musculöser Schlauch neben dem ausführenden Abschnitt der Prostata. Auf die eigenthümlichen Abreichungen einzelner Arten, die meines Erachtens einen ziemlich beträchtlich modificirten Zustand darstellen, brauche ich hier nicht noch einmal einzugehen.

Ein weiterer Unterschied gegen die Bulliden ist der, dass eine deutliche Flimmerrinne fehit, da beide Geschlechtsöffnungen dicht neben einander, am Boden einer Furche liegen.

Das Verhalten der eben betrachteten beiden Organsysteme spricht auch für die Zugehörigkeit der Siphonarien zu den Tectibranchiern, - ber weiter gehen und insbesondere ihre Stellung so präcisiren, wie es Haller gethan hat, möchte ich nicht. Zunächst kann ich Siphonaria nicht für einen der ältesten Opisthobranchier halten, denn die Hauptgründe, auf welche Halder seine Ansicht stützt (9, p. 27), scheinen mir zum Theil wenigstens nicht stichhaltig. HaLLer führt zunächst das Nervensystem an: dasselbe zeigt allerdings einzelne Eigenschaften, die schliessen lassen, dass es primitiver sei als das der Umbrellen, z. B. die längern Connective und das Osphradium, aber die phylogenetische Entwicklung der Umbrellen selust ist noch nicht 
festgestellt; dann das Vorhandensein doppelter Nieren, solche sind aber bei keiner Siphonaria ausser gigas gefunlen worden, und es ist mir nicht unwahrscheinlich, dass bei dieser form ein lieobachtungsfehler vorliegt. Der beschlechtsapparat, auf den IIALLER weiter hinweist, ist aber in Allgemeinen nicht einfacher als der der Cephalaspideen gebaut. Auch dafür, dass die K ie me wirklich einer Cteuidienreihe entspricht, scheint mir kein Beweis erbracht, ich habe vielmehr oben bei Besprechung der Athemhöhle den Nachweis geführt, dass sie sich ohne Schwierigkeit als ein einziges Ctenidium auffassen lässt. Was endlich die $\mathrm{K}$ i e me $n$ v e $\mathrm{n}$ e $\mathrm{n}$ anlangt, so ist ihre Existenz durch die Entfernung des Herzens von der kieme bedingt, und ich glaube nicht, dass hier ein primares Verhalten vorliegt, es scheint vielmehr, wie ich schon oben ausführte, gerade ein erworbener \%ustand zu sein.

Dann möchte ich die Siphonarien nicht so nahe, wie es Hact.ek thut, mit den Umbrellen vereinigen, denn wenn auch Schale, Körperform und Nervensystem dies rechtfertigen künnten, so sprechen doch der Besitz einer wohl ausgebildeten Athemhöhle mit ()sphradium und der Bau der Geschlechtsorgane, der sich dem bei den Cephalaspideen herrschenden Typus anschliesst, dagegen.

Dazu kommt noch ein drittes, nämlich gewisse Bezichungen, die vielleicht zu Formen bestehen, die man zu den Pulmonaten, speciell zu den Basommatophoren rechnet. Es sind Gadinia, Auricula und Amphibola. Am ähnlichsten, schon durch die äussere Form, ist Gadinia. Auch die Athemhïhle zeigt nach Dald. (13) und LarazeDuthiers (6) eine gewisse Uebereinstimmung mit der von Siphonaria. Sie breitet sich allerdings nicht so weit aus, sondern lisst, wie ich bei Gadinia peruviana constatiren konnte, den rechten, hintern Theil frei, die Nicre ist auf das Dach der Athemhöhle beschränkt, an dem auch der Herzbeutel grösstentheils liegt; ein typisches Osphradium ist allerdings nicht vorhanden. An dem Dach der Athemhöhle, vor der Niere, ist aber ein ähnliches Gefissnetz entwickelt wie bei Siphonaria, übrigens ist aber nicht allein diese Stelle der Athemhöhlenwand gefässreich, sondern auch auf dem Boden derselben und ausserhall, im Mantelrand (nach LACAzE-IUtHifrs), findet man zahlreiche Blutraume. Die Organe der Leibeshöhle, besonders die Geschlechtsorgane, deren durch LaCAzE-Dutmers gegebene Beschreibung ich bei meiner vorläufigen Untersuchung bestatigt finde, weichen aber ziemlich stark von Siphonaria al). Die beiden andern Gattungen sind noch nicht gründlich unter Anwendung der neuern Methoden untersucht worden; 
ich halte es deshalb für das Gerathenste, von einer Discussion der Beziehungen, die sich eventuell zwischen Siphonaria und diesen Pulmonaten auf Grund der vorliegenden Beobachtungen vermuthen lassen, abzusehen und weitere Untersuchungen abzuwarten, vielleicht wird es in einiger Zeit mir selbst möglich sein, durch Untersuchung des mir gegenwärtig zur Verfügung stehenden Materials, zwei Exemplare von Gadinia peruviana und zwei Exemplare von Ampullarina fragilis, die ich der Liberalität des Berliner Museums verdanke, etwas zur Lösung dieser Frage beizutragen.

Das eine scheint mir aber jetzt schon sicher zu stehen: die hier nachgewiesenen Beziehungen von Siphonaria zu den Tectibranchien werden bei der Beurtheilung der systematischen Stellung dieser Gattung stets in erster Reihe in Rücksicht gezogen werden müssen.

\section{Nachtrag.}

Während des Drucks der vorliegenden Arbeit habe ich in Neapel durch die Güte des Herrn Dr. Schienenz zwei Exemplare der von HaLler untersuchten Siphonaria gigas erbalten. Ich habe einstweilen den Geschlechtsapparat und die Niere genauer untersucht und will hier nur kurz die von mir beobachteten Thatsachen mittheilen.

Was zunächst die Niere anlangt, so habe ich keine wirkliche Treunung des obern Nierenlappens durch die hintere secundäre Kiemenvene (hintere Kiemenvene, HALLER) beobachten können, auf manchen Querschnitten erscheint vielmehr das Gefäss völlig in die Nierensubstanz eingebettet, ohne dass dorsal oder ventral von ihm eine scharfe Grenze zwischen den rechts und links gelegenen Theilen der Niere zu erkennen wäre. Ebensowenig ist es mir gelungen, einen zweiten Nierenporus und die damit in Verbindung stehende Renopericardialpforte zu finden: die von HALLER gezeichnete Oeffnung ist ein Kunstproduct, wahrscheinlich dadurch entstanden, dass er beim Ablösen der Decke der Athemhöhle das linke zuführende Nierengefäss von dem Sinus, aus dem es entspringt, abgeschnitten hat; ein präformirter, das Nierenlumen mit der Mantelhöhle in Verbindung setzender Porus ist es sicher nicht.

Auch Haller's Darstellung des Geschlechtsapparats muss ich in zwei Punkten entgegentreten: erstens ist nämlich kein Vas deferens 
vorhanden (ich habe die distalen Theile des Geschlechtsapparats in toto herauspräparirt, geschnitten, und bei der Durchsicht der Serie hatte mir ein Vas defereus nicht entgehen können), und zweitens sitzt das Receptaculum nicht mit einem kurzen Stiel auf dem Spermoviduct auf, sondern mündet durch einen langen, neben dem genannten Canal verlaufenden Gang neben Spermoviduct und P'enis aus. Die Geschlechtsorgaue sind also im Wesentlichen deneu der beiden von mir untersuchten südamerikanischen Arten ähnlich gebaut. Auf diese kurze Mittheilung muss ich mich einstweilen beschränken, weil sich eine ausführliche Darstellung nicht ohue Abbildungen geben lässt; bei der Beschreibung einer Anzahl anderer, ebenfalls von der Reise des Vettor Pisani stammender Siphonarien, die mir Herr Graf Hal.Ler gütigst zur Bearbeitung überliess, werde ich das Fehlende nachholen.

Ebenfalls erst nach Abschluss der Arbeit an andern Opisthobranchiern (\%. B. Actaeon und Scaphander) angestellte Untersuchungen machen es mir wahrscheinlich, dass auch hinsichtlich eines hier nicht weiter discutirten Organs, namlich des Wimperbandes, zwischen den Siphonarien und den genannten Arten eine Uebereinstimnung besteht, die auch Zeuguiss von der Verwandtschaft der genannten Formen ablegt.

\section{Literaturrerzeichniss.}

\section{a) Literatur über Siphonaria.}

1) Quor et Gaimarn, Voyage de l'Astrolabe, Zoologie, Tome 2, 3. Paris $1832-1835$.

2) W. H. Dafi, Remarks on the anatomy of the genus Siphonaria with a description of a new species, in: Amer. Journ. of Conch., Vol. 6, Philadelphia 1870/71.

3) v. JnEmisi, Vergleichende Anatonic des Nervensystems und Phylogenie der Mollusken, Leipzig 1877.

4) STTuE, Vortrag über die Anatomio von Siphonaria redimicnlum Reeve, in: Mitth. der Nat. (ies. zu Bern ans dem Jahre 1850, Bern 1881.

5) F. W. Hettos, Notes on the structure and development of Siphonaria anstralis (2\%) et Gamand, in: Ann. and Mag. of Nat. History (5), Vol. 9, London 1882.

(i) H. ne Lacaze-Drtmers, Anatomie du Gadinia Garnoti, in: Compt. Rend. Acad. Paris, Tome 100, 1885. 
7) Ađgusto Nobre, Contribuições para a anatomia das Siphonarias, in: Revista de Sciencias naturaes e sociaes, orgão dos trabalhos da Sociedade Carlos Ribeiro, Vol. 1, No. 3, Porto 1889.

8) E. L. Bouvier, Recherches anatomiques sur les Gastéropodes provenant des campagnes du Yacht L' Hirondelle. Première note, in: Bull. Soc. Z. France, Tome 16, Paris 1891.

9) B. Hallek, Die Anatomie von Siphonaria gigas Less., eines opisthobranchen Gastropoden, in: Arbeiten a. d. Zool. Institut zu Wien, Bd. 10, Heft 1, Wien 1892.

10) A. KöHLER, Beiträge zur Anatomie von Siphonaria. Vorläufige Mittheilung, in: 29. Bericht der Oberhessischen Gesellschaft für Naturund Heilkunde, Giessen.

\section{b) Literatur über andere Gastropoden.}

11) H. DE LACAZE-Duthiers, Histoire anatomique et physiologique du Pleurobranche orangé, in: Ann. Sc. Nat. Zool. (4), Tome 11, 1859.

12) Moqutn-Tandon, Recherches anatomiques sur l' Ombrelle de la Méditerranée, in: Ann. Sc. Nat. Zool. (5), Tome 14, 1870.

13) IV. H. DALL, Materials towards a Monograph of the Gadiniidae, in: Am. Journ. of. Conch., Vol. 6, 1870-1871.

14) A. Vayssière, Recherches anatomiques sur les mollusques de la famille des Bullidés, in: Ann. Sc. Nat. Zool. (6), T. 9, 1879-1880.

15) J. W. Spenger, Die Geruchsorgane und das Nervensystem der Mollusken, in: Zeitschr. f. wiss. Zool., Bd. 35, 1881.

16) A. Vayssitire, Recherches anatomiques sur les genres Pelta et Thylodina, in: Ann. Sc. Nat. Zool. (6), T. 15, 1883.

17) - - Recherches zoologiques et anatomiques sur les mollusques opisthobranches du Golfe de Marseille, in: Ann. du Musée d'Hist. Nat. de Marseille, Zoologie, T. 2, 1885.

18) H. de Lacaze-Duthiers, Le système nerveux et les formes embryonnaires du Gadinia Garnoti, in: Compt. Rend. Acad. Paris, Tome 100, 1885.

19) F. Bernard, Recherches sur les organes palléaux des Gastéropodes prosobranches, in: Ann. Sc. Nat. Zool. (7), T. 9, 1890.

20) R. Perrier, Recherches sur l'anatomie et l' histologie du rein des Gastéropodes prosobranches, in: Ann. Sc. Nat. Zool. (7), T. 8, 1889.

21 G. F. Mazzarelli, Richerche sulla morfologia e fisiologia dell' apprarato riproduttore nelle Aplysie del Golfo di Napoli, in: Atti Accad. Napoli, Vol. 4, Serie 2 a, Append. No. 5, 1891.

22) - - Intorno all' apparato riproduttore di alcuni Tectibranchi (Pleurobranchaea, Oscanius, Acera), in: Zool. Anz., Jahrg. 14, $18 ! 1$.

23) - - Richerche sulla morfologia delle Oxynoidae, in: Soc. Ital. d. Scienze (detta dei XL), T. 9, No. 1, 1892. 


\section{Erklärung der Abbildungen.}

Die simmtlichen Querselmitte von Siphonarien sind so gezmiohne. dass ihre dem Kopfende zugekehrte Fläche dem Br-schanur zugewamle ist. ebenso sind die meisten andern (2uerschnitte gezeichnet, mit Ausnahmo derjenigen, deren Nummer mit "inem * bezeichnet ist.

Folgende Bezeichumgen hahen fïr alle Fignren (rültiglieit:

a Arteria anterior.

ad Adductor.

ad, Theil des Adductors vor dem Athemloch.

af After.

ag Abdominalganglion.

ah Athemhöble.

al Anallappen.

alo Athemloch.

ap Arteria posterior, Eingeweidearterie.

bg Buccalganglion.

cc Cerebralcommissur.

cg Cerebralganglion.

cp Cerebropedalconnectiv.

cpl Cerebropleuralconnectiv.

ct Kieme.

$d_{1}-d_{5}$ Darmcanal.

dah Dach der Athemhühle.

$e d$ Eiweissdrüse.

fl Flagellum.

gcl Grenitalcloake.

go Ganglion olfactorium, Kiemenganglion.

hep, linke Leber.

hep, rechte Leber. $k$ Kiefer.

$k a$ zuführendes Kiemengefäss.

$k v_{1}$ vordere secundäre Kiemenvene.

$l v v$, hintere secundäre Kiemenvene.

$k v_{y}$ abführendes Kiemengefäss.

lzn linkes zuführendes Nierengefäss.

$m$ Magen.

$\boldsymbol{m} \boldsymbol{f}$ Mantelfalte.

$m h$ Mundhöhle.

$m u$ Muskel in der Kiemenvene.

$n$ Nerven.

$\boldsymbol{n} \boldsymbol{v}$ abfübrende Nierengefässe.

oc Ange.

oe Oesophagus.

os Geruchsorgan.

ot Otocyste.

pc Pericard.

pe Penis.

1 pec 1. Pedalcommissur.

2 pec 2. Pedalcommissur.

pg Pedalganglion.

plg Pleurointestinalganglion.

pr Prostata.

pr $_{1}$ Prostatastiel.

prr Prostatarinne des Spermoviducts. 
r Radula.

ren Niere.

renp Nierenpapille.

renpo Nierenporus.

rp Renopericardialpforte.

rs Receptaculum.

$\boldsymbol{r s}_{1}$ Stiel des Receptaculums.

ot Radulatasche.

rzn rechtes zuführendes Nierengefäss.

so Samenblase.

sd Schleimdrüse. si Pallialsinus.

spdr Speicheldruise.

spov Spermoviduct.

sr Schleimrinne desselben.

st Stützbalken der Radula.

ve Ventrikel.

vi Visceralcommissur.

wb Wimperband.

$z w$ Zwitterdrüse.

zwg Zwittergang.

$\alpha, \beta, \gamma$ Blutgefässe (Aeste der Arteria anterior).

Tafel 1.

Alle Figuren dieser Tafel beziehen sich auf Siphonaria pectinata L.

Fig. 1. Das Thier nach Entfernung der Schale von der rechten Seite gesehen. $m f$ Mantelfalte, $l$ Ansatzlinie der Mantelfalte zwischen den Vorderenden des Adductors. Vergr. 3.

Fig. 2. Dasselbe von der Bauchseite gesehen, $f$ Fuss, $k$ Kopf, $\mu$ Spalte, an deren Boden die Mundöffnung liegt. Vergr. 3.

Fig. 3. Das Thier von der Rückenseite gesehen. Die Decke der Athemhöhle ist rechts, vorn und hinten abgelöst und nach links hinübergeschlagen. Auch der Herzbeutel ist zum Theil eröffnet. Vergr. 6.

Fig. 4. Dasselbe. Das Dach der Athemhöhle ist ganz entfernt, ehenso der Boden, so dass die Leibeshöhle eröffnet ist. Vergr. 71/2.

Fig. 5. Die Geschlechtsorgane aus dem Thier herauspräparirt und ron der Bauchseite gesehen. Der Theil der Genitalcloake, der in der Fussmusculatur steckt, ist abgeschnitten, ebenso der Retractor. Vergrösserung $61 / 2$.

Fig. f. Darm, Leher und Herz von der ventralen Seite gesehen, der Schlundkopf ist nicht mit dargestellt. Vergr. 8.

Fig. 7. Querschnitt eines jüngern Exemplars durch die Gegend der Geschlechtsöffnung. $r s_{1}$ Stiel des Receptaculums, spov Spermoviduct, gcl Genitalcloake, $m h$ hinteres Ende der Mundhöhle, in den Schlundkopf ringebettet, spdr die Ausführgünge der beiden Speicheldrüsen, ah vorderer Theil der Athemhöhle. Vergr. 22.

Fig. 8. Desgl. weiter nach hinten. Ausser den im Vorhergehenden genannten Organen zeigt der Schnitt noch os das Geruchsorgan, $m r_{1}$ don Prostatagang und die Mündung des Receptaculumstiels $\boldsymbol{r s}_{\mathbf{1}}$. oe Oesophagus, bg Buccalganglien. Vergr. 22.

Fig. 9. Deserl. Der Schnitt hat den Vorderrand des Athemlochs tangirt (alo). $r$ Retractor der Genitalcloake, $p r$ vorderes Ende der Prostata, ng Genitalnerv. Vergr. 28.

Fig. 10. Desgl. Der Schnitt fällt wio die folgonden durch das Athemloch. plg rechtes Pleurointestiualganglion, cg rechtes und linkes Cerebralganglion. Vergr. 28. 
Fig. 11. Sitick ans einem dicht auf den vorhergehenden folgenden Schnitt. Zwischen cg und plg rechtes cerehropleuralcunnectiv, $p g$ vorderste Spitze des Pedalganglions. Vergr. 33.

Fig. 12. Sehnitt dicht hinter dem vorhergehenden. Er hat alle Ganglien des schlundrings und den grüssten Theil der Cerebralcommissur $c c$ getroffien. $m$ Vorderende des Miterens. Vergr. 33.

Fig. 13. Stiick aus dem nächstfolgrnden Schnitt. pg Perlalganglion mit Pleuropedalconnectiv. Vergr. 33.

Fig. 14. Querschnitt etwas weiter nach hinten. vi rechte Halfte der Visceralcommissur. aa Arteria cephalica, 1 pec erste l'eulalcommissur, pe Pericard. Vergr. 28.

Fig. 15. Desgr. ag Abdominalganglion. vi link. Halfte der Visceralcommissur, plg linkes Plenrointestinalganglion. V'ergr. ¿̨x.

\section{Tafel 2}

Die Figuren 16-21 beziehen sich auf Siphonaria pectinata I... die Figuren :-2-25 auf Siphonaria laeviuscula ReEve und die Figiren 27-29 auf Siphonaria subrugosa Sow.

Fig. 16. Querschnitt durch die Gegend des Athemlrichs hinter den auf der vorangehenden Tafel dargestellten. $k v_{1}$ rerhtes Ende des ahführenden Kiemengefässes, aa Arteria crphalica, 2 pec zweite P'odalcommissur. Vergr. 22.

Fig. 17. Desgleichen. ct rechtes Fnde der Kieme, ren oberer Nierenlappen, $k v_{2}$ Ursprung der vordern Kiemenvene. $d_{1} d_{2}$ erste Darmschlinge, spov Spermoviduct. sd Schleimdrüse. Tergr. 2.2.

Fig. 18. Desgl. etwa ${ }^{1}{ }_{20} \mathrm{~mm}$ hinter dem vorangrehenden. renp Nierenpapille, at Atrium in Verbindung mit der vordern Kiemenvene $k v_{2}$, rs Receptaculum seminis und Stiel, die sich in einem der folgurden Schnitte vereinigen. Vergr. 22.

Fig. 19. Desgl. etwa durch die Mitte des Athemlor.hs. ka zuführendes Kiemengefäss, $k v_{3}$ hintere Kiemenvene, renp Nierenpajille. $d_{5}$ Euddarm, in den Anallappen al rintretend, ed Eiweissilrüs* durch den gekörnelten Ton von der Schleimdrüse unterschienlen, sb Tanenblase, swg Zwittergang.

Fig. 20. Desgl. durch das hintere Ende des Athemlnchs. ran rechtes zuführendes Nierengefass mit dem Frenulum ${ }^{*}$ fre. durch * ist der Crsprung des linken zutïhrenden Nierengefässes und les zufizhenden Kiemengefisses ans dem Pallialsinus bezeichnet. a) Arteria posterior, $d_{3} d_{4}$ zweite Darmschlinge. Vergr. 22.

Fig. 21. Einige Radulazahne. Die äher den einzelnen Zaihnen stehenden Zahlen bedenten iiren Platz in einer Qnerrilue: der Medianzahn ist mit 0 bezrichnet, der zweite von ibm aus mit 2 ete. Vergrösserung 190.

Fig. 2.2. Querschnitt durch den Knpf von Siphonaria laeviuscula Reeve. Er entepricht Fig. 7, Taf. 1. pe Penis. Vergr. 15. 
Fig. 23. Desgl. weiter ṅach hinten. $r s_{1}$ Mündung des Receptaculumstiels, spov Mündung des Spermoviducts, $p r$ Prostata. Der Schnitt entspricht sonst etwa Fig. 9, Taf. 1. Vergr. 15.

Fig. 24. Desgl. durch das vordere Ende des Athemlochs. In der Prostata $p r$ ist die Drüsensubstanz hell angelegt, das Epithel durch eine dunklere Linie bezeichnet. Wegen der innerhalb der Prostata angebrachten Bezeichnungen muss ich auf den Text S. 25 verweisen. Vergr. 15.

Fig. 25. Desgl. durch den vordern Theil der Kieme, Nierenpapille und Herz. Er entspricht etwa Fig. 17.

Fig. 26. Desgl. ungefähr durch die Mitte des Athemlochs. Das rechte Ende der Kieme ist etwa an der Stelle getroffen, wo die Blättchen am höchsten und ihre Faltung und Verzweigung am stärksten sind. Der Ventrikel ve in Verbindung mit dem Anfang der Arterien a. Vergr. 15.

Fig. 27. Penis und Prostata von Siphonaria subrugosa Sow. von aussen und oben gesehen.

Fig. 28. Desgl. von innen und unten.

Fig. 29. Querschnitt, der die Geschlechtsöffnung getroffen hat. pe Vorderende des Penis, der zum Theil vorgestülpt ist, seine Mündung ist bei * tangirt. Vergr. 11

Fig. 30. Schema einer Hautdrüse von Siphonaria. $d$ Drüsenzellen, $k$ Kerne der dazwischen liegenden Zellen, mus Muskelfasern, ep Epidermis des Thieres.

\section{Tafel 3.}

Die Figuren $31-43$ beziehen sich auf Siphonaria redimiculum REeve und zwar Fig. 31-41 auf ein ganz junges, Fig. 42 u. 43 auf ein älteres Exemplar. Fig. 44 bezieht sich auf Siphonaria pectinata L.

Fig. 31. Querschnitt durch die Mundöffnung. $k$ Kiefer, oc Auge. Vergr. 74.

Fig. 32. Querschnitt durch den Kopf, 18 Schnitte (à $10 \mu$ ) hinter dem vorangehenden. $F$ Vorderrand des Fusses, pe Penis, pr Prostataanlage. Vergr. 74.

Fig. 32 a. Stück eines um $30 \mu$ weiter nach hinten gelegenen Querschnitts mit Penis und Prostataanlage. Vergr. 150.

Fig. 32 b. Desgleichen aus einem Schnitt, der $20 \mu$ hinter dem Fig. 32 a abgebildeten liegt. gö Geschlechtsöffnung. Vergr. 150.

Fig. 33. Querschnitt, $210 "$ hinter dem vorangehenden, er entspricht etwa Fig. 8, Taf. 1. gg Geschlechtsgang. Vergr. 74.

Fig. 34. Desgleichen $70 \mu$ hinter dem vorhergehenden, entspricht mit Ausnahme der Ganglien etwa Fig. 9, Taf. 1.

Fig. 35. Desgl. $40 \mu$ hinter dem vorigen. Vergr. 74.

Fig. 36. Desgl. $110 \mu$ hinter dem vorigen. Vergr. 74 .

Fig. 37. Desgl. $170 \mu$ hinter dem vorigen. Vergr. 74.

Fig. 37 a. Ende des Geschlechtsgangs gg und Anfang des Zwittergangs $z w g$, aus einem (Querschnitt $70 \mu$ hinter dem vorangehenden. Vergr. 340. 
Fig. 38. Dexuleichen 1(x) " hinter dem vorigen. Vergr. 74.

Fig. 39. Diserl. 270 $\mu$ hinter dem vorigen. Vergr. 74.

Fig. 40). Dexinl. 34" " hinter dem vorigen. Vergr. 74.

Fig. 41. Das gauz junge Exrmplar von Siphonaria redimiculum RaEve nach Entfernung der Sichale von Rückern Eresehen. Vergr. 19.

Fig. 42. Das altere Exemplar derselben Art, ebenso. Vergr. 5.

Fig. 43. Nicrenpapille und Nirrenjerus renpo aus einem Querschnitt durch das ältere Exemplar. Vergr. 58.

Fig. 44. Ange von Siphomaria pectinata L.. aus einem (Querschnitt durch das Thier. ep Epidermis, ac änsmere Cornea, ic innere Cornea, re Retina, $p i$ Pigment, $l$ Linse.

\section{Tafel 4.}

Die Figuren 45-51 bezichen sich anf Sighonaria aspera KuAr-, in Betreff der ïlrigen vrorleiche die einzrlnen Nummern.

Fig. 45. Decke der Athemböhle von Siphonaria aspera, von inmen gesehen. Vergr. 11.

Fig. 46. Torderer Theil des Geschlechtsajparats von derseibun Art.

Fig. 47. Rechte Hälfte eines Querschnits durch den Kopf. Vergrösserung 15.

Fig. 48. Rerbte Hälfte rines Querschnitts durreh die Gregend der Geschlechtsöffnung. Vergr. 15.

Fig. 49. Querschnitt durch den vordern Theil des Athenlochs, entsprioht ungefähr Fig. 25, Taf. 2. Vergr. 15.

Figr. j). Desgl. etwa durch die Mirte des Atlemulochs. Vererr. 15.

Fig. 51. Desgl. hinter drm Athemloch. $a_{l_{1}} a_{\mu_{2}}$ die Eingewrilearterien. Vergr. 15.

Fig. 5.2. Schnitt durch die Wand der Sehlomdriist won Siphonaria stellata var. luzonica. sz Śhleimzellen, wz Wimperzellen. Verkr. 1!n).

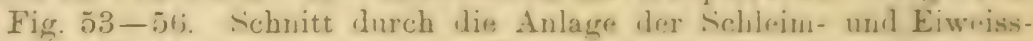
drise von Siphonaria redimiculum Rr. $\varrho$ aus der Eiwcissilrüse in die: Schleimdrüse führende Rinne.

Fig. 57\%. Schnitt durch den Nierenporus von finstropteron meckeli Kusse. Dar Sichnitt ist kein reiner (purerschnitt durch das Thier. sondern geht schragg ron oben nach hinten und unten. etwa parallel dem hintern Raud der Kiene. mr Mantelrand, sh trhalenhihle. ren Nirre, d Finddarm. renpo Nierenöftiung, la zuführendes Kirmengefiss, ct Kieme. Vergr. 15.

Fig. 58\%. Sichnitt ans derselfern sirir. etwas weitrer nach vorn. bl Kimenblittchen. $k v$ Sipze der Kirmenvene. $k v_{1}$ abfilirendes Gefass an Rand der einzelnen Blattcheu: dir vibrigen Berejchnungen wie oben. Tergr. 15.

Fig. 54. Derke der Athembohle von Scaphander lignarius von innen gesehen. mr Mantelrand, ct Kirme. ar abfuhrender Rand der. selluen, lia zuführenies Gefiss. ren Niere, renpo Nierenuftumng, at Atrium, ve Ventrikel. Natürl. Grösse. 
Fig. 60. Desgleichen von Bulla striata. renpo Nierenöffnung, sonst die Bezeichnungen wio oben. Vergr. 3.

Fig. 61. Desgl. von Acera bullata. Die Bezeichnungen wie oben.

Fig. 62. Querschnitt durch das Dach der Athemhöhle von Acera bullata. ct Hinterende der Kieme, $m$ Mantel, sonst sind die Bezeichnungen wie oben.

Tafel 5.

Fig. 1. Dorsaler Nierenlappen von Siphonaria pectinata, Stück eines Querschnitts. $n$ Nierenlumen, $r z n$ rechtes zuführendes Nierengefäss.

Fig. 2. Querschnitt durch den vordern Theil der Athemhöhle von derselben Art. dah Dach der Athemhöhle mit den Bluträumen $b$, pr Prostata, spdr Speicheldrüse, oe Oesophagus.

Fig. 3. Vorderer rechter Theil eines Horizontalabschnitts durch Siphonaria pectinata var. lineolata. gcl Genitalcloake, $r$ ihr Retractor, spov Spermoviduct, $r s_{1}$ Receptaculumstiel.

Fig. 4. Kiefer von Siphonaria striatocostata Dkr., Westafrika, einer der Siphonaria aspera nahestehenden Form. ep Epithel, cu Cuticula. st Stäbchen des Kiefers, st ${ }_{1}$ den Epithelzellen aufsitzende Stäbchen, po Muskelpolster.

Fig. J. Stück eines Querschnitts von Siphonaria laeviuscula, der den rordern Rand des Kiefers getroffen hat. ep Epithel, st Stäbchen, cu Cuticula.

Fig. 6. Querschnitt durch den musculösen Theil des Spermoviducts und den Stiel des Receptaculums von Siphonaria subrugosa. spov Spermoviduct, $r s_{1}$ Stiel des Receptaculums.

Fig. 7. Stück eines Querschnitts von derselben Art. pe Penis, $r$ Retractoren, $p r$ ein Stück der Prostata, oe Oesophagus. $f$ Fasern.

Fig. 8. Zungenbalken von Siphonaria redimiculum. $k$ Kerne,

\section{T a fel 6.}

Fig. 9. Stück eines Querschnitts von Siphonaria redimiculum. pe Penis, $\boldsymbol{p} \boldsymbol{r}, x$ Theile der Prostata, $\boldsymbol{m}$ Magen.

Fig. 10. Schnitt durch die Anlage des Spermoviducts von derselluen Art. $p r r$ Prostatarinne, sr Schleimrinne, $f$ Falte, ke Kerne der Driisenzellen, $m$ Epithel des Magens, $a$ Epithel der Athemhöhle.

Fig. 11. Querschnitt durch den Spermoviduct von Siphonaria aspera. prr Prostatarinne, sr Schleimrinne.

Fig. 12. Stiick eines Querschnitts, der zwischen den Fig. 48 u. 49, Taf. 4, abcrebildeten Schnitten liegt, von Siphonaria aspera. pr ${ }_{1}$ Prostatastiel, pe Penis, $r$ Retractor.

Fig. 13. Stiick eines Schnitts durch dio Wand der Prostata von Sipihonaria stellata. wh Wimperhaare, $k$ Kerne des Wimperepithels, $K$ Kerne der Drüsenzellen. 
Fig. 14. Stück eines Schnitts durch die Schleim- mn Eiweissilriine ron derselhen Art. ed Eiweissdrise, sd Schleimdrüse.

Fig. 15. Srhnitt durch die Zwitterilrise von durselben Art. spg Spermatogonien, sp Spermatozoen, o Eier.

Fig. 1f. Kieme von einem jungen Oscanius. der Schnitt i=t senkrecht zur Axe der Kieme, unirefalir parallel der Medianebene des Thiers. a Axe, $f i$ gefiederte Kiemenblïtehe+1l.

Fig. 17. Schnitt durch den nowint noir" von Gastropteron meckeli. ep Epidermis, ag Ansfiihrgang pi pigmentirte Wand des Blasidurns.

Fig. 18. Kieme von Seapluander lignarius, aus einem Quersehnine durch das Dach der Athemhinhle. $k$ Kieme, ren Niere, mr Mantelmand.

Fig. 19\%. Nirrenoffinung von Scaphander lignarius. Siusk ans einem ähnlich gerichtoten, aber weiter nach hinten grefïlıten sichnits. wie Fig. 18. mr Mantelrand, ren Niere, renpo Nierenporus, bg 13lu1gefäss der Niere, ka Kiemenarterie. zuführondes Kienengefass. 


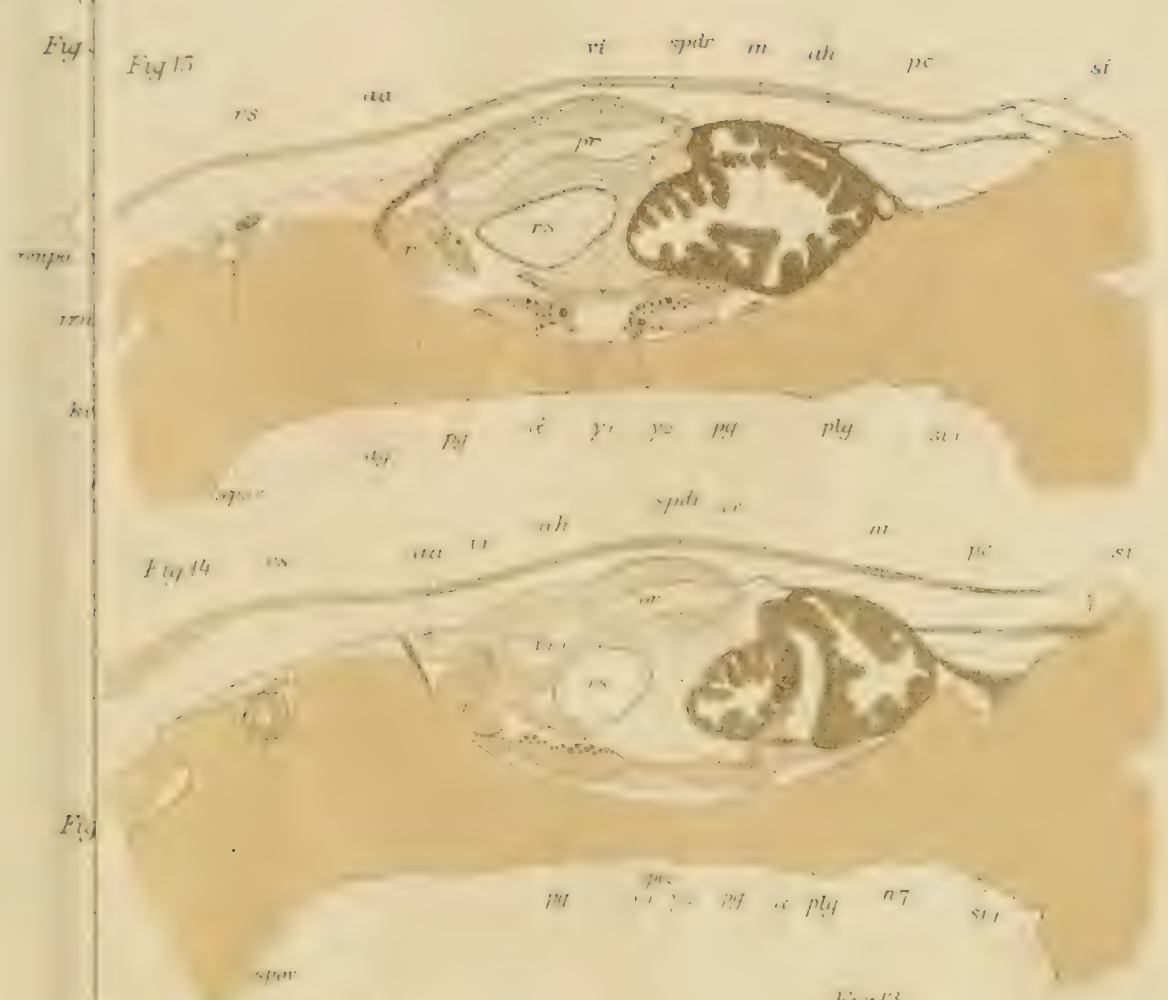

Fuifl

$5: 13$
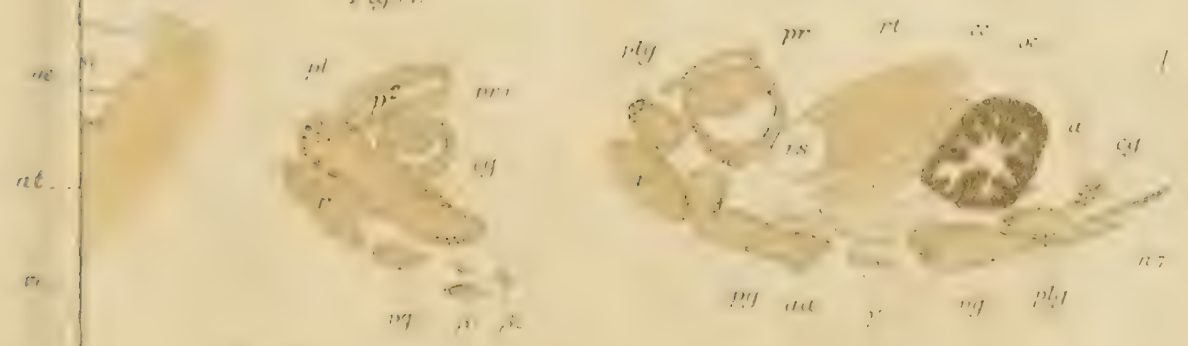

Fig

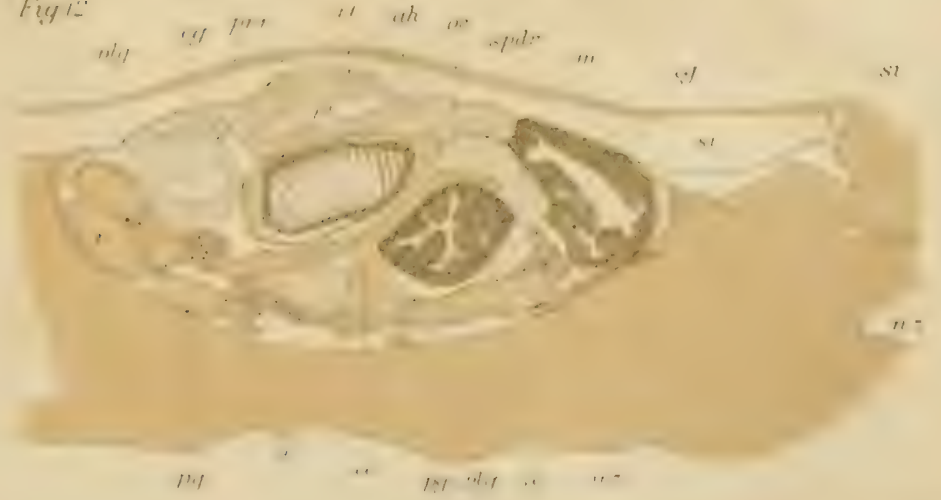





\section{Zoologische Jahroücher Bd. Z Abth.f. Mor phol.}
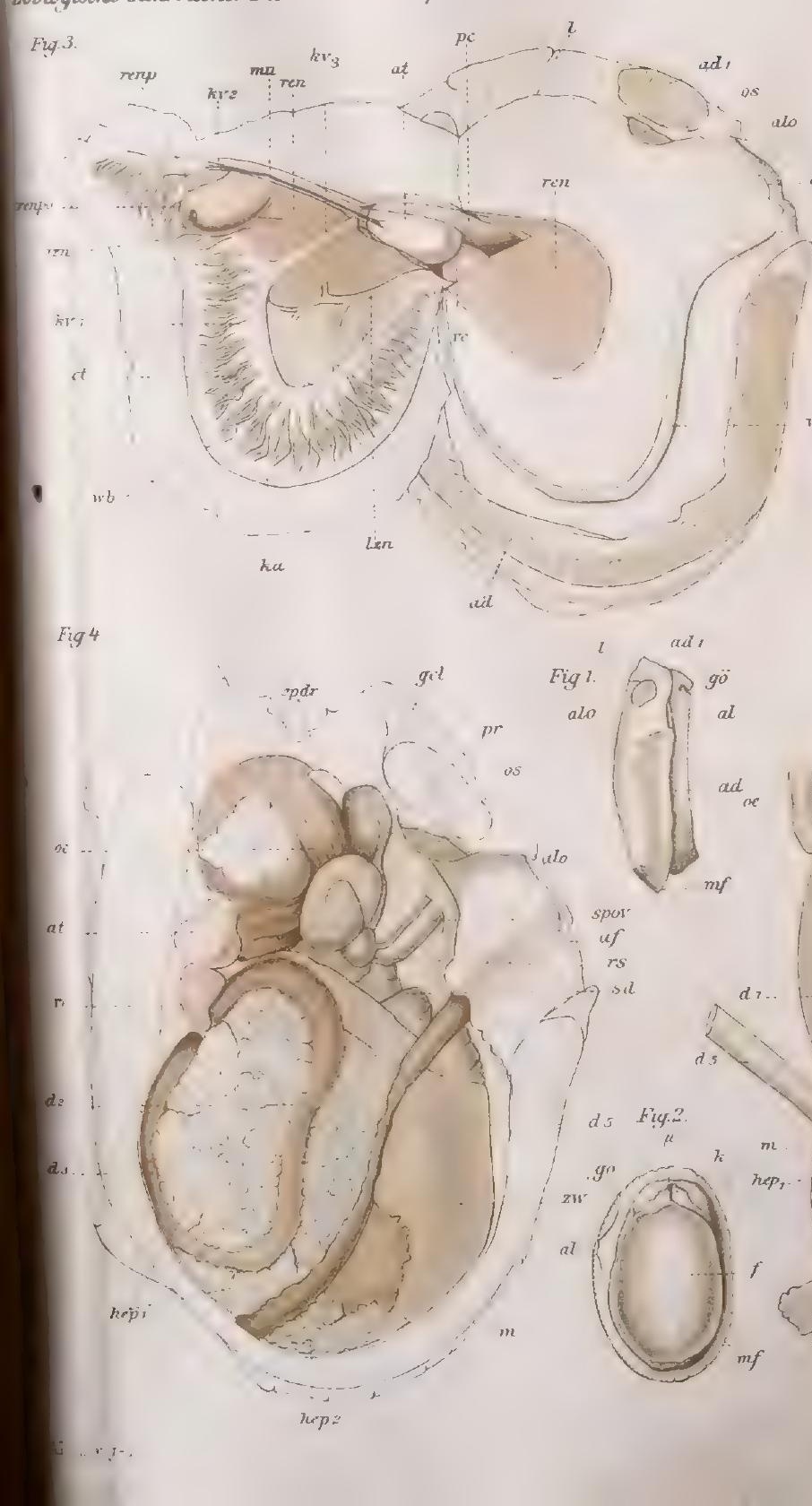
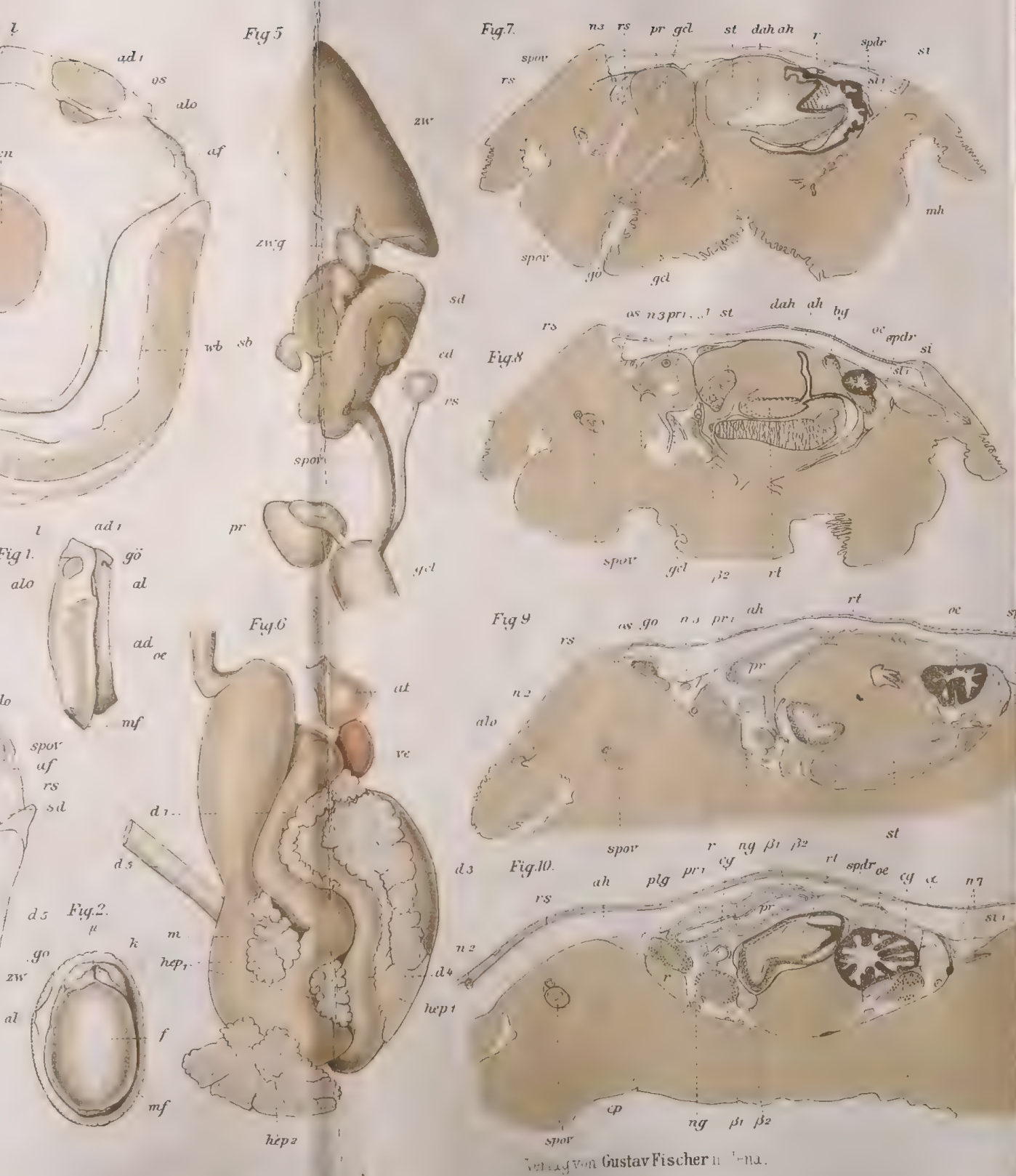





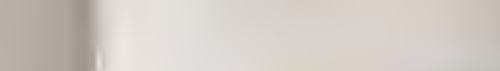







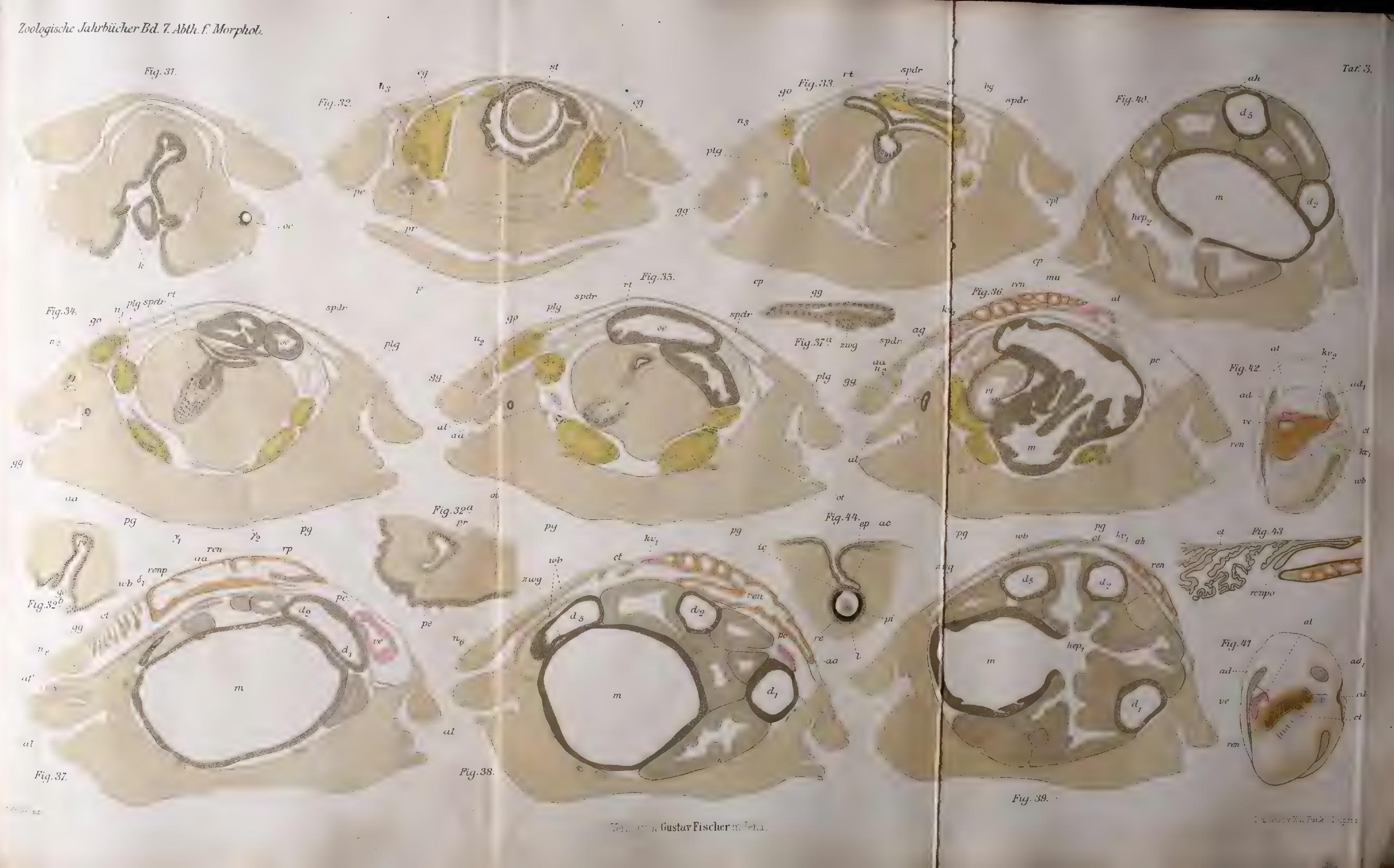





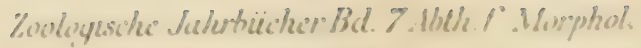

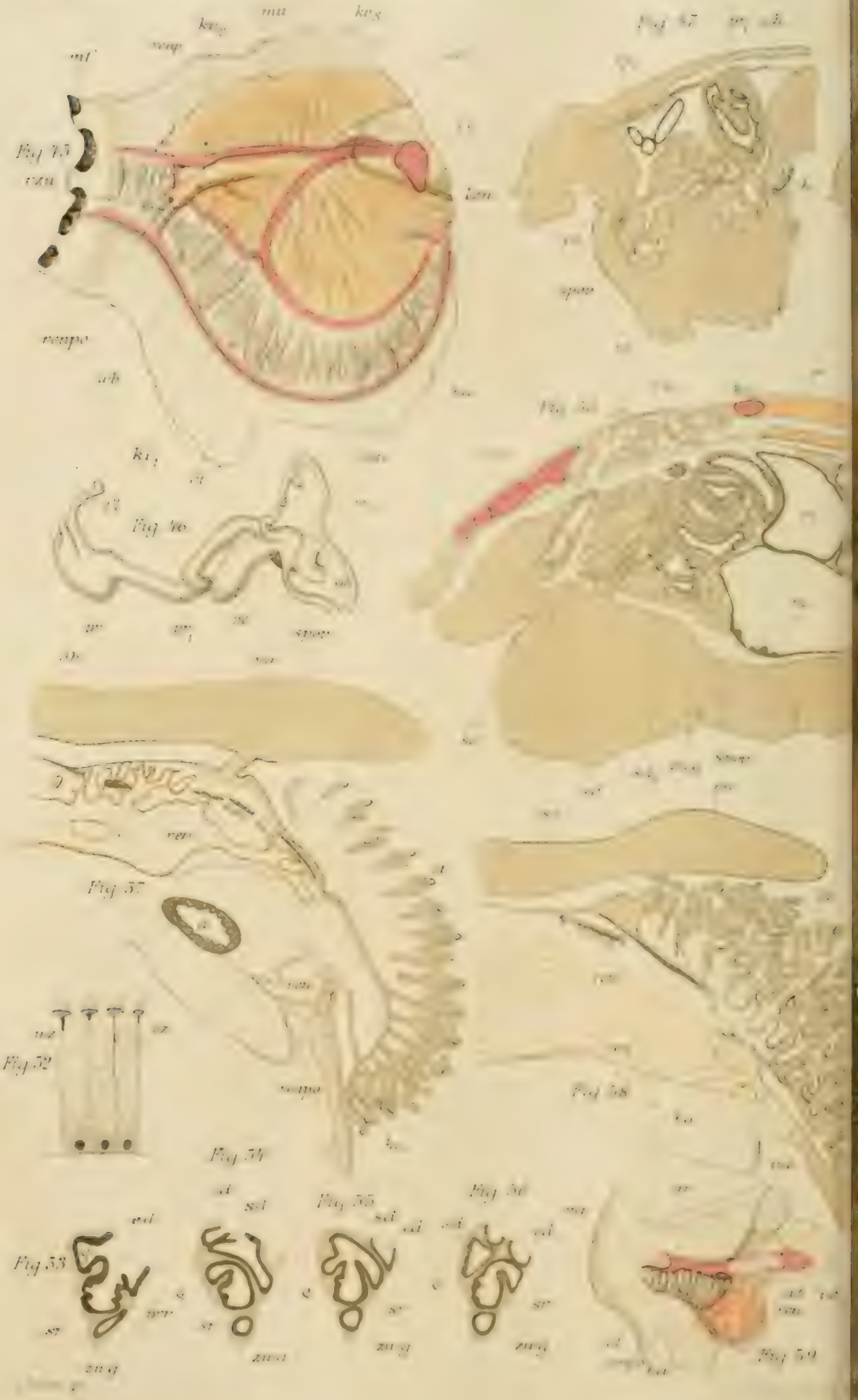





Zoolog. Jahrbuicher. Bd. 7. Abth. f. Murphol.
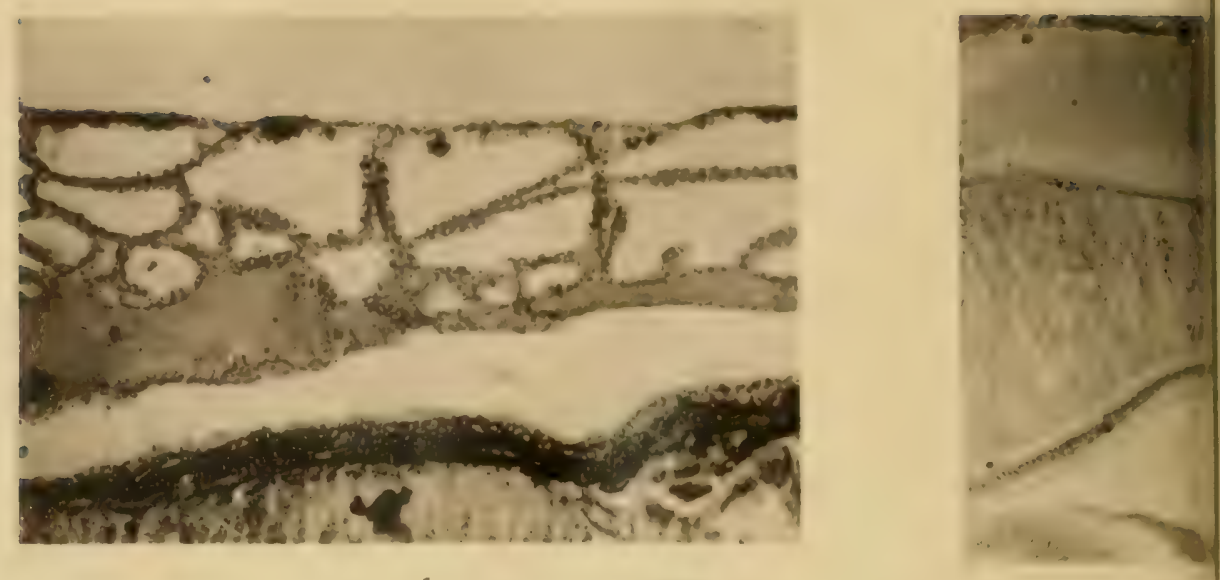

1.

Vergt. 117.
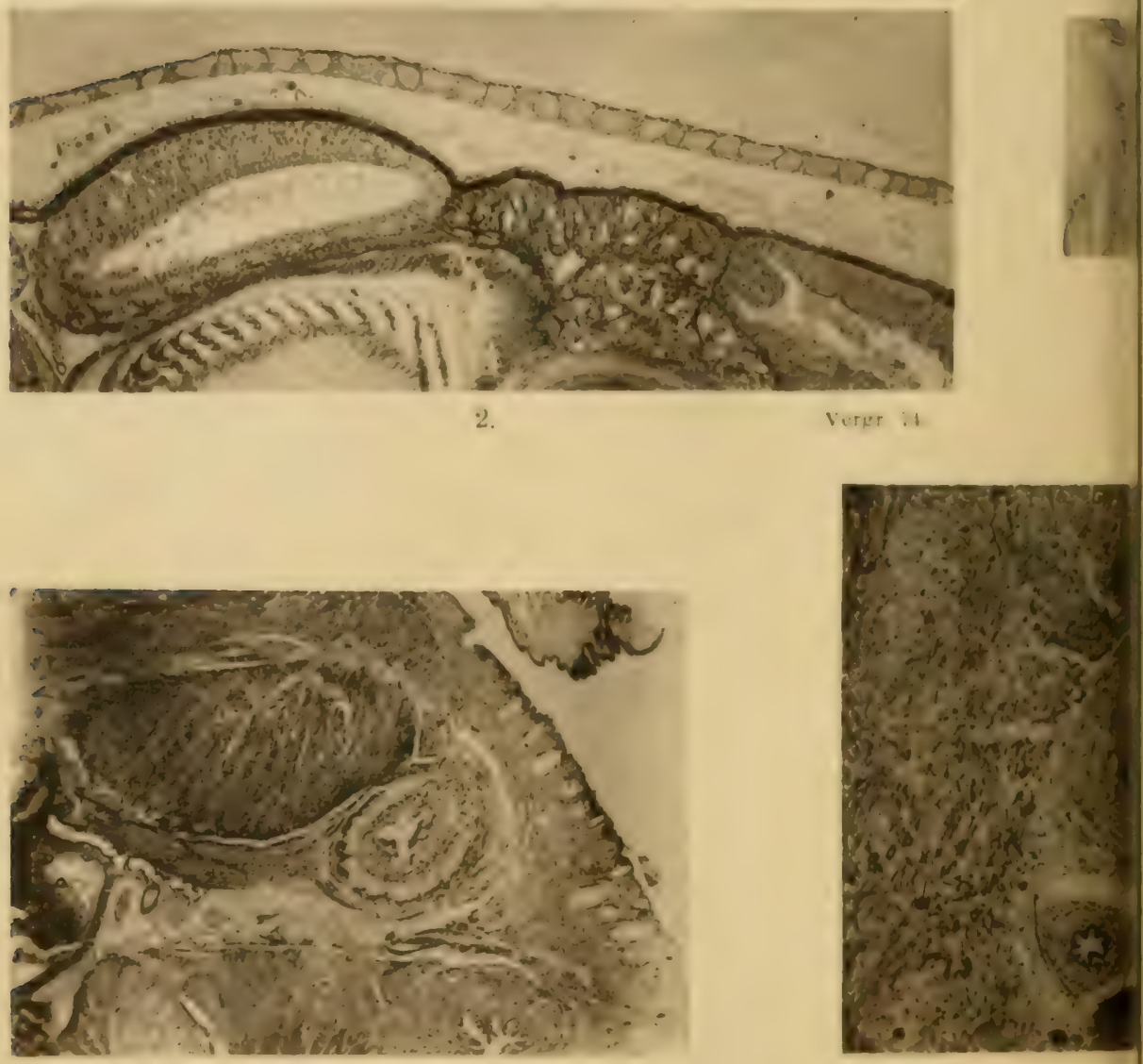



\section{1}
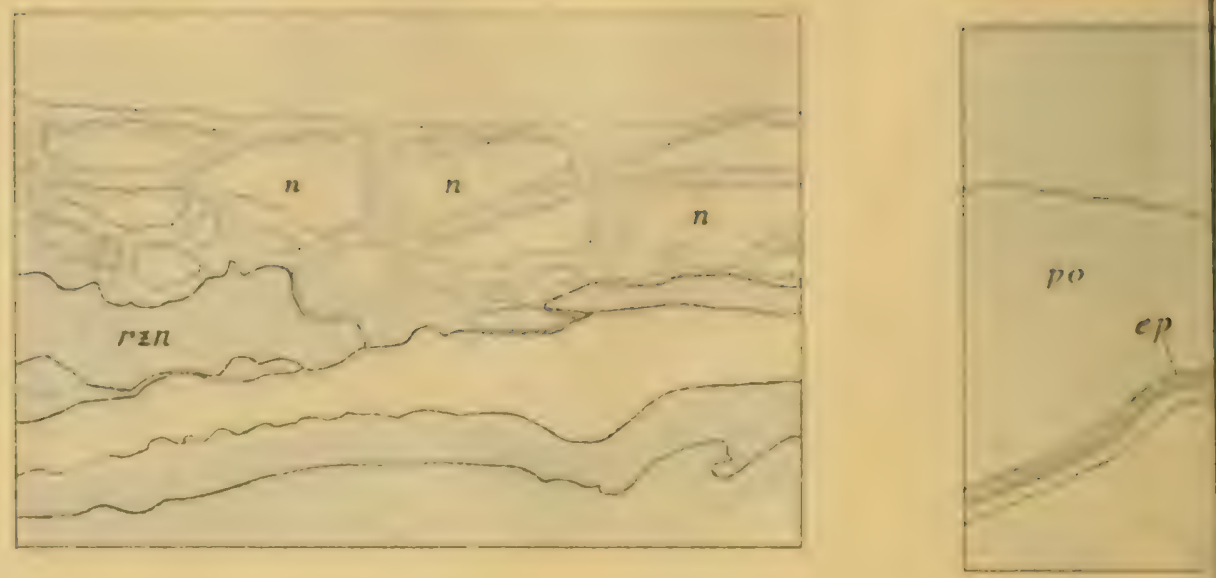

\section{2}

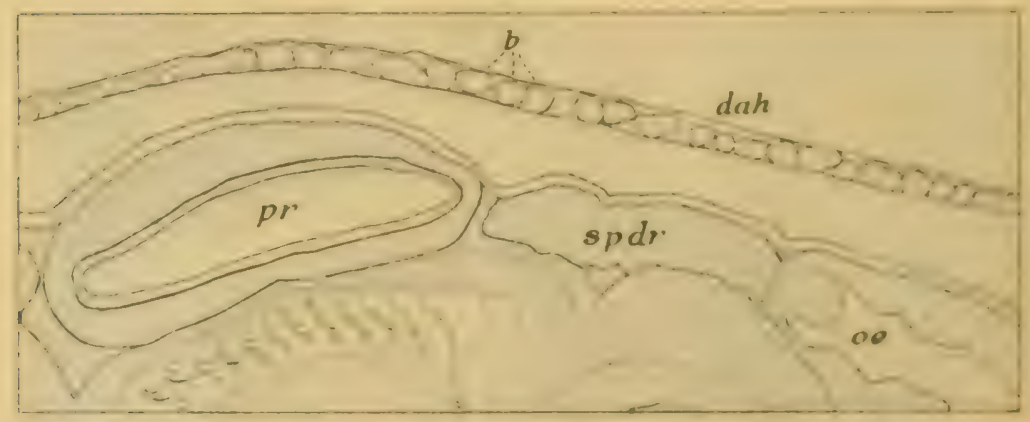

3.
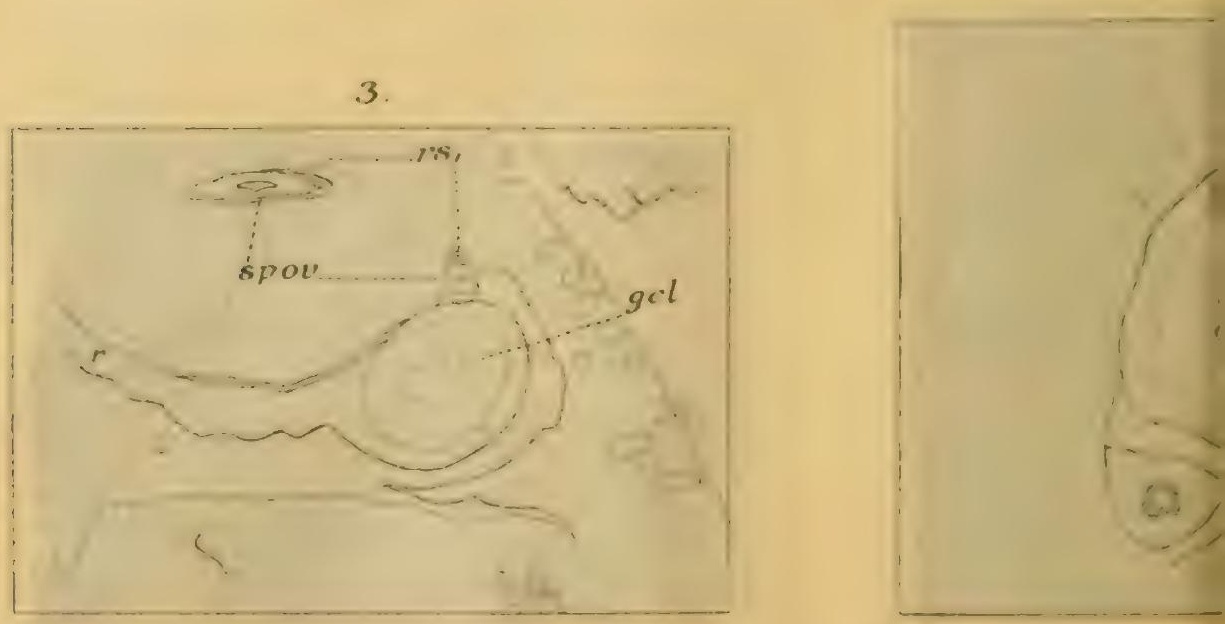

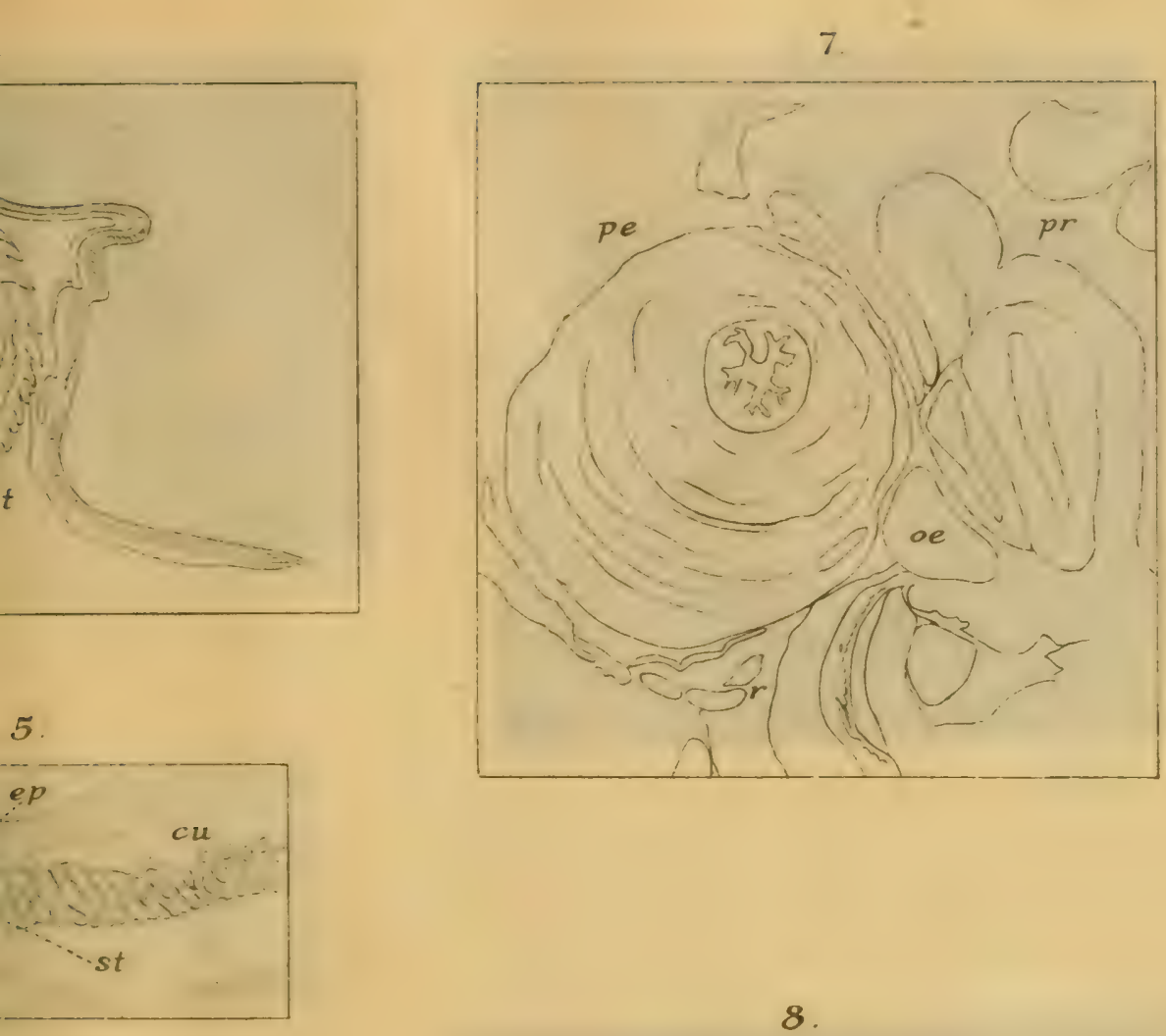

8.

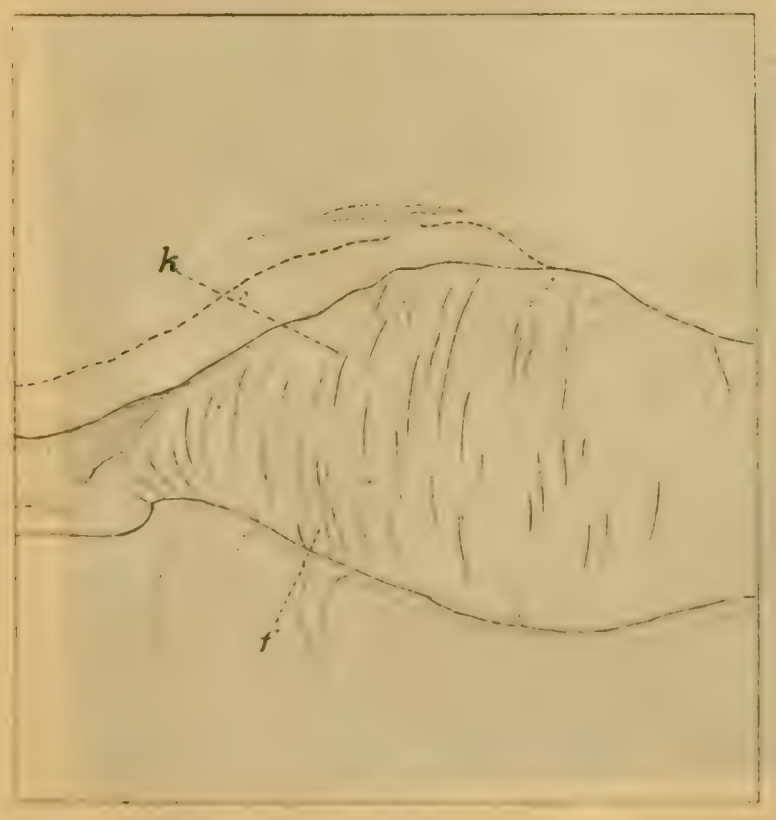




15.

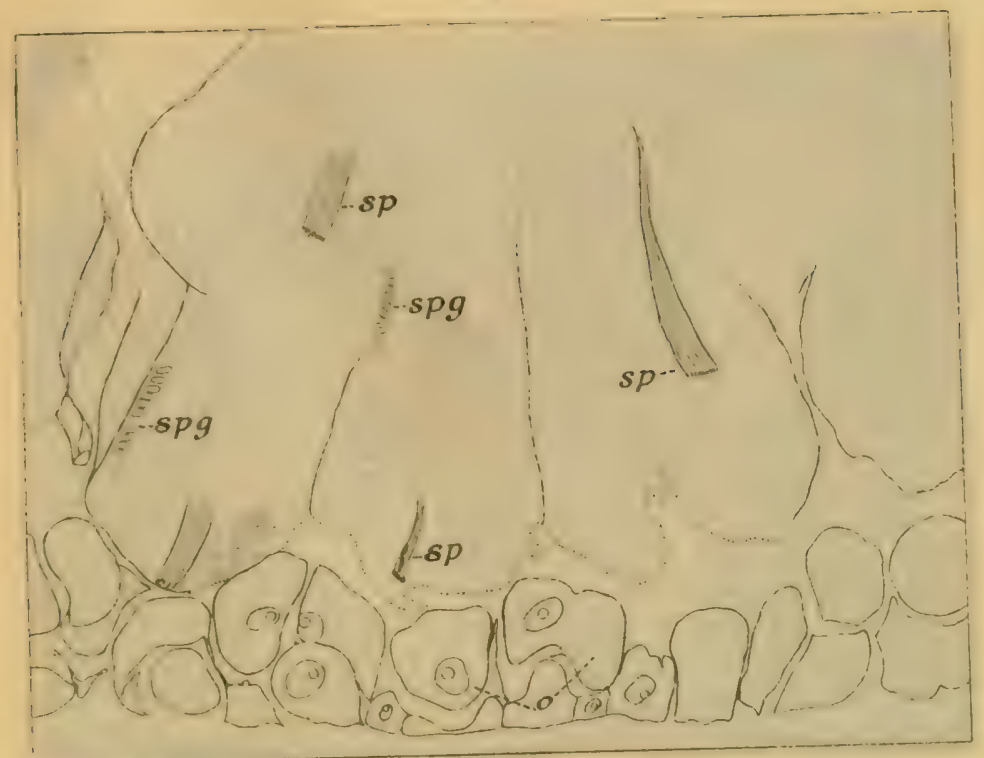

18.

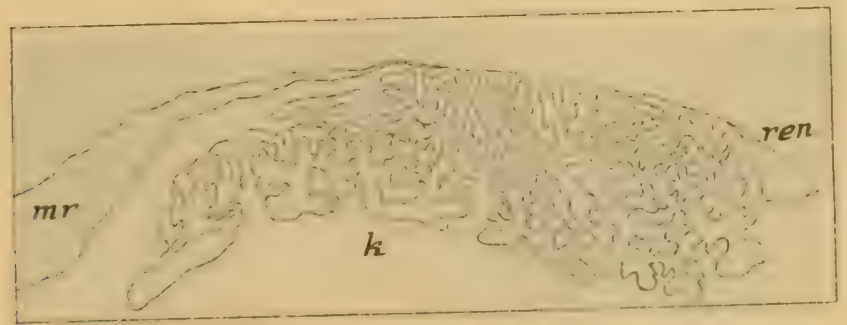

19.

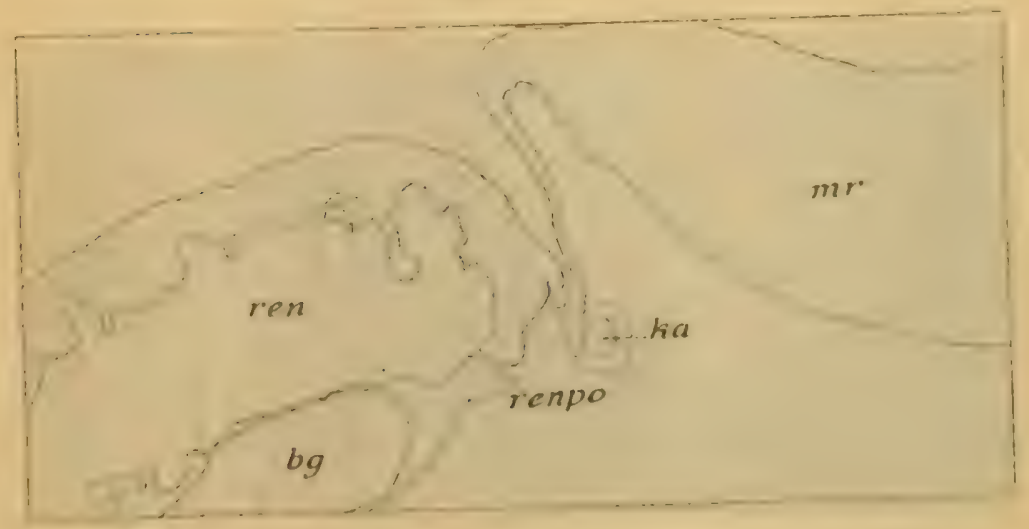




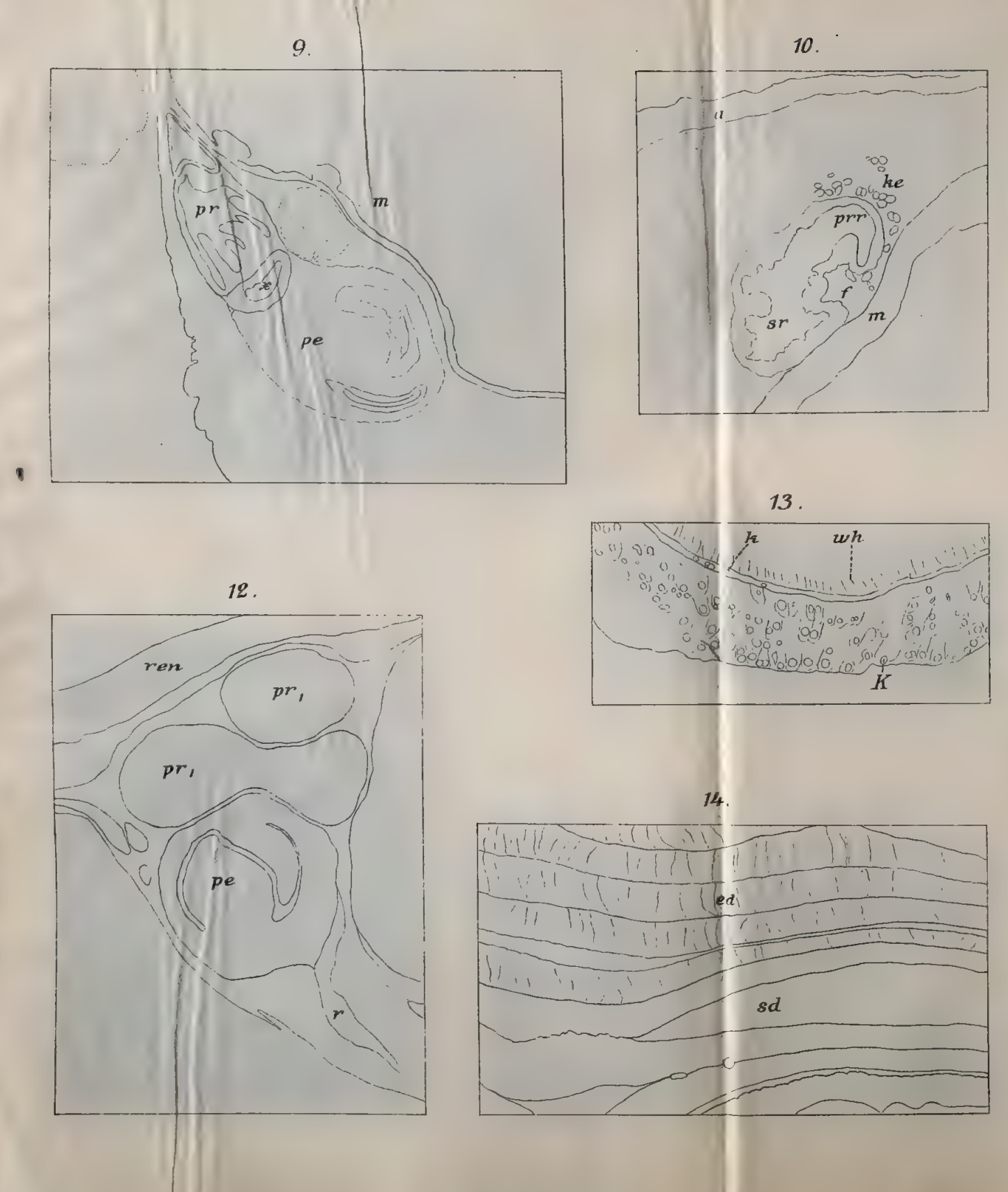
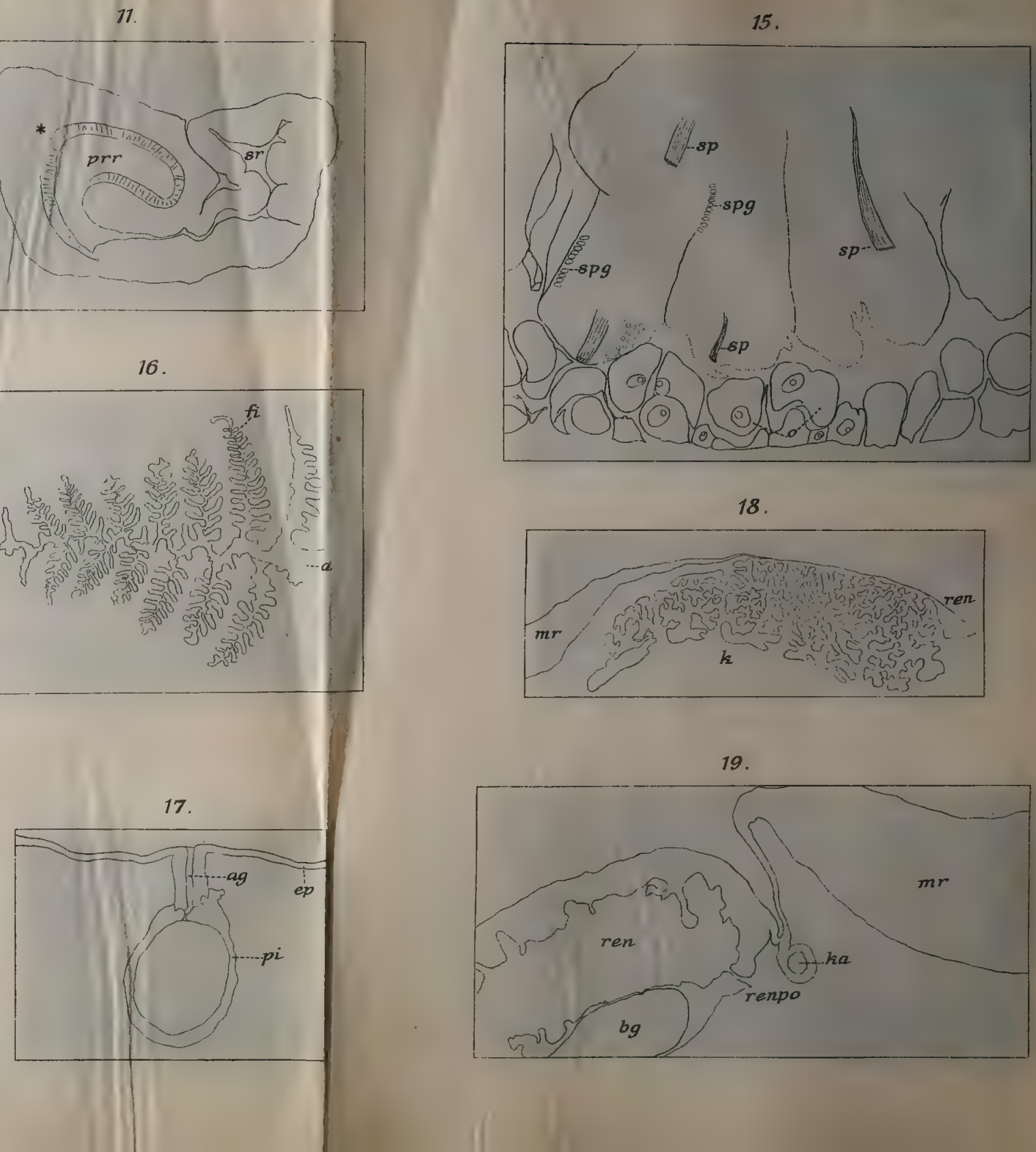

Zoolog. Jahrbücher. Bd. 7. Abth. f. Morphol.

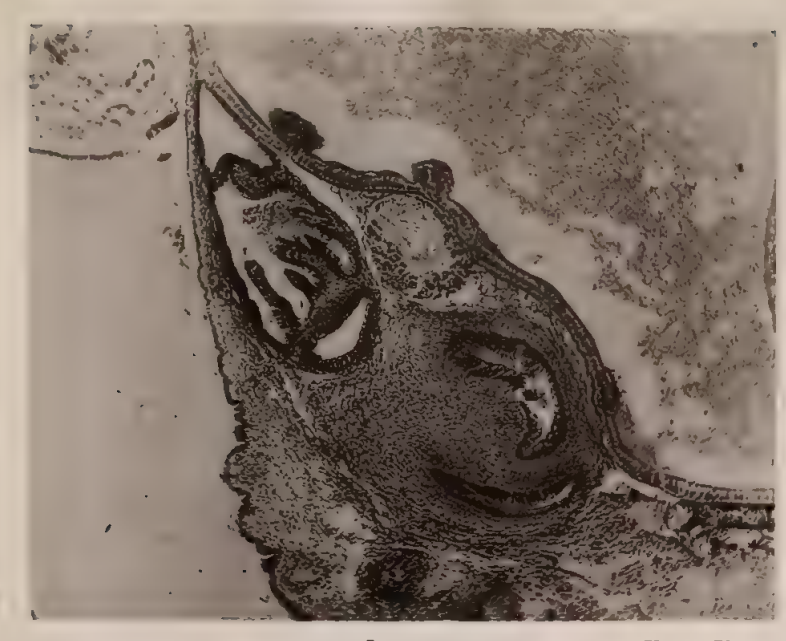

9.

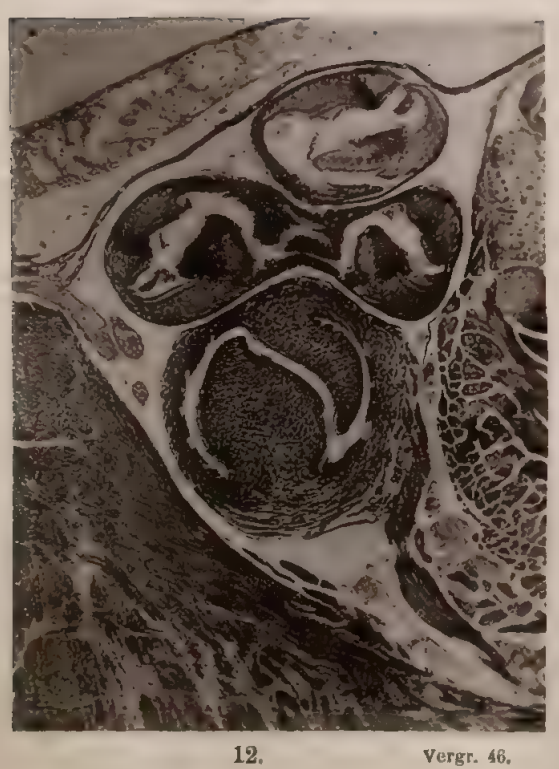

12.
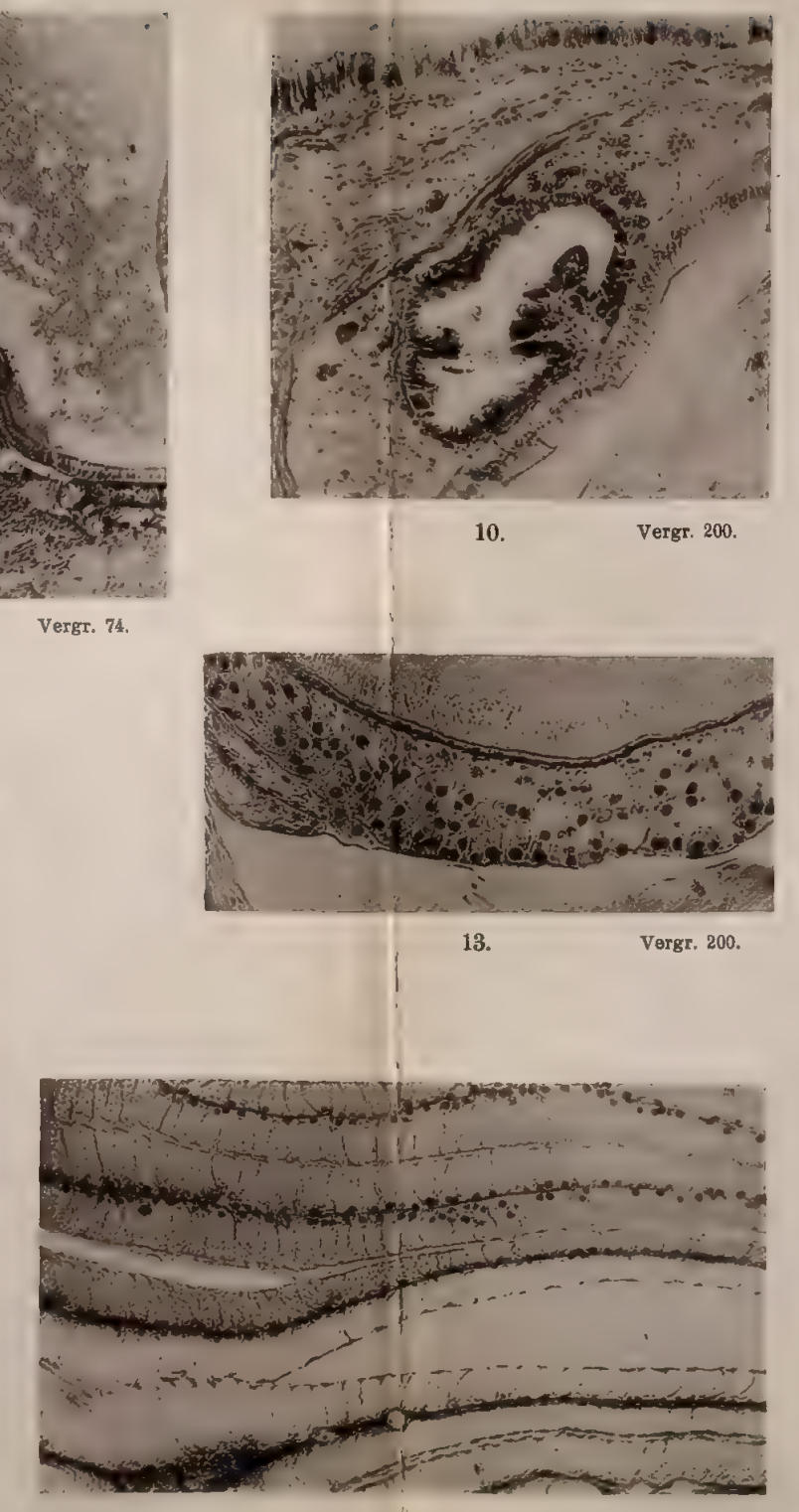

Vergr, 117.

14.

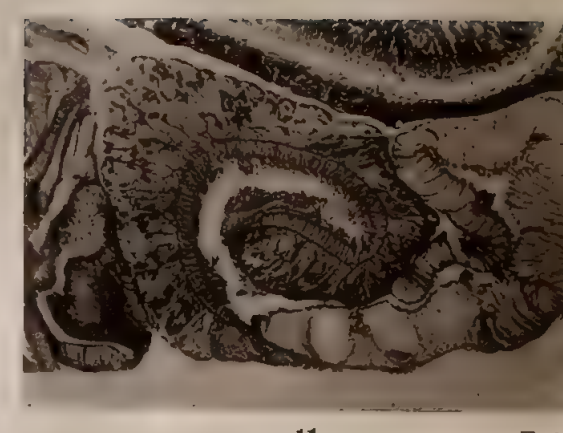

11.
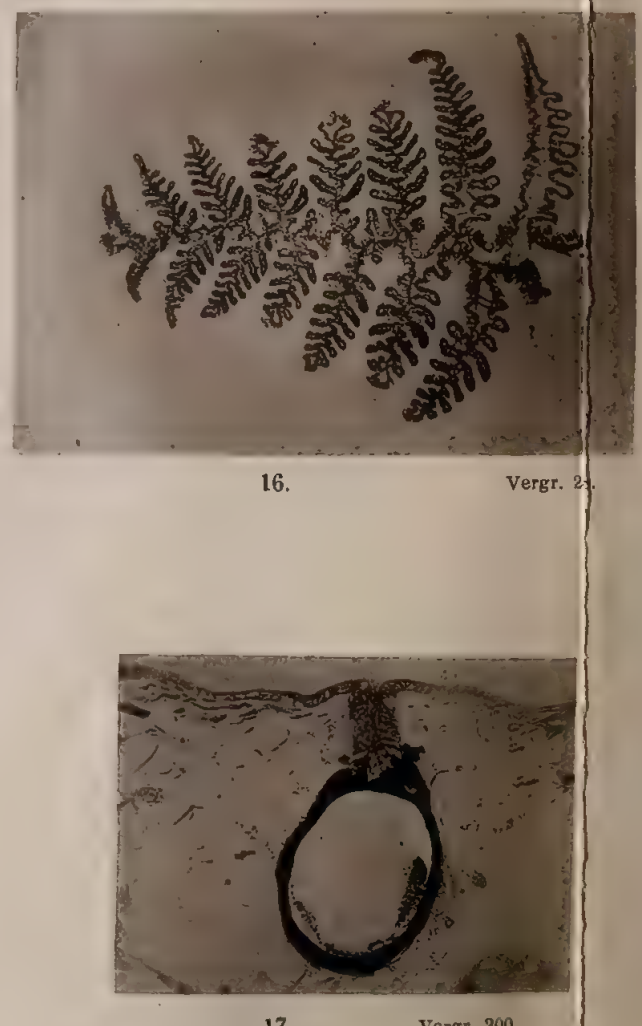

Vergr. 200.
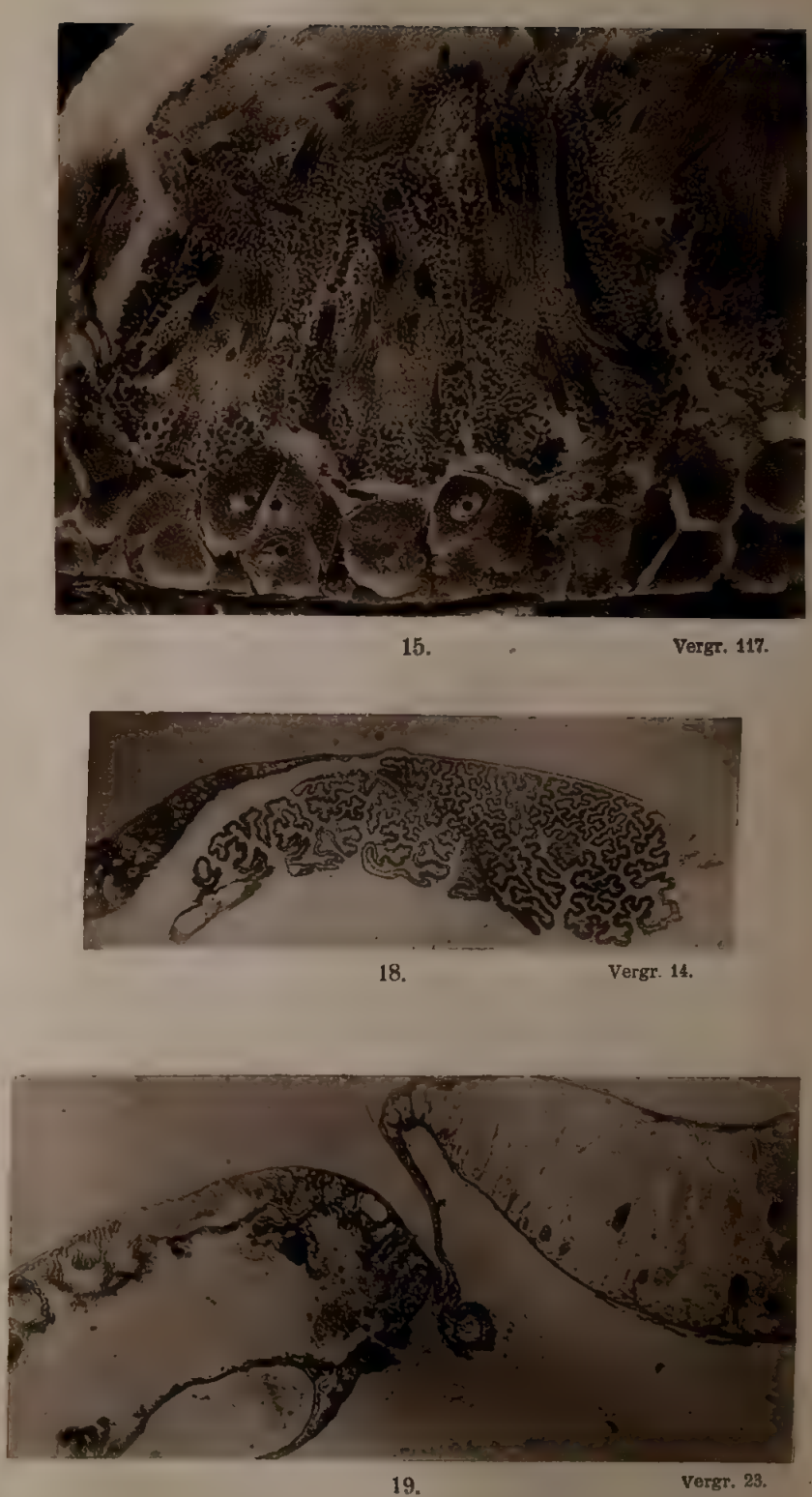

Frommannsche Buchdruckeroi (Hermaun Pohle) in dena. 


\section{PAMPHLET BINDERS}

This is No. 1524

also carried in stock in the following slzes

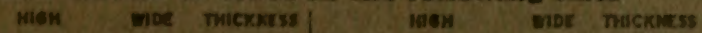

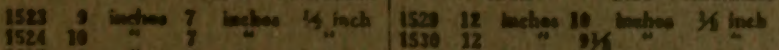

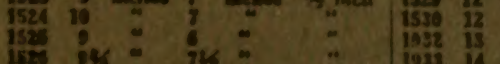

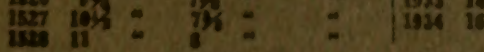

Other stes inade to ordes.

MANUTACTUERO BY

LIBRARY BUREAU

Divielon of REMINGTON RAND INC.

Lobarz Suppliee of ell Kinds 
